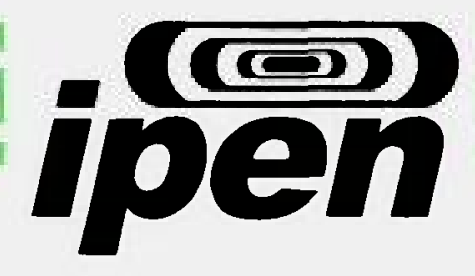

AUTARQUIA ASSOCIADA À UNIVERSIDADE DE SÃO PAULO

\title{
AVALIAÇÃO DE TRATAMENTOS QUÍMICOS E RECOBRIMENTO BIOMIMÉTICO EM CERÂMICAS DE ALUMINA-ZIRCÔNIA
}

\section{AMANDA ABATI AGUIAR}

Dissertação apresentada como parte dos requisitos para obtenção do Grau de Mestre em Ciências na Área de Tecnologia Nuclear - Materiais.

Orientador:

Dr. Nelson Batista de Lima 


\title{
INSTITUTO DE PESQUISAS ENERGÉTICAS E NUCLEARES
}

AUTARQUIA ASSOCIADA À UNIVERSIDADE DE SÃO PAULO

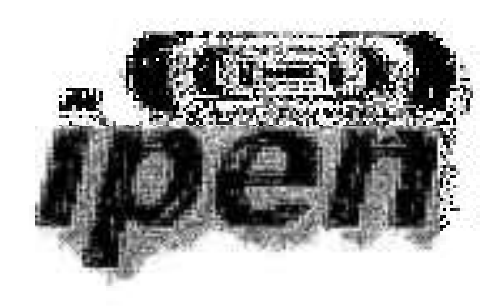

\section{AVALIAÇÃO DE TRATAMENTOS QUÍMICOS E RECOBRIMENTO BIOMIMÉTICO EM CERÂMICAS DE ALUMINA-ZIRCÔNIA}

\author{
Amanda Abati Aguiar
}

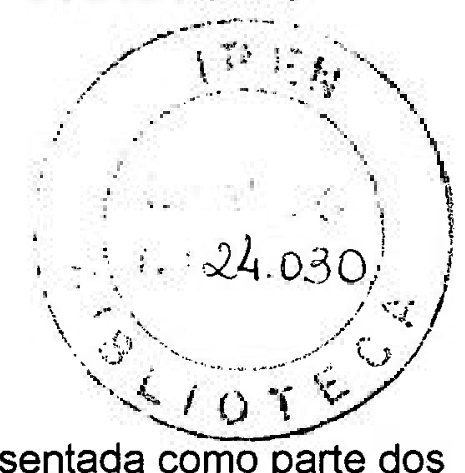

Dissertação apresentada como parte dos requisitos para obtenção do Grau de Mestre em Ciência na Área de Tecnologia Nuclear-Materiais.

Orientador:

Dr. Nelson Batista de Lima 
Aos meus queridos pais, lara e Edson, minha eterna gratidão pela minha formação, e ao Nelson pelo constante suporte, dẹdico esta realização. 


\section{AGRADECIMENTOS}

Ao Instituto de Pesquisa Energéticas e Nucleares, pela oportunidade de rcalizar este trabalho.

À CNPq, pelo apoio financeiro que tornou possível a realização deste trabalho.

Ao Dr.Nelson Batista de Lima, por sua constante disposição e empenho na orientação deste trabalho.

À Christiane Ribeiro pela amizade, carinho e constante empenho na realização do trabalho, além da enorme colaboração na preparação do SBF.

À Dra. Dolores Ribeiro Ricci Lazar pelo incentivo, pela disposição no esclarecimento das dúvidas e paciência com que conduziu a co-orientação desta dissertação.

Ao Dr. Valter Ussui, por sua amizade, por dividir sua experiência na execução das atividades experimentais.

Ao Msc. Rafael Garcia, pela amizade e colaboração na realização da síntese do material.

Ao Msc. Marcos Scapin e Dra. Vera Lúcia Ribeiro Salvador, pela colaboração nas medidas realizadas por fluorescência de raios $\mathrm{X}$.

Ao Rene Ramos de Oliveira, pela amizade, pelo companheirismo e colaboração na parte experimental do trabalho (BET, sinterização e MEV).

À colega do laboratório de Insumos, Joana Domingos de Andrade, pela grande ajuda durante a parte experimental do trabalho.

Ao Nildemar Aparecido Ferreira e Celso Vieira de Moraes, pela amizade e realização das micrografias.

Ao Dr.José Roberto Martinelli, pelas medidas do tamanho médio de partículas dos materiais analisados neste trabalho.

Aos meus amigos, Anderson Rodrigues Matos, Deiby Santos Gouveia, Reinaldo de Azevedo Vargas, que sempre estavam ao meu lado, apoiando diretamente e indiretamente durante a execução do trabalho.

e à todos, cujo apoio, interesse e sugestões foram indispensáveis para a conclusão deste trabalho. 
Uma mãe é uma pessoa que ao ver que só ficam quatro bocados de torta de chocolate tendo cinco pessoas, é a primeira em dizer que nunca gostou de chocolate. 


\section{AVALIAÇÃO DE TRATAMENTOS QUIMICOS E RECOBRIMENTO BIOMIMÉTICO EM CERÂMICAS DE ALUMINA-ZIRCÔNIA}

\section{RESUMO}

Materiais cerâmicos, como a alumina e a zircônia têm sido explorados ao longo dos anos na aplicação como biomateriais. Sua natureza bioinerte, tem estimulado o desenvolvimento de novas alternativas, como tratamentos químicos para tornar o desempenho biológico destas cerâmicas mais adequadas. O recobrimento biomimético de cerâmicas bioinertes a partir de soluções com concentrações iguais às do plasma sanguíneo humano, SBF, permite o crescimento de uma camada bioativa na superfície dos implantes. A bioatividade do material está relacionada com a formação de uma camada constituída por cristais de hidroxiapatita carbonatada de baixa cristalinidade, similar à apatita biológica. A biocompatibilidade associada às propriedades estruturais da alumina e da zircônia tem estimulado o uso clínico destes materiais, inclusive em règiões de maiores solicitações mecânicas. Neste trabalho foram produzidas amostras de alumina, zircônia dopada com ítria ( $3 \% \mathrm{~mol}$ ) e compósitos de alumina e zircônia dopada com ítria $(3 \% \mathrm{~mol})$ preparadas pelo método de co-precipitação, calcinadas, sinterizadas, tratadas quimicamente com soluções de ácido fosfórico e hidróxido de sódio e imersas em 1,0M e 1,5M SBF. Os pós calcinados foram analisados por difração de raios $\mathrm{x}$ (DRX), microscopia eletrônica de varredura (MEV), análise de área de superfície específica (BET) e análise de distribuição granulométrica (CILAS). Os resultados por DRX indicam que as amostras possuem baixa cristalinidade. Observou-se que por BET as amostras apresentam alta área de superfície específica. Os resultados de CILAS e MEV mostraram que os pós encontram-se na forma de aglomerados. As amostras sinterizadas, foram analisadas por difração de raios x (DRX), microscopia eletrônica de varredura (MEV) e fluorescência de raios x (FRX), apresentando $96 \%$ da densidade teórica e as fases analisadas pelo método de Rietveld foram identificadas e quantificadas como: cúbica, tetragonal e monoclínica da zircônia, além da fase alfa da alumina. O tratamento químico com ácido fosfórico não apresentou uma tendência de maior formação de apatita em relação às amostras não tratada quimicamente. O tratamento com hidróxido de sódio provocou transformação acentuada da fase cúbica para tetragonal e da fase tetragonal para a fase monoclínica da zircônia. Os ensaios biomiméticos proporcionaram a formação de apatita sobre as superfícies das amostras, identificadas por DRX, e sua espessura foi medida por FRX. 


\title{
CHEMICAL TREATMENT AND BIOMIMETIC COATING EVALUATING IN ZIRCONIA-ALUMINA CERAMICS
}

\begin{abstract}
Ceramic materials, as alumina and zirconia have been explored along the years as biomaterials application. The bioinert nature has been stimulating the development of new alternatives, as chemical treatments to improve the biological application of these ceramics. The biomimetic process of bioinerts ceramics for coating apatite is based on soaking the implant in a simulated body fluid, SBF, with ion concentrations nearly equal to those of human blood plasma. The bioactivity of the material is related with the formation of a layer constituted of hidroxiapatite low crystalline, similar to the biological apatite. The biocompatibility associated to the structural properties of the alumina and zirconia has been stimulating the clinical use of these materials, mainly in areas of larger mechanical requests, places not recommended for bioactive hidroxiapatite, for instance. In this work samples of alumina, zirconia doped with yttria $(3 \% \mathrm{~mol})$ and composites of alumina and zirconia doped with yttria $(3 \% \mathrm{~mol})$ were prepared by co-precipitation method, calcinated, sintered, chemically treated with solutions of acid phosphoric and sodium hydroxide and them immersed in $1.0 \mathrm{M}$ and 1.5M SBF. The calcinated powders were analyzed by X-ray diffraction (XRD), scanning electron microscopy (SEM), gas adsorption (BET) and laser diffraction. The XRD results indicate that the samples are low crystalline. It was observed for BET that the samples present high specific surface area. The results of laser diffraction and SEM showed that the powders are agglomerates. The sintered samples were analyzed by XRD, SEM and X-ray fluorescence (XRF). The phases quantified by Rietveld method were: cubic, tetragonal and monoclinic of the zirconia, besides the phase alpha of the alumina. The chemical treatment with phosphoric acid didn't present a tendency of larger apatite formation in relation to the samples no chemically treated. The treatment with sodium hydroxide provoked accentuated transformation of the cubic phase for tetragonal phase and of tetragonal phase for the monoclinic phase of the zirconia. The immersion of samples in SBF provided apatite coating formation on the surfaces of the samples, identified by XRD, and the coating thickness was measured by XRF.
\end{abstract}




\section{I.INTRODUÇÃO}

IV. FUNDAMENTOS TEÓRICOS

IV.1. BIOCERÂMICAS

IV. 1.1. CLASSIFICAÇÃO DAS BIOCERÂMICAS

IV. 1.1.1. BIOCERÂMICAS INERTES OU TOLERÁVEIS

IV. 1.1.2. BIOCERÂMICAS ATIVAS

IV. 1.1.3. BIOCERÂMICAS REABSORVÍVEIS

IV. 2. CERÂMICAS À BASE DE FOSFATO DE CÁLCIO 26

IV. 3. RECOBRIMENTO BIOMIMÉTICO

IV.4. DIAGRAMA DE FASES DO SISTEMA $\mathrm{ZrO}_{2}-\mathrm{Y}_{2} \mathrm{O}_{3}$

IV. 5. DIFRAÇÃO DE RAIOS $X \quad 28$

IV. 5.1. INTENSIDADE DO FEIXE DIFRATADO

IV. 5.2. FATOR DE ESTRUTURA

IV. 5.3. FATOR DE LORENTZ 32

IV. 5.4. FATOR DE POLARIZAÇÃO

IV. 5.5. TÉCNICAS DE DIFRAÇÃO DE RAIOS $X$

IV. 5.6. DIFRATÔMETRO DE RAIOS X

IV. 5.7. GEOMETRIA DE BRAGG-BRENTANO

IV. 5.8. ANÁLISE QUANTITATIVA DE FASES - MÉTODO DE RIETVELD 36

IV. 5.9. AVALIAÇÃO DO REFINAMENTO

IV. 5.9.1. RESÍDUOS 39

IV.6.ÍNDICE DE QUALIDADE DO REFINAMENTO ("GOODNESS OF FIT"-
GOF)

IV. 7. FLUORESCÊNCIA DE RAIOS X POR DISPERSÃO DE COMPRIMENTO DE ONDA (WDXRF)

IV. 7.1. MÉTODO DE PARÂMETROS FUNDAMENTAIS (FP)

.IV. 7.1.1. CÁLCULO DA INTENSIDADE TEÓRICA 42

V. PROCEDIMENTO EXPERIMENTAL

V.1. SÍNTESE DOS PÓS

V.2. PROCESSAMENTO CERÂMICO

V.3. PREPARAÇÃO SUPERFICIAL DAS AMOSTRAS SINTERIZADAS

V.4. RECOBRIMENTO BIOMIMÉTICO 46

V.5. CARACTERIZAÇ̃̃O DOS PÓS

V.6. CARACTERIZAÇÃO DAS AMOSTRAS SINTERIZADAS 48

VI. RESULTADOS E DISCUSSÕES

VI.1. CARACTERIZAÇÃO DOS PÓS SINTETIZADOS

VI.2. CARACTERIZAÇÃO DAS CERÂMICAS APÓS SINTERIZAÇÃO

VI.3. CARACTERIZAÇÃO DAS CERÂMICAS SUBMETIDAS A ATAQUE QUÍMICO

VI.4. TESTES DE IMERSÃO EM SBF 
VII. CONCLUSÕES

VIII. REFERÊNCIAS BIBLIOGRÁFICAS 


\section{LISTA DE TABELAS}

Página

\begin{tabular}{|c|c|}
\hline Tabela 1: Concentrações iônicas das soluções empregadas $\left(\mathrm{mmol}^{-} \mathrm{dm}^{-3}\right)$. & 46 \\
\hline Tabela 2: Quantidade de reagentes para o preparo de $1,0 \mathrm{M} \mathrm{e} 1,5 \mathrm{SBF}$ & 47 \\
\hline $\begin{array}{l}\text { Tabela 3: Valores de área superficial especifica dos pós sintetizados: 100A, } \\
\text { 80A20TZP, 20A80TZP e 100TZP. }\end{array}$ & 51 \\
\hline $\begin{array}{l}\text { Tabela 4: Quantificação de fases das cerâmicas à base de alumina e zircônia, sem } \\
\text { tratamento químico de superfície. }\end{array}$ & 58 \\
\hline $\begin{array}{l}\text { Tabela 5: Propriedades das cerâmicas à base de alumina e zircônia sem } \\
\text { tratamento químico de superfície }\end{array}$ & 59 \\
\hline $\begin{array}{l}\text { Tabela 6: Quantificação de fases das cerâmicas à base de alumina e zircônia, } \\
\text { após tratamento químico de superfície com } \mathrm{H}_{3} \mathrm{PO}_{4} \mathrm{e} \mathrm{NaOH} \text {. }\end{array}$ & 62 \\
\hline $\begin{array}{l}\text { Tabela 7: Resultado de refinamento das cerâmicas à base de alumina e zircônia } \\
\text { sem tratamento químico e após tratamento químico de superfície com } \mathrm{H}_{3} \mathrm{PO}_{4} \text { e } \\
\mathrm{NaOH} \text {. }\end{array}$ & 62 \\
\hline $\begin{array}{l}\text { Tabela 8: Equivalente em espessura da camada de apatita nas amostras sem } \\
\text { tratamento químico e com tratamento químico de } \mathrm{H}_{3} \mathrm{PO}_{4} \text { após a imersão em } 1,5 \\
\mathrm{SBF} \text { por } 3 \text { dias, } 6 \text { dias, } 15 \text { dias e } 21 \text { dias. }\end{array}$ & 84 \\
\hline
\end{tabular}




\section{LISTA DE FIGURAS}

Página

\begin{tabular}{|c|c|}
\hline $\begin{array}{l}\text { Figural: Área óssea a ser preenchida por tempo em SBF para formação de } \\
\text { apatita }\end{array}$ & 8 \\
\hline $\begin{array}{l}\text { Figura 2: Diagrama de fases proposto por Scott do sistema zircônia-ítria na } \\
\text { região rica em zircônio, onde } \mathrm{M}, \mathrm{T} \text { e } \mathrm{C} \text { representam as fases monoclínica, } \\
\text { tetragonal e cúbica, respectivamente. }\end{array}$ & 28 \\
\hline Figura 3: Difratômetro de raios x esquemático (PADILHA; AMBRÓSIO, 1985). & 34 \\
\hline $\begin{array}{l}\text { Figura 4: Arranjo geométrico do difratômetro de } \\
\text { (KLUG;ALEXANDER, 1974). }\end{array}$ & 36 \\
\hline $\begin{array}{l}\text { Figura 5: Fluxograma esquemático da metodologia adotada para síntese, } \\
\text { processamento e caracterização de cerâmicas de alumina e zircônia estabilizada. }\end{array}$ & 44 \\
\hline $\begin{array}{l}\text { Figura 6: Micrografias obtidas por microscopia eletrônica de varredura dos pós } \\
\text { cerâmicos sintetizados. a) 20A80TZP ; b) } 100 \mathrm{~A} \text {;c)100TZP e d) 80A20TZP }\end{array}$ & 51 \\
\hline Figura 7: Distribuição granulométrica do pó sintetizado (100A) & 52 \\
\hline Figura 8: Distribuição granulométrica do pó sintetizado (100TZP) & 52 \\
\hline Figura 9: Distribuição granulométrica do pó sintetizado (80A20TZP) & 53 \\
\hline Figura 10: Distribuição granulométrica do pó sintetizado (20A80TZP) & 53 \\
\hline Figura 11: Difratograma do pó sintetizado (100A) & 54 \\
\hline Figura 12: Difratograma do pó sintetizado (80A20TZP) & 54 \\
\hline Figura 13: Difratograma do pó sintetizado (20A80TZP) & 55 \\
\hline Figura 14: Difratograma do pó sintetizado (100TZP) & 55 \\
\hline $\begin{array}{l}\text { Figura 15: Micrografias obtidas por microscopia eletrônica de varredura de } \\
\text { superfícies de fratura das amostras sinterizadas. a) 20A80TZP; b)80A20TZP; } \\
\text { c)100TZP e d) } 100 \mathrm{~A}\end{array}$ & 56 \\
\hline $\begin{array}{l}\text { Figura 16: Difratogramas das cerâmicas sem tratamento químico de superfície } \\
\text { com as seguintes composições: } 80 \mathrm{~A} 20 \mathrm{TZP} \text { e } 100 \mathrm{~A}\end{array}$ & 57 \\
\hline $\begin{array}{l}\text { Figura 17: Difratogramas das cerâmicas sem tratamento químico de superfície } \\
\text { com as seguintes composições: } 20 \mathrm{~A} 80 \mathrm{TZP} \text { e } 100 \mathrm{TZP}\end{array}$ & 57 \\
\hline $\begin{array}{l}\text { Figura 18: Difratograma da cerâmica (100A) com tratamento químico de } \\
\text { superfície com ácido }\left(\mathrm{H}_{3} \mathrm{PO}_{4}\right) \text { e base }(\mathrm{NaOH})\end{array}$ & 60 \\
\hline
\end{tabular}


Figura 19: Difratograma da cerâmica (100TZP) com tratamento químico de superfície com ácido $\left(\mathrm{H}_{3} \mathrm{PO}_{4}\right)$ e base $(\mathrm{NaOH})$

Figura 20: Difratograma da cerâmica $(20 \mathrm{~A} 80 \mathrm{TZP})$ com tratamento químico de superfície com ácido $\left(\mathrm{H}_{3} \mathrm{PO}_{4}\right)$ e base $(\mathrm{NaOH})$

Figura 21: Difratograma da cerâmica (80A20TZP) com tratamento químico de superfície com ácido $\left(\mathrm{H}_{3} \mathrm{PO}_{4}\right)$ e base $(\mathrm{NaOH})$

Figura 22: Micrografias obtidas por microscopia eletrônica de varredura das amostras sem tratamento e das amostras após tratamento químico superficial. $\begin{array}{llll}\text { a)20A80TZP } & \left(\mathrm{H}_{3} \mathrm{PO}_{4}\right) ; \quad \text { b)20A80TZP(NaOH); c)20A80TZP; } & \text { d) }\end{array}$ 80A20TZP $\left(\mathrm{H}_{3} \mathrm{PO}_{4}\right)$; e) 80A20TZP(NaOH) e f) 80A20TZP

Figura 23: Micrografias obtidas por microscopia eletrônica de varredura das amostras sem tratamento e das amostras após tratamento quimico superficial. a) $100 \mathrm{~A}\left(\mathrm{H}_{3} \mathrm{PO}_{4}\right)$; b) $100 \mathrm{~A}(\mathrm{NaOH})$;c) $100 \mathrm{~A}$; d) $100 \mathrm{TZP}\left(\mathrm{H}_{3} \mathrm{PO}_{4}\right)$;e) $100 \mathrm{TZP}$ $(\mathrm{NaOH})$ e f) $100 \mathrm{TZP}$

Figura 24: Micrografias obtidas por microscopia eletrônica de varredura da amostra sem tratamento e da amostra após tratamento químico superficial após a imersão em SBF por 21 dias. a) 80A20TZP; b) 80A20TZP $\left(\mathrm{H}_{3} \mathrm{PO}_{4}\right)$

Figura 25: Micrografias obtidas por microscopia eletrônica de varredura das amostras sem tratamento e das amostras com tratamento químico superficial após a imersão em $1,5 \mathrm{SBF}$ por 3 dias. a) $20 \mathrm{~A} 80 \mathrm{Z}$; b) $20 \mathrm{~A} 80 \mathrm{Z}\left(\mathrm{H}_{3} \mathrm{PO}_{4}\right)$; c) $80 \mathrm{~A} 20 \mathrm{Z}$; d) $80 \mathrm{~A} 20 \mathrm{Z}\left(\mathrm{H}_{3} \mathrm{PO}_{4}\right)$; e) $100 \mathrm{~A}$; f) $100 \mathrm{~A}\left(\mathrm{H}_{3} \mathrm{PO}_{4}\right)$; g) $100 \mathrm{TZP}$; h) $100 \mathrm{TZP}\left(\mathrm{H}_{3} \mathrm{PO}_{4}\right)$

Figura 26: Micrografias obtidas por microscopia eletrônica de varredura das amostras sem tratamento e das amostras com tratamento químico superficial após a imersão em $1,5 \mathrm{SBF}$ por 6 dias. a) 20A80Z; b) $20 \mathrm{~A} 80 \mathrm{Z}\left(\mathrm{H}_{3} \mathrm{PO}_{4}\right)$; c) 80A20TZP; d) 80A20TZP $\left(\mathrm{H}_{3} \mathrm{PO}_{4}\right)$; e) 100A; f) 100A $\left(\mathrm{H}_{3} \mathrm{PO}_{4}\right)$; g) 100TZP; h) $100 \mathrm{TZP}\left(\mathrm{H}_{3} \mathrm{PO}_{4}\right)$

Figura 27: Micrografias obtidas por microscopia eletrônica de varredura das amostras sem tratamento e das amostras com tratamento químico superficial após a imersão em $1,5 \mathrm{SBF}$ por 15 dias. a) $20 \mathrm{~A} 80 \mathrm{Z}$; b) $20 \mathrm{~A} 80 \mathrm{Z}\left(\mathrm{H}_{3} \mathrm{PO}_{4}\right)$; c) 80A20TZP; d) 80A20TZP $\left(\mathrm{H}_{3} \mathrm{PO}_{4}\right)$; e) 100A; f) 100A $\left(\mathrm{H}_{3} \mathrm{PO}_{4}\right)$; g) 100TZP; h) $100 \mathrm{TZP}\left(\mathrm{H}_{3} \mathrm{PO}_{4}\right)$

Figura 28: Micrografias obtidas por microscopia eletrônica de varredura das amostras sem tratamento e das amostras com tratamento químico superficial após a imersão em $1,5 \mathrm{SBF}$ por 21 dias. a) $20 \mathrm{~A} 80 \mathrm{Z}$; b) $20 \mathrm{~A} 80 \mathrm{Z}\left(\mathrm{H}_{3} \mathrm{PO}_{4}\right)$; c) 80A20TZP; d) 80A20TZP $\left(\mathrm{H}_{3} \mathrm{PO}_{4}\right)$; e) 100A; f) 100A $\left(\mathrm{H}_{3} \mathrm{PO}_{4}\right)$; g) 100TZP; h) $100 \mathrm{TZP}\left(\mathrm{H}_{3} \mathrm{PO}_{4}\right)$ 


\begin{tabular}{|c|c|}
\hline $\begin{array}{l}\text { Figura 30: Difratograma da amostra 80A20TZP sem tratamento químico e com } \\
\text { tratamento químico de } \mathrm{H}_{3} \mathrm{PO}_{4} \text { após a imersão em } 1,5 \mathrm{SBF} \text { por } 3 \text { dias. }\end{array}$ & 76 \\
\hline $\begin{array}{l}\text { Figura 31: Difratograma da amostra } 100 \mathrm{~A} \text { sem tratamento químico e com } \\
\text { tratamento químico de } \mathrm{H}_{3} \mathrm{PO}_{4} \text { após a imersão em } 1,5 \mathrm{SBF} \text { por } 3 \text { dias. }\end{array}$ & 77 \\
\hline $\begin{array}{l}\text { Figura 32: Difratograma da amostra 100TZP sem tratamento químico e com } \\
\text { tratamento químico de } \mathrm{H}_{3} \mathrm{PO}_{4} \text { após a imersão em } 1,5 \mathrm{SBF} \text { por } 3 \text { dias. }\end{array}$ & 77 \\
\hline $\begin{array}{l}\text { Figura 33: Difratograma da amostra 20A80TZP sem tratamento químico e com } \\
\text { tratamento químico de } \mathrm{H}_{3} \mathrm{PO}_{4} \text { após a imersão em } 1,5 \mathrm{SBF} \text { por } 6 \text { dias. }\end{array}$ & 78 \\
\hline $\begin{array}{l}\text { Figura 34: Difratograma da amostra 80A20TZP sem tratamento químico e com } \\
\text { tratamento químico de } \mathrm{H}_{3} \mathrm{PO}_{4} \text { após a imersão em } 1,5 \mathrm{SBF} \text { por } 6 \text { dias. }\end{array}$ & 78 \\
\hline $\begin{array}{l}\text { Figura 35: Difratograma da amostra } 100 \mathrm{~A} \text { sem tratamento químico e com } \\
\text { tratamento químico de } \mathrm{H}_{3} \mathrm{PO}_{4} \text { após a imersão em } 1,5 \mathrm{SBF} \text { por } 6 \text { dias. }\end{array}$ & 79 \\
\hline $\begin{array}{l}\text { Figura 36: Difratograma da amostra 100TZP sem tratamento químico e com } \\
\text { tratamento químico de } \mathrm{H}_{3} \mathrm{PO}_{4} \text { após a imersão em 1,5SBF por } 6 \text { dias. }\end{array}$ & 79 \\
\hline $\begin{array}{l}\text { Figura 37: Difratograma da amostra 20A80TZP sem tratamento químico e com } \\
\text { tratamento químico de } \mathrm{H}_{3} \mathrm{PO}_{4} \text { após a imersão em } 1,5 \mathrm{SBF} \text { por } 15 \text { dias. }\end{array}$ & 80 \\
\hline $\begin{array}{l}\text { Figura 38: Difratograma da amostra 80A20TZP sem tratamento químico e com } \\
\text { tratamento químico de } \mathrm{H}_{3} \mathrm{PO}_{4} \text { após a imersão em } 1,5 \mathrm{SBF} \text { por } 15 \text { dias. }\end{array}$ & 81 \\
\hline $\begin{array}{l}\text { Figura 39: Difratograma da amostra } 100 \mathrm{~A} \text { sem tratamento químico e com } \\
\text { tratamento químico de } \mathrm{H}_{3} \mathrm{PO}_{4} \text { após a imersão em } 1,5 \mathrm{SBF} \text { por } 15 \text { dias. }\end{array}$ & 81 \\
\hline $\begin{array}{l}\text { Figura 40: Difratograma da amostra 100TZP sem tratamento químico e com } \\
\text { tratamento químico de } \mathrm{H}_{3} \mathrm{PO}_{4} \text { após a imersão em } 1,5 \mathrm{SBF} \text { por } 15 \text { dias. }\end{array}$ & 82 \\
\hline $\begin{array}{l}\text { Figura 41: Difratograma da amostra 20A80TZP sem tratamento químico e com } \\
\text { tratamento químico de } \mathrm{H}_{3} \mathrm{PO}_{4} \text { após a imersão em 1,5SBF por } 21 \text { dias. }\end{array}$ & 82 \\
\hline $\begin{array}{l}\text { Figura 42: Difratograma da amostra 80A20TZP sem tratamento químico e com } \\
\text { tratamento químico de } \mathrm{H}_{3} \mathrm{PO}_{4} \text { após a imersão em } 1,5 \mathrm{SBF} \text { por } 21\end{array}$ & 83 \\
\hline $\begin{array}{l}\text { Figura 43: Difratograma da amostra } 100 \mathrm{~A} \text { sem tratamento químico e com } \\
\text { tratamento químico de } \mathrm{H}_{3} \mathrm{PO}_{4} \text { após a imersão em } 1,5 \mathrm{SBF} \text { por } 21 \text { dias. }\end{array}$ & 83 \\
\hline $\begin{array}{l}\text { Figura 44: Difratograma da amostra 100TZP sem tratamento químico e com } \\
\text { tratamento químico de } \mathrm{H}_{3} \mathrm{PO}_{4} \text { após a imersão em } 1,5 \mathrm{SBF} \text { por } 21 \text { dias. }\end{array}$ & 84 \\
\hline
\end{tabular}




\section{INTRODUÇÃO}

As cerâmicas, de um modo geral, apresentam algumas vantagens quanto à utilização na área biomédica, devido a algumas características como estética, biocompatibilidade e resistência química (HENCH, 1998). Quando comparada aos materiais metálicos, um aspecto problemático de materiais cerâmicos é sua baixa resistência mecânica e tenacidade à fratura (MORAES et.al., 2004), por isso, tem sido proposto, atualmente, o uso do compósito alumina-zircônia de alta densidade como biomaterial. A alumina apresenta umà excelente biocompatibilidade e resistência ao desgaste, entretanto exibe baixa resistência à flexão e tenacidade (MORAES, 2004; HENCH, 1998). Por sua vez, cerâmicas de zircônia estabilizada na fase tetragonal apresentam um bom aspecto estético após o polimento e são inertes em ambiente fisiológico, apresentando melhor resistência à flexão e tenacidade, possuindo um baixo módulo de Young (rigidez) quando comparadas com a alumina pura (MORAES et.al., 2004).

A zircônia geralmente é utilizada com a adição de agentes de estabilização estrutural, uma vez que a transformação da fase tetragonal para monoclínica, durante o resfriamento subseqüente à etapa de sinterização, provoca expansão volumétrica e conseqüente ruptura da cerâmica. Quando estabilizada com 3 mol\% de ítria, a zircônia pode manter sua estrutura tetragonal a altas temperaturas e ser metaestável a temperatura ambiente. Este material, designado Y-TZP (yttria tetragonal zirconia polycrystals) tem sido uma alternativa para a alumina como biomaterial, tanto para aplicações dentais como em implantes ortopédicos (MORAES, 2004; HENCH, 1998).

A preocupação maior referente ao uso da zircônia é a sua degradação a baixas temperaturas $\left(<300^{\circ} \mathrm{C}\right)$, em presença de umidade. O envelhecimento ocorre por uma lenta transformação na superfície, para a fase monoclínica estável, na presença de água ou vapor de água. A transformação começa primeiro em grãos isolados na superfície por corrosão sob tensão. A transformação inicial de grãos específicos pode ser devido ao estado de desequilíbrio microestrutural ocasionado por diferentes fatores: tamanho maior de grãos, menor quantidade de ítria, orientação específica da superfície, presença de tensão residual ou presença de fase cúbica (CHEVALIER et.al., 2004). Essa transformação induz a uma série de eventos ocorrendo de grão vizinho para grão vizinho. A transformação de um grão conduz para um aumento de volume tensionando grãos vizinhos e formando microtrincas. Este mecanismo oferece um caminho para a 
penetração da água no volume da amostra. Essa transformação ocorre por nucleação e processo de crescimento do grão (CHEVALIER, 2006).

É difícil falar em ausência de envelhecimento, já que a fase monoclínica é seu estado de equilíbrio.

Dada à moderada tenacidade da alumina e a questão do envelhecimento da zircônia, há uma tendência em desenvolver compósitos de alumina-zircônia. Este pode ser o caminho para se beneficiar da tenacidade gerada pela zircônia sem o maior obstáculo associado à sua transformação sob vapor ou sob ação de fluídos corpóreos. A adição de alumina à zircônia e a adição da ítria como dopante, retarda o envelhecimento, reduzindo drasticamente sua cinética (CHEVALIER, 2006).

Tratamentos químicos de superfície induzem a formação de cargas negativas. Essas cargas favorecem a nucleação da apatita durante a imersão dos compósitos em SBF - Simulated Body Fluid. Estes tratamentos são realizados a $90^{\circ} \mathrm{C}$ com soluções de ácido fosfórico e hidróxido de sódio (UCHIDA et.al., 2002), com o intuito de aumentar a área específica e a energia superficial do substrato facilitando o crescimento da apatita. Uma vez formada a apatita, a justaposição osso-implante aumenta a osseointegração, termo este definido como sendo o contato estabelecido entre o osso normal e remodelado com a superfície do implante, sem a interposição de tecidos conectivos que não sejam de células ósseas, promovendo uma camada bioativa em cerâmicas bioinertes (VERCIK et.al., 2003).

O método denominado biomimético foi introduzido por Abe. É realizado com a imersão do substrato, a ser recoberto, em uma solução sintética (SBF-Simulated Body Fluid) de composição química e pH semelhantes ao plasma sanguíneo e temperatura similar à do corpo humano. Devido a essas condições é possível recobrir materiais de formas complexas, como materiais porosos e também materiais sensíveis a temperaturas, como é o caso dos polímeros (VERCIK et.al., 2003).

Materiais artificiais implantados dentro de ossos defeituosos são geralmente encapsulados por um tecido fibroso, isolando-o do contato com o tecido do osso. Entretanto, em 1972, Hench et.al. mostraram que alguns biovidros espontaneamente aderem ao osso sem a formação do tecido fibroso em sua volta. Desde então, muitos tipos de cerâmicas como a hidroxiapatita sinterizada, fosfato tricálcico $\beta$ sinterizado e vitro-cerâmica $\mathrm{A}-\mathrm{W}$ contendo apatita cristalina e wollastonita, têm mostrado aderência óssea e são usados clinicamente como importantes substitutos ósseos. Entretanto essas cerâmicas não são compatíveis mecanicamente à estrutura óssea. Nesse sentido, o 
desenvolvimento de materiais que possibilitem boa aderência óssea e diferentes propriedades mecânicas é desejado (KOKUBO et.al., 2006).

Em 1991, foi proposto que o requerimento essencial para um material artificial aderir ao osso é a formação de uma camada superficial de apatita com características semelhantes ao osso natural, quando implantado no corpo humano. Essa formação da apatita pode ser reproduzidà em um fluído que simula a atuação do corpo humano, com concentrações de íons iguais a do plasma sanguíneo humano. Isso significa que a bioatividade de um material pode ser avaliada a partir da formação da apatita em sua superfície quando imerso em SBF. Desde então, a bioatividade de vários tipos de materiais têm sido avaliada pela formação da apatita em SBF (KOKUBO et.al., 2006). 


\section{OBJETIVOS}

Considerando a importância do compósito alumina-zircônia como biomaterial, neste trabalho, foram preparados compósitos de $\mathrm{Al}_{2} \mathrm{O}_{3} /(\mathrm{Zr}, \mathrm{Y}) \mathrm{O}_{2}$ com diferentes concentrações, a partir de pós sintetizados pela rota de co-precipitação de hidróxidos em meio amoniacal, submetidos a processos de conformação e sinterização, avaliando a realização de tratamentos químicos superficiais com posterior imersão das cerâmicas em SBF para a deposição da hidroxiapatita, determinando a espessura da camada de apatita formada. A análise de Rietveld dos dados obtidos por difração de raios $\mathrm{X}$ foi utilizada para quantificar as fases presentes no material. 


\section{REVISÃO BIBLIOGRÁFICA}

Uchida, Kim, Kokubo, Nawa, et al.(2002), investigaram a formação de grupos de $\mathrm{Zr}$-OH em cerâmicas de $\mathrm{Ce} \mathrm{TZP} / \mathrm{Al}_{2} \mathrm{O}_{3}$ visando a indução da formação de apatita via tratamento químico com diferentes soluções aquosas. Esse compósito demonstrou ter alta resistência à degradação à baixa temperatura.

Substratos de Ce TZP/ $\mathrm{Al}_{2} \mathrm{O}_{3}$ foram imersos em $5 \mathrm{ml}$ de solução de $\mathrm{H}_{3} \mathrm{PO}_{4}$ concentrado, $\mathrm{H}_{3} \mathrm{PO}_{4} 5 \mathrm{M} ; \mathrm{H}_{2} \mathrm{SO}_{4}, \mathrm{H}_{2} \mathrm{SO}_{4} 5 \mathrm{M} ; \mathrm{HCl}$ ou $\mathrm{NaOH} 15 \mathrm{M}$, acondicionados em tubos de teflon mantidos à $95^{\circ} \mathrm{C}$ por 4 dias. Após os tratamentos químicos, foram imersos em $30 \mathrm{ml}$ de $\mathrm{SBF}$ em um frasco de poliestireno à $36,5^{\circ} \mathrm{C}$, mantendo o $\mathrm{pH}$ em 7,4 com trishidroximetilaminometano e $1 \mathrm{M} \mathrm{HCl}$. Após vários períodos de imersão, as amostras foram removidas do SBF, lavadas com água ultrapura e secadas a $40^{\circ} \mathrm{C}$. As superfícies dos substratos antes e após a imersão em soluções aquosas e após a imersão em SBF foram analisadas usando filme fino de raios X, espectroscopia fotoeletrônica de raios X e microscopia eletrônica de varredura de emissão de campo.

Os resultados obtidos por difração de raios $\mathrm{X}$, mostraram que as amostras não tratadas, não apresentaram mudanças, mesmo após a imersão em SBF por 7 dias. Após 3 dias, os substratos tratados com $\mathrm{H}_{3} \mathrm{PO}_{4} 5 \mathrm{M}$, revelaram picos que foram associados à apatita e aqueles tratados com outras soluções, revelaram picos de apatita após 7 dias. Por microscopia eletrônica de varredura detectou-se uma maior quantidade de apatita depositada no substrato tratado com $\mathrm{H}_{3} \mathrm{PO}_{4} 5 \mathrm{M}$ do que nos substratos tratados com outras soluções. Já por espectroscopia fotoeletrônica de raios X, picos do grupo $\mathrm{OH}$ ou $\mathrm{H}_{2} \mathrm{O}$ se tornam mais intensos após os tratamentos, mas particularmente depois do tratamento com $\mathrm{H}_{3} \mathrm{PO}_{4} . \mathrm{H}_{3} \mathrm{PO}_{4} 5 \mathrm{M}$ ou $\mathrm{H}_{2} \mathrm{SO}_{4}$. O decréscimo da razão atômica $\mathrm{Zr} / \mathrm{Al}$ foi pequena após o tratamento com $\mathrm{H}_{3} \mathrm{PO}_{4} 5 \mathrm{M}, \mathrm{H}_{2} \mathrm{SO}_{4} 5 \mathrm{M}$ ou $\mathrm{NaOH} 15 \mathrm{M}$, moderado após o tratamento com $\mathrm{H}_{3} \mathrm{PO}_{4}$ ou $\mathrm{HCl}$ e grande após o tratamento com $\mathrm{H}_{2} \mathrm{SO}_{4}$. Quando o substrato é tratado com $\mathrm{H}_{3} \mathrm{PO}_{4}, \mathrm{H}_{3} \mathrm{PO}_{4} 5 \mathrm{M}$, ou $\mathrm{H}_{2} \mathrm{SO}_{4}$, uma grande quantidade de zircônio é liberada da superfície e grande quantidade de alumínio só é liberado após tratamentos com soluções de $\mathrm{H}_{3} \mathrm{PO}_{4} \mathrm{e} \mathrm{H}_{3} \mathrm{PO}_{4} 5 \mathrm{M}$. Todos esses tratamentos produziram grupos $\mathrm{OH}^{-}$na superfície do compósito, o qual pode ser $\mathrm{Zr}-\mathrm{OH}$ ou $\mathrm{Al}-\mathrm{OH}$. Os resultados mostraram que os compósitos Ce-TZP/ $\mathrm{Al}_{2} \mathrm{O}_{3}$ possuem habilidade de formação de apatita em SBF após tratamentos com soluções de $\mathrm{H}_{3} \mathrm{PO}_{4}, \mathrm{H}_{2} \mathrm{SO}_{4}, \mathrm{HCl}$ e $\mathrm{NaOH}$, porque ocorre a formação superficial de grupos $\mathrm{Zr}-\mathrm{OH}$ via estes tratamentos. O 
tratamento com $\mathrm{H}_{3} \mathrm{PO}_{4} 5 \mathrm{M}$ apresentou a maior taxa de formação de apatita e os autores atribuem este fato, à maior densidade de grupos $\mathrm{Zr}-\mathrm{OH}$ obtido com este tratamento.

Miyaji, Kim, Kokubo,et.al.(1999), utilizaram o silicato de sódio como agente nucleante para a formação de apatita em polímeros orgânicos. As soluções foram preparadas com metasilicato de sódio em concentrações de $\mathrm{SiO}_{2}$ correspondentes a 0,5 , $1,0,2,0$ e 3,0M. À temperatura ambiente, as soluções com concentrações $\mathrm{SiO}_{2} 3,0 \mathrm{M}$ não foram eficazes. Outras séries de experimentos utilizando-se soluções com várias razões molares $\mathrm{SiO}_{2} / \mathrm{Na}_{2} \mathrm{O}$ de $0,5,0,67,0,8,1,0,1,5$ e 2,0 também foram realizadas. Os polímeros, após o tratamento com silicato de sódio com várias concentrações e várias razões molares $\mathrm{SiO}_{2} / \mathrm{Na}_{2} \mathrm{O}$ por $6 \mathrm{~h}$ a $36,5^{\circ} \mathrm{C}$, foram imersos em $20 \mathrm{ml}$ de $1,5 \mathrm{SBF}$ por vários períodos a $36,5^{\circ} \mathrm{C}$.

Após a imersão em 1.5SBF, as amostras foram caracterizadas por difração de raios $\mathrm{X}$ em filme fino, infravermelho è microscopia eletrônica de varredura. A análise dos dados obtidos por difração de raios $\mathrm{X}$ em filme fino e infravermelho, mostraram que as amostras imersas em metasilicato de sódio por $6 \mathrm{~h}$ e imersas em 1,5SBF por 6 dias, apresentaram picos relacionados à apatita somente nas amostras tratadas com concentração de 2,0M de metasilicato de sódio. Por microscopia eletrônica de varredura, no caso de $0,5 \mathrm{M}$, foi detectado algumas partículas de apatita na superfície do substrato, sendo que o número de partículas de apatita aumentaram para o tratamento com 1,0M de solução. As superfícies dos substratos foram completamente cobertas com apatita para tratamentos com 2,0M e 3,0M de solução de metasilicato. Esses resultados indicam que a formação da apatita aumenta com o aumento da concentração de metasilicato de sódio. Observou-se por DRXFF, picos relacionados à apatita para razões molares de $\mathrm{SiO}_{2} / \mathrm{Na}_{2} \mathrm{O}$ de 1,0 e 1,5. Entretanto, a análise por infravermelho, indicou a presença de picos de apatita também para razões molares de 2,0, com intensidade consideravelmente mais baixa. Nenhuma apatita foi observada para razões molares de $0,5,0,67$ e 0,8 . Todas as superfícies dos substratos foram cobertas com apatita para razões molares de 1,0 e 1,5. Partículas de apatita foram depositadas em parte para razões molares de 2,0, indicando assim que razões molares de soluções de silicato de sódio $\mathrm{SiO}_{2} / \mathrm{Na}_{2} \mathrm{O}$ de 1,0 e 1,5 são mais eficientes para a formação da apatita. A formação da apatita aumentou com o aumento da concentração do metasilicato de sódio, isso é explicado porque os íons silicato aderidos nos substratos aumentaram com o aumento da concentração de metasilicato de sódio, formando maior nucleação da 
apatita. É notável que o grau da formação da apatita seja quase o mesmo entre 2,0 e $3,0 \mathrm{M}$, sugerindo que o número de íons silicato aderidos no substrato é saturado com concentração $2,0 \mathrm{M}$.

A apatita foi formada com sucesso em polímeros orgânicos pelo processo biomimético usando silicato de sódio como agente nucleante. A formação da apatita foi mais alta quando a concentração de $\mathrm{SiO}_{2}$ e razão molar da solução foi de 2,0M e 1,01,5 , respectivamente. A camada de apatita foi formada não somente em regiões limitadas, mas em toda superfície da fibra do polímero. Esse método é capaz de aderir apatita em materiais com formas complexas.

Kim et al.(1995), mostrou que em vidros $\mathrm{Na}_{2} \mathrm{O}-\mathrm{CaO}-\mathrm{SiO}_{2}$ sem $\mathrm{P}_{2} \mathrm{O}_{5}$ com uma faixa grande de composição de $\mathrm{SiO}_{2}$ variando de 50 a $70 \%$, é observada a formação de apatita em sua superfície quando imersos em SBF, com o tempo de imersão necessário variando de 0,5 dia para 28 dias. Fujibayashi et al.(2003), implantou partículas granulares desses vidros no interior da tíbia de um coelho. A espessura do osso cresceu da periferia para o interior e foi avaliado após 3 e 6 semanas. Após o implante, a espessura aumentou com o aumento da formação prévia da apatita em SBF. De acordo com a Figura 1, tem-se:

0,5 dia para a formação da apatita têm-se tanto para 3 quanto para 6 semanas aproximadamente $50 \%$ de espaço a ser preenchido na tíbia do coelho.

3 dias para a formação da apatita têm-se tanto para 3 quanto para 6 semanas aproximadamente $48 \%$ de espaço a ser preenchido na tíbia do coelho.

7 dias para a formação da apatita têm-se tanto para 3 quanto para 6 semanas aproximadamente $38 \%$ e $20 \%$ respectivamente de espaço a ser preenchido na tíbia do coelho.

21 dias para a formação da apatita têm-se tanto para 3 quanto para 6 semanas aproximadamente $30 \%$ e $12 \%$ respectivamente de espaço a ser preenchido na tíbia do coelho.

28 dias para a formação da apatita têm-se tanto para 3 quanto para 6 semanas aproximadamente $20 \%$ e $5 \%$ respectivamente de espaço a ser preenchido na tíbia do coelho. 


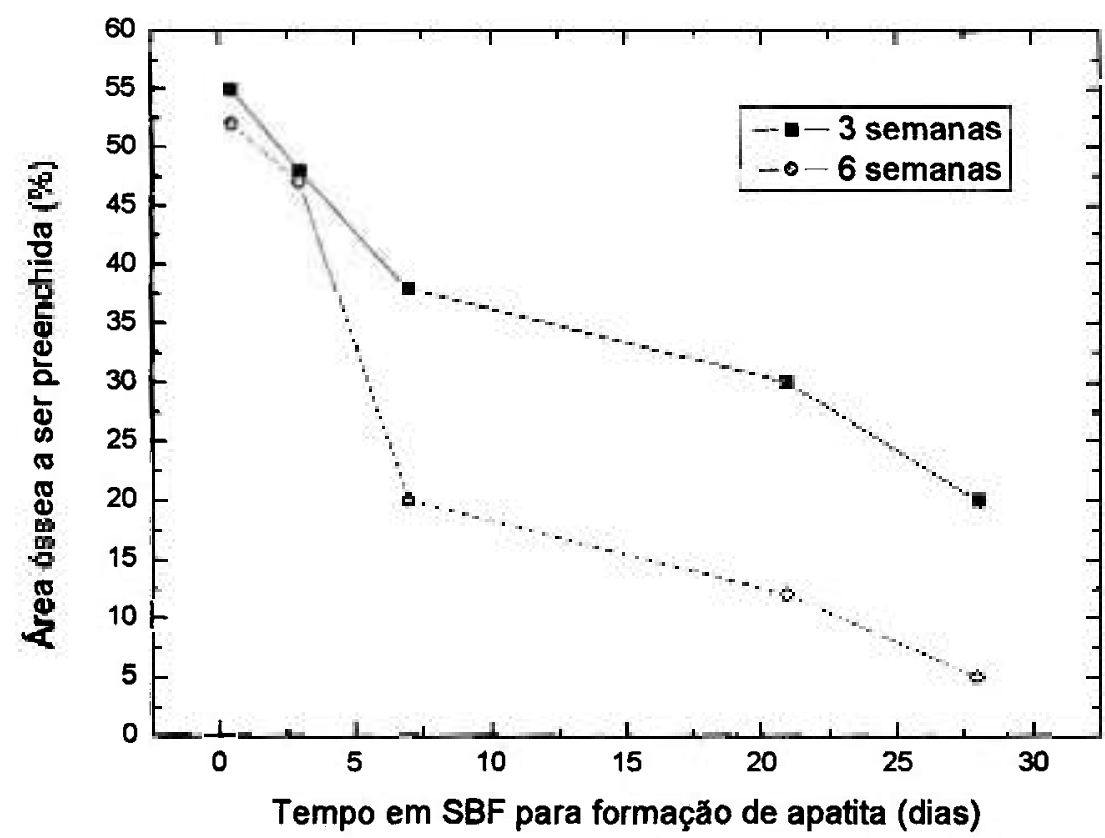

Figura1: Área óssea a ser preenchida por tempo em SBF para formação de apatita

O grau da habilidade de formar apatita na superficie de um material em SBF pode predizer o grau da bioatividade "in vivo". Um material capaz de formar apatita na superficie em SBF em um curto período adere ao osso em um curto período, como resultado da formação da apatita na superficie em um menor período dentro do corpo. $O$ exame da formação da apatita na superfície do material em SBF, geralmente é usada para predizer a bioatividade do material no osso "in vivo", não somente qualitativamente, mas também quantitativamente.

Chevalier, Deville, Munch, Jullian, Lair (2004), prepararam quatro amostras de 3Y-TZP sinterizadas nas seguintes condições: $1450^{\circ} \mathrm{C}$ por 2 horas, $1450^{\circ} \mathrm{C}$ por 5 horas, $1550^{\circ} \mathrm{C}$ por 2 horas e $1550^{\circ} \mathrm{C}$ por 5 horas. $\mathrm{O}$ tamanho de grão é pequeno e homogêneo para amostras sinterizadas $1450^{\circ} \mathrm{C} / 2$ horas, ficando maior a $1450^{\circ} \mathrm{C} / 5$ horas e $1550^{\circ} \mathrm{C} / 2$ horas, mas ainda continua unimodal. A microestrutura se torna claramente bimodal quando a temperatura de sinterização é $1550^{\circ} \mathrm{C} / 5$ horas. Há presença de grãos cúbicos, que devem ter uma maior quantidade de ítria do que grãos tetragonais. Os grãos tetragonais estão na periferia e longe dos grãos cúbicos. Há uma relação entre a quantidade de fase monoclínica com o tempo de envelhecimento para os quatro materiais. Quanto maior a temperatura e o tempo, maior a taxa de transformação. Quanto maior o tamanho de grãos tetragonais, menor sua estabilidade. $\mathrm{O}$ tamanho de 
grão do material $1450^{\circ} \mathrm{C} / 5 \mathrm{~h}$ e $1550^{\circ} \mathrm{C} / 2 \mathrm{~h}$ é praticamente o mesmo, a única diferença é a possibilidade de formar uma maior porção de grãos cúbicos a $1550^{\circ} \mathrm{C} / 2 \mathrm{~h}$. Esses grãos atraem ítria dos grãos tetragonais vizinhos, os quais os tornam menos estáveis. Quanto maior a quantidade de fase cúbica presente no material, maior é a taxa de nucleação da transformação de fase. $O$ envelhecimento se inicia preferencialmente em regiões ao redor de grãos cúbicos, esses grãos atuam como sítios de nucleação para transformação, pois ao redor, os grãos tetragonais exibem menor quantidade de ítria do que inicialmente. Por comparação, o início do envelhecimento ocorre em uma taxa muito menor no material processado a $1450^{\circ} \mathrm{C} / 5 \mathrm{~h}$ do que no $1550^{\circ} \mathrm{C} / 5 \mathrm{~h}$. Esses resultados são confirmados por MEV, o qual mostra que após o envelhecimento há uma degradação da superfície (descolamento de grãos/microtrincas) no material $1550^{\circ} \mathrm{C} / 5 \mathrm{~h}$, especialmente na periferia dos grãos cúbicos. Microtrincas nos grãos cúbicos ocorre pelas tensões que são induzidas pela transformação de grãos vizinhos tetragonais sem que haja opção de acomodação. A presença de grãos cúbicos, tensão residual, trincas ou poros residuais devem ter um papel importante no envelhecimento da zircônia. Concluiu-se que a presença de grãos cúbicos tem um impacto ruim na resistência ao envelhecimento. $\mathrm{O}$ processamento da $3 \mathrm{Y}$-TZP deve ser conduzido a temperaturas suficientemente baixas para evitar a ocorrência da microestrutura cúbica- tetragonal, mas suficientemente alta para obter materiais completamente densos. Isso significa que uma estreita faixa de temperatura de sinterização certamente entre $1400^{\circ} \mathrm{C}$ e $1450^{\circ} \mathrm{C}$ tem sido escolhida para processar 3Y-TZP resistente ao envelhecimento.

Alguns estudos mostraram experiências clínicas positivas no uso da zircônia como implante, enquanto que outros mostram degradações superficiais nos implantes e em alguns casos foi relatado desgaste severo em torno do implante. As consequiências no processo de envelhecimento em implantes de zircônia após muito tempo de uso pode ser associada à rugosidade, causada pelo uso e microtrincas, causada pelo arrancamento de grãos e geração de detritos de partículas. Estes dois fatores são pouco documentados, mesmo após 20 anos de uso e milhares de implantes. Jerome Chevalier (2006) avaliou as falhas que ocorreram com os implantes de cabeça de fêmur de zircônia. Houve uma discussão, em função das falhas dos implantes de Prozyr em 2001-2002, sobre o futuro da zircônia como biomaterial. Foi mostrado, que havia uma grande variação no comportamento de degradação "in vivo", como conseqüência dos diferentes processamentos e condições de envelhecimento. Os problemas de desempenho dos 
implantes da Prozyr têm levado a comunidade científica e ortopédica a estudar mais profundamente o comportamento da zircônia in vitro e "in vivo". Em contraste com as experiências clínicas mal sucedidas, alguns resultados ainda se mostram bons. Cabeça de fêmur de zircônia com $22 \mathrm{~mm}$ de diâmetro mostrou menos de $10 \%$ de fase monoclínica após 45 meses, sem aumento de aspereza e sem grãos arrancados. Cabeças extraídas do mesmo tipo devem ser vistas com especial interesse, uma vez que LTD (degradação a baixas temperaturas) ocorre por nucleação e crescimento e podem estar no estágio de nucleação (pequena, mas com significante conteúdo de monoclínica). É, portanto, necessários estudos mais avançados nos implantes de zircônia, com uma profunda correlação entre microestrutura e resistência a deformação a baixas temperaturas "in vivo".

Recentemente dois cirurgiões independentes forneceram duas cabeças de fêmur recuperadas, uma foi recuperada após 8 anos e a origem da revisão foi relacionada a falhas ou perda de assepsia, a segunda cabeça foi recuperada devido há uma quebra, resultante do envelhecimento de uma cabeça de fêmur de zircônia após somente 4,5 anos "in vivo". As peças recuperadas foram analisadas por DRX em vários pontos para estimar a quantidade de transformação de fase "in vivo". Foram utilizados MEV e microscopia de força atômica para avaliar possiveis degradações superficiais induzidas por transformação de fase. As partes extraídas foram cortadas em partes para obter seções do núcleo da cabeça, livres de qualquer transformação superficial, isto é, sem contato com o fluído do corpo. Em uma das seções polidas de cada cabeça, cinéticas de envelhecimento foram realizadas a $134^{\circ} \mathrm{C}, 2$ bars em autoclave para obter a cinética esperada de $37^{\circ} \mathrm{C}$ para cada cabeça e comparar com os resultados obtidos experimentalmente na superfície que estava em contato com o fluído do corpo. Em outra peça polida, foi feito um ataque térmico a $1300^{\circ} \mathrm{C}$ por 30 minutos para obter informação do tamanho de grão. A densidade e composição foram checadas de acordo com a norma ISO, obedecendo ao padrão. A maior diferença recai no tamanho de grão para a segunda cabeça, provavelmente pelo processo de sinterização (tempo, temperatura). Isso pode ser a principal origem nas diferenças dos conteúdos de monoclínica "in vivo": Em torno de 10\% após 8 anos para a primeira cabeça e 20\% após 4,5 anos para a segunda cabeça, com a ocorrência de grandes zonas danificadas parecendo crateras, as quais estão relacionadas com os núcleos de fase monoclínica formadas pelo envelhecimento. Os testes em autoclave por 3 horas a $134^{\circ} \mathrm{C}$ mostraram que a cabeça que durou 4,5 anos tem aproximadamente $45 \%$ da fase monoclínica, 
enquanto que a cabeça que durou 8 anos, tem $15 \%$ de fase monoclínica. Os experimentos "in vivo" tiveram um comportamento muito parecido com os testes.

O estudo do envelhecimento da zircônia na parte biomédica torna-se muito importante e ferramentas poderosas podem ser usadas para acessar sua sensitividade contra o envelhecimento. Nesse campo, parece que o futuro está na combinação de alumina zircônia para obter compósitos avançados.

Maria Cecília Correa de Sá, Carlos Nelson Elias, et.al.(2004), prepararam diferentes composições com mistura de óxidos variando a quantidade de zircônia de 5 a $80 \%$ em peso. Foram determinados a dureza utilizando uma carga de $10 \operatorname{Kgf}(98,1 \mathrm{~N})$ durante 10 segundos. A tenacidade à fratura é dada pelos valores de $\mathrm{K}_{\mathrm{IC}}$. $\mathrm{O}$ fator $\mathrm{K}_{\mathrm{IC}}$ foi determinado usando o método da medida direta da trinca. O módulo de elasticidade foi obtido pela regra das misturas sendo 210GPa para zircônia e $380 \mathrm{GPa}$ para alumina.

Foram realizados os seguintes testes:

\section{Densidade}

Os óxidos sinterizados puros e compósitos mostraram densidade relativa na faixa de $99,13 \%$ a 99,86\%. Em geral, amostras sinterizadas com maiores densidades relativas exibem melhores propriedades mecânicas, entretanto é também uma influência da uniformidade microestrutural nas propriedades mecânicas. A maior densidade foi da amostra contendo $80 \%$ zircônia. Para a alumina pura e com $21 \%$ de zircônia, a densidade do compósito aumenta com o aumento da zircônia, indicando que a adição de zircônia permite a densificação da matriz de alumina, como a alumina permite a densificação da matriz de zircônia. Observações por $\mathrm{MEV}$ indicaram que as microestruturas são altamente homogêneas sem aglomerados, poros ou excepcionalmente crescimento de grãos de alumina. DRX identificou que a alumina alfa, zircônia tetragonal e monoclínica são as fases cristalinas presentes, tanto para amostras puras quanto para compósitos. O uso de $0,6 \%$ de ácido cítrico como dispersante foi efetivo para prevenir aglomerados que são fontes de imperfeições durante a sinterização.

\section{Indentacão e dureza vickers}

A dureza vickers obedece à regra das misturas. Com o aumento do teor da zircônia, a dureza do compósito diminui. Maiores valores de dureza implicam em 
melhor resistência ao desgaste e ao risco. A força aplicada pode afetar a dimensão da indentação e o comprimento da trinca, sendo dependentes da dimensão da amostra e da microestrutura do material.

\section{Medidas de Tenacidade à fratura}

Nos compósitos com matriz de alumina ou mesmo com alta porcentagem de alumina, o aumento da quantidade de zircônia tetragonal geralmente envolve um considerável aumento de $\mathrm{K}_{\mathrm{IC}}$. Valores de dureza são reduzidos com o aumento da zircônia no compósito. Valores superiores de $\mathrm{K}_{\mathrm{IC}}$ para $80 \%$ de zircônia podem ser explicados pela melhor densificação do compósito, conseqüência do reduzido tamanho e distribuição da partícula, além da elevada área de superfície específica e uma maior retenção de fase tetragonal. Concluiu-se que a adição de zircônia em matriz de alumina promove compósitos com maiores densidades, maiores resistências à flexão e tenacidade à fratura. Verificou-se também, que ocorre uma dependência inversa entre $K_{\text {IC }}$ e dureza. Esses compósitos podem ter $93 \%$ de resistência à flexão e $29 \%$ de tenacidade à fratura superior quando comparado com alumina pura. Os compósitos com maior conteúdo de zircônia exibiram maiores resistências à flexão e tenacidade à fratura quando comparados com alumina pura e mesmo zircônia pura. Esses compósitos parecem ser materiais adequados para serem usados em implantes em substituição aos óxidos puros atualmente em uso.

L.C. de O. Vercik, et.al.(2003), realizaram um tratamento em solução de $\mathrm{NaOH}$ nos substratos de titânio. Após esse tratamento, os mesmos foram imersos em uma solução de silicato de sódio e posteriormente em uma solução de SBF para uma nucleação mais lenta e organizada da apatita a ser depositada. Em seguida, os substratos foram imersos em uma solução $1,5 \mathrm{SBF}$ para crescimento mais rápido da mesma. $\mathrm{O}$ tratamento químico com $\mathrm{NaOH}$ foi realizado com o objetivo de aumentar a área específica e a energia superficial do substrato, com o intuito de produzir uma superfície mais favorável e ativa para induzir a precipitação de apatita. Durante o tratamento alcalino a superfície do substrato pode reagir da seguinte forma: 


$$
\begin{aligned}
& \mathrm{MO}_{2}+\mathrm{OH}^{-} \rightarrow \mathrm{HMO}_{3}^{-} \\
& \mathrm{M}+3 \mathrm{OH}^{-} \rightarrow \mathrm{M}(\mathrm{OH})_{3}{ }^{+}+4 \mathrm{e}^{-} \\
& \mathrm{M}(\mathrm{OH})_{3}{ }^{+}+\mathrm{e}^{-} \rightarrow \mathrm{MO}_{2} \mathrm{H}_{2} \mathrm{O}+1 / 2 \mathrm{H}_{2}(\mathrm{~g}) \\
& \mathrm{M}(\mathrm{OH})_{3}{ }^{+}+\mathrm{OH}^{-} \rightarrow \mathrm{M}(\mathrm{OH})_{4} \\
& \mathrm{MO}_{2} \mathrm{nH}_{2} \mathrm{O}+\mathrm{OH}^{-} \rightarrow \mathrm{HMO}_{3}^{-} \mathrm{nH}_{2} \mathrm{O}
\end{aligned}
$$

$\mathrm{O}$ símbolo $\mathrm{M}$ em questão é o metal titânio, podendo ser qualquer outro substrato metálico. Essas espécies carregadas negativamente combinam com os íons alcalinos na solução aquosa, resultando na formação de uma camada alcalina de hidrogel de titanato. A baixa capacidade de obtenção de grupos Ti-OH, decorrente do caráter anfótero do $\mathrm{TiO}_{2}$. faz com que os substratos não formem núcleos suficientes para produzir uma camada densa e uniforme de apatita. Portanto, a imersão destes substratos em uma solução de um sal que apresente uma tendência a incrementar pontes de-OH e não desloque o equilíbrio do meio, possibilitará o aumento dos sítios ativos sobre a superfície do material. A solução de silicato de sódio aumenta a nucleação das apatitas, através da formação de grupos silanol ( $\mathrm{Si}-\mathrm{OH})$, sendo acelerada quando imersos em uma solução de SBF. Com a imersão dos substratos em uma solução 1,5 vez mais concentrada que a solução de SBF original, os núcleos das apatitas crescem espontaneamente pelo consumo dos íons cálcio e fosfato da solução, formando uma camada uniforme de apatita.

Os recobrimentos de apatitas sobre a superfície do hidrogel foram tratados termicamente por 400,500 e $600^{\circ} \mathrm{C}$ e foram caracterizados por DRX. Apareceram três bandas largas salientes características às fases apatitas, localizadas aproximadamente em $2 \theta=26^{\circ}, 29^{\circ}$ e $32^{\circ}$, indicando uma estrutura pouco cristalina, bem similar à apatita biológica. A baixa cristalinidade das fases, no recobrimento, leva a instabilidade do material quando implantado. De acordo com a literatura, Gil et.al. (2002) e Gross et.al. (1997), fosfatos de cálcio amorfos e principalmente as fases fosfato tetracálcio e fosfato tricálcio possuem uma solubilidade bem superior a hidroxiapatita, levando o recobrimento a uma rápida desintegração e, portanto à perda de fixação do implante, fenômeno conhecido como reabsorção. Há um aumento da cristalinidade quando os recobrimentos de apatitas são tratados termicamente por 700 e $800^{\circ} \mathrm{C}$, formando picos referentes à fase octacálcio $(\mathrm{OCP})$ e fosfato de magnésio hidratado, além da fase da hidroxiapatita. A fase OCP é considerada muito promissora devido à sua participação na formação óssea, e também por ser precursora da fase hidroxiapatita. Quando observada 
por $\mathrm{MEV}$, a fase de fosfato de magnésio hidratado tem uma morfologia de aspecto esponjoso. Os resultados obtidos utilizando-se o processo biomimético em duas etapas proporcionaram um recobrimento com uma camada de apatita uniforme, homogênea e com uma boa porosidade. Com o processo de nucleação lento, a fase marjoritária encontrada foi a hidroxiapatita. As outras fases presentes apareceram em pequenas quantidades, sendo a fase fosfato octacálcio um precursor da fase hidroxiapatita. Com tratamentos térmicos entre 400 e $600^{\circ} \mathrm{C}$, as fases apresentaram-se pouco cristalinas, com uma evolução a temperaturas superiores. Esse processo de recobrimento de apatitas mostrou-se extremamente eficiente para obtenção da fase hidroxiapatita semelhante à biológica, com baixa cristalinidade mesmo quando submetidas a tratamentos térmicos entre 400 e $600^{\circ} \mathrm{C}$.

Dora A. Cortés, Sérgio Ortega, et.al.(2006), estudaram amostras de Mg-PSZ e $\mathrm{Mg}-\mathrm{PSZ} / \mathrm{CaSiO}_{3}$ tratadas quimicamente com $\mathrm{H}_{3} \mathrm{PO}_{4} 5 \mathrm{M}$ a $90^{\circ} \mathrm{C}$ por 4 dias. As amostras tratadas quimicamente de $\mathrm{Mg}-\mathrm{PSZ}$ e $\mathrm{Mg}-\mathrm{PSZ} / \mathrm{CaSiO}_{3}$ foram imersas em uma cama de 1,5 gramas de pó de wollastonita $\left(\mathrm{CaSiO}_{3}\right)$ em $150 \mathrm{ml}$ de $\mathrm{SBF}$ por 3, 5 e 7 dias. Amostras não tratadas também foram imersas em SBF com o objetivo de avaliar o efeito do tratamento químico na formação de apatita nos materiais. Testes também foram realizados sem o uso da wollastonita. As amostras tratadas e não tratadas foram imersas em SBF por períodos de tempos maiores (14 e 21 dias) utilizando o método da re-imersão. Esse procedimento consiste na imersão de amostras em SBF por 7 dias em uma cama de wollastonita e então re-imersos em 1,5SBF. Testes foram feitos sem o uso da wollastonita durante os primeiros 7 dias da imersão. Após a imersão em SBF e 1,5 SBF durante 7 dias, utilizando uma cama de wollastonita, foi verificado que nas amostras não tratadas quimicamente de $\mathrm{Mg}-\mathrm{PSZ}$ houve a formação de apatita. Realizando-se a imersão por 14 dias houve uma formação maior de apatita com picos intensos da Ca e P segundo análise por EDS. Se a imersão ocorrer por 21 dias, o pico da Zr desaparece, indicando a formação de apatita em maior quantidade. Para as amostras não tratadas e sem a presença de wollastonita imersa em SBF, nenhuma mudança na superfície foi observada, indicando que a presença de wollastonita, que é um material bioativo, tem um forte efeito no mecanismo da formação da apatita quando as amostras não são tratadas quimicamente. Se as amostras de Mg-PSZ são tratadas quimicamente e então imersas por 14 e 21 dias em SBF e 1,5 SBF, sem a cama de wollastonita, uma camada rica de $\mathrm{Ca}$ e $\mathrm{P}$ é também observada, entretanto, sua microestrutura consiste de 
mais finos aglomerados do que nas amostras sem tratamento químico, indicando que a taxa de nucleação de $\mathrm{Ca}$ e $\mathrm{P}$ é mais alta nas amostras tratadas quimicamente do que nas amostras que não foram tratadas.

A literatura (Uchida, 2002), indica que o tratamento químico leva a formação de grupos $\mathrm{Zr}-\mathrm{OH}$ na superfície da cerâmica. Esses grupos induzem a nucleação da apatita durante a imersão dos compósitos em SBF. Para as amostras tratadas quimicamente e utilizando-se a cama de wollastonita, com 3 dias, observa-se a presença de Ca e P, já que a wollastonita tem um forte efeito positivo na formação da apatita. Para as amostras $\mathrm{Mg}-\mathrm{PSZ} / \mathrm{CaSiO}_{3}$, geralmente é observada uma bioatividade mais alta quando $\mathrm{CaSiO}_{3}$ é um dos constituintes do compósito. Foi observado que nos compósitos não tratados quimicamente, após a imersão em SBF e 1,5 SBF sem a cama de wollastonita, uma homogênea camada rica em Ca e P foi formada após 7 dias de imersão. Após 14 dias, essa camada é mais espessa do que a formada em Mg-PSZ puro sobre as mesmas condições. Já para as amostras $\mathrm{Mg}-\mathrm{PSZ} / \mathrm{CaSiO}_{3}$ não tratadas e em cama de wollastonita, resultados similares foram obtidos, entretanto a presença de mais finos aglomerados está presente quando a cama de wollastonita é utilizada, indicando a nucleação de componentes ricos em $\mathrm{Ca}$ e $\mathrm{P}$. A fase $\mathrm{CaSiO}_{3}$ do compósito $\mathrm{Mg}-\mathrm{PSZ} / \mathrm{CaSiO}_{3}$ tratado quimicamente, foi parcialmente dissolvida durante o tratamento químico levando a uma superfície porosa. Após 7 dias em SBF, compostos ricos de $\mathrm{Ca}$ e $\mathrm{P}$ foram formados preferencialmente na porosidade. Esses resultados indicam que os mecanismos da formação da apatita em $\mathrm{CaSiO}_{3}$ tratados quimicamente são:

- Durante o tratamento químico de amostras com uma solução de ácido fosfórico, ocorre a formação de grupos $\mathrm{Zr}-\mathrm{OH}$ e Si-OH na superfície do compósito.

- Cristais de apatita crescem consumindo íons $\mathrm{Ca}$ e P das soluções mais concentradas $(1,5 \mathrm{SBF})$.

Geralmente a razão atômica $\mathrm{Ca} / \mathrm{P}$ cai com o aumento do tempo de imersão. Isso pode ser explicado levando-se em conta que a duração da imersão de um material bioativo em SBF, provoca uma troca iônica entre $\mathrm{H}^{+}$do $\mathrm{SBF}$ e $\mathrm{Ca}^{2+}$ do pó de wollastonita. Eventualmente, o aumento do valor de $\mathrm{pH}$ leva a uma nucleação de cristais ricos em Ca no substrato. Com o aumento do tempo de imersão, os cristais ricos em Ca

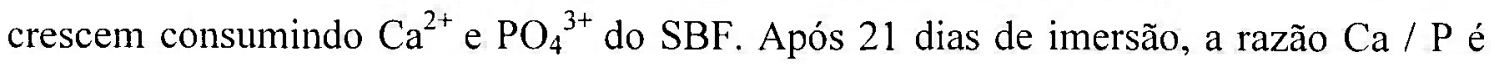
mais baixa do que a composição ideal de hidroxiapatita, mas dentro da faixa da razão 
$\mathrm{Ca} / \mathrm{P}$ da apatita óssea. Essa diminuiçãó é mais alta para as amostras tratadas quimicamente e para os compósitos $\mathrm{Mg}-\mathrm{PSZ} / \mathrm{CaSiO}_{3}$, o qual deve indicar que ambos, tratamento químico e cama de wollastonita, melhoram a habilidade da formação da apatita nesses materiais. Concluiu-se que o potencial de $\mathrm{Zr}$ bioativa foi desenvolvida pelo tratamento biomimético consistindo de um tratamento químico em uma solução de ácido fosfórico seguido da imersão das amostras tratadas em SBF e 1,5 SBF. Se a cama de wollastonita é utilizada durante a imersão das amostras em SBF, um efeito sinérgico entre a cama de wollastonita e amostras tratadas quimicamente ocorre, levando a formação de apatita no substrato após 5 dias de imersão. Os compósitos $\mathrm{Mg}$ $\mathrm{PSZ} \mathrm{CaSiO}_{3}$ mostraram maior bioatividade devido a formação de uma densa e mais aderente camada de apatita.

Xuanyong, Chuanxian, Paul (2004), depositaram em Ti-6Al-4V por plasma spray, pós de wollastonita. As amostras cobertas com wollastonita foram imersas em ácido lático $\left(\mathrm{CH}_{3}-\mathrm{CH}(\mathrm{OH})-\mathrm{COOH}\right)$ por 1, 3 e 7 dias. Essas amostras foram chamadas de WL1, WL3 e WL7. Algumas WL3 foram imersas em solução de trimetanol aminometano e chamadas de WL3T. As amostras WL3 e WL3T foram imersas em SBF por 4 dias. Após o recobrimento com wollastonita por plasma spray, foi formada uma rugosidade na superfície, indicando que o recobrimento é formado por partículas fundentes, e isso é favorável para biomateriais. Após a imersão em ácido lático por 1 dia, o recobrimento na superfície leva a uma fina camada, caracterizada por microtrincas que se manifestam. Com o aumento do tempo de imersão em ácido lático, o cálcio no recobrimento gradualmente se dissolve dentro da solução de ácido lático formando uma rica camada de sílica na superfície da wollastonita. O produto da atividade iônica da apatita em SBF é considerado ser a chave para a formação da apatita na superfície do substrato. $\mathrm{O}$ aumento da concentração de íons cálcio e $\mathrm{pH}$ do SBF pode resultar no aumento do produto da atividade iônica da apatita e isso é benéfico para a precipitação da apatita na superfície do substrato.

No trabalho de Xuanyong, o WL3 foi imerso com o dobro da concentração de $\left[\mathrm{Ca}^{2+}\right]$ na solução de SBF para investigar a contribuição do cálcio para a formação da apatita. Após a imersão por 4 dias, nenhuma formação de apatita foi encontrada na superfície rica em sílica do WL3, isso infere que a concentração de cálcio no SBF não é fator crítico para a precipitação da apatita na superfície da wollastonita. A superfície do WL3T, após a imersão em SBF por 4 dias é completamente coberta por partículas 
arredondadas, onde microtrincas aparecem na camada formada; a camada de apatita exibe poucos cristalitos. O espectro de EDS indica a presença de cálcio e fósforo, o sódio, magnésio e o cloro são provenientes do SBF. Há diferenças entre a superfície com apatita e sem apatita. A superfície sem apatita mostra uma camada rica em sílica. A composição do recobrimento de wollastonita é similar ao vidro silicato de cálcio. Quando a wollastonita é imersa em solução de ácido lático, trocas de íons ocorrem entre a camada da superfície do recobrimento e a solução, como resultado dos diferentes potenciais químicos dos íons. Simultaneamente com a dissolução dos íons cálcio da superfície para a solução e a penetração dos prótons do ácido lático para a superfície. Grupos silanóis são formados na superfície:

$$
\equiv \mathrm{Si}-\mathrm{OH}+\mathrm{OH}^{-}=\equiv \mathrm{Si}-\mathrm{O}^{-}+\mathrm{H}_{2} \mathrm{O}
$$

Uma carga negativa na superfície é formada com o grupo funcional (三Si-O־). A carga negativa atrai cátions da solução diminuindo a energia total do sistema levando a um aumento de cátions na interface. O produto da atividade iônica da apatita na interface é maior do que na solução. Quando o produto da atividade iônica é alto o suficiente, ocorre a precipitação e a nucleação da apatita na superfície, crescendo espontaneamente e os íons Ca e P são consumidos do SBF. O mecanismo de formação de apatita na superfície de wollastonita em SBF pode ser descrito da seguinte maneira: Quando a wollastonita é imersa em SBF, íons cálcio da wollastonita trocam com o hidrogênio da solução levando a formação do silanol ( $\equiv \mathrm{Si}-\mathrm{OH})$ na camada da superfície, o $\mathrm{pH}$ aumenta e finalmente há a formação de uma carga negativa na superfície com o grupo funcional $\left(\equiv \mathrm{Si}-\mathrm{O}^{-}\right)$. Os íons cálcio do $\mathrm{SBF}$ são inicialmente atraídos para a interface entre o recobrimento e a solução. Subsequentemente, a atividade iônica da apatita na interface é alta o suficiente para precipitar apatita na superfície. Conclui-se que uma carga negativa é formada na superfície do material com o grupo funcional ( $\equiv \mathrm{Si}-\mathrm{O}^{-}$), contribuindo para a formação de apatita. O aumento da concentração de cálcio no SBF não é fator crítico para afetar a precipitação da apatita na wollastonita.

Estudos recentes mostram que os metais de titânio, ligas de titânio e tântalo quando submetidos a tratamentos químicos com $\mathrm{NaOH}$ e subseqüente tratamento térmico, formam uma camada de apatita em suas superfícies quando imersos em SBF. Da mesma forma que ocorre no SBF, os metais tratados termicamente e quimicamente 
com $\mathrm{NaOH}$ formam apatita no corpo humano, ligando-se ao osso através dessa camada de apatita. Esses metais podem ser utilizados como substituto ósseo em fêmur e tíbia, pois apresentam alta tenacidade à fratura e alta habilidade de ligação óssea. É cientificamente e tecnicamente interessante saber, que existem outros metais tratados com $\mathrm{NaOH}$ que podem ser utilizados para indução da formação de apatita. Um deles é o metal zircônio, que tem altas propriedades mecânicas e alta biocompatibilidade, sendo um material de grande interesse para implante cirúrgico. Esse metal é considerado como um importante componente de liga para o metal titânio com a finalidade de melhorar as propriedades mecânicas. A habilidade da formação de apatita em SBF no metal de zircônio tratado com $\mathrm{NaOH}$ tem sido estudada. É conhecido, que materiais que formam uma camada de apatita em suas superfícies em SBF, formam a mesma camada de apatita no corpo humano, podendo quimicamente se ligar ao osso através dessa camada. Uchida, Kim, Miyaji, Kokubo, Nakamura (2002), utilizaram chapas de metal de zircônio comercialmente puro, polidas e lavadas com acetona e água destilada em ultrassom. Essas chapas foram imersas por 24 horas em $5 \mathrm{ml}$ de $1-15 \mathrm{M}$ de solução aquosa de $\mathrm{NaOH}$ a $95^{\circ} \mathrm{C}$, lavadas com água destilada e secadas a $40^{\circ} \mathrm{C}$ por 24 horas. As amostras de zircônio não tratadas e tratadas com $\mathrm{NaOH}$ foram imersas em $30 \mathrm{ml}$ de SBF a $36,5^{\circ} \mathrm{C}$ por vários períodos. Após 28 dias, as chapas de zircônio foram retiradas do $\mathrm{SBF}$, lavadas com água destilada e secadas.

Por meio de microscopia eletrônica de varredura, nenhuma mudança estrutural foi observada na superfície do metal zircônio após a imersão em solução de 1-15M de $\mathrm{NaOH}$ a $95^{\circ} \mathrm{C}$ por 24 horas. Foram observadas também, as amostras não tratadas e tratadas com $\mathrm{NaOH}$ com posterior imersão em SBF por 4 e 28 dias. Houve formação de apatita cristalina em forma de esferas em regiões do zircônio metálico tratado com soluções de $\mathrm{NaOH}$ com concentrações maiores do que 5M, após a imersão em SBF por 4 dias. Concluiu-se que, zircônio forma apatita em sua superfície quando imerso em SBF após prévio tratamento em soluções de $\mathrm{NaOH}$ com concentrações acima de $5 \mathrm{M}$.

A nucleação da apatita é induzida por grupos $\mathrm{Zr}-\mathrm{OH}$ em uma camada hidrogel de zircônia, que se forma no metal quando em contato com a solução de $\mathrm{NaOH}$. $\mathrm{O}$ resultado indica a possibilidade de obter zircônio bioativo por um simples tratamento químico. A formação da apatita em zircônio tratado com solução de $\mathrm{NaOH}$ é menor do que em Ti e Ta tratados com a mesma solução. O metal tântalo tem excelente tenacidade à fratura e boa trabalhabilidade, sendo clinicamente utilizado em suturas e 
como um componente de liga de titânio em campo ortopédico e dental, entretanto não apresenta bioatividade. Muita atenção tem sido dada a metais bioativos, devido a sua alta reparação em defeitos ósseos, bem como sua alta afinidade biológica com tecidos moles. A bioatividade de um material artificial pode ser avaliada pela sua habilidade de formar apatita em SBF. Recentemente, Miyazaki, Kim, Kokubo, et.al.(2002), observaram que o metal tântalo comercialmente puro, forma apatita em sua superfície quando imerso em SBF por um período maior do que 4 semanas. Já no metal tântalo que foi previamente submetido á uma solução aquosa de $\mathrm{NaOH}$ com concentração $0,5 \mathrm{M}$ a $60^{\circ} \mathrm{C}$ por 24 horas, seguido de um tratamento térmico à $300^{\circ} \mathrm{C}$ por 1 hora, foi observado a formação de apatita em apenas 1 semana. Isso sugere que com o tratamento no metal tântalo puro, há um maior potencial para a bioatividade.

Observou-se por microscopia eletrônica de varredura, a formação de partículas esféricas na superfície do metal tratado após 3 dias de imersão em SBF e para o metal não tratado observou-se as mesmas partículas após 4 semanas de imersão em SBF. Os resultados indicam que as partículas esféricas formadas na superfície das amostras imersas em SBF são apatita e que a taxa da formação de apatita é mais alta em materiais tratados do que em materiais não tratados. Pelos resultados de espectroscopia de raios $\mathrm{X}$ e por difração de raios $\mathrm{X}$, nota-se que o tântalo tratado é recoberto em sua superfície por tantalato de sódio amorfo, antes da imersão em SBF, enquanto o tântalo não tratado é recoberto em sua superfície por óxido de tântalo. Após a imersão das amostras em SBF, a concentração de sódio proveniente do tratamento químico, diminuiu com o aumento do tempo de imersão em SBF, indicando que o sódio foi liberado da superfície do tântalo tratado. Pelos resultados de XPS foram observados picos sobrepostos que são relacionados aos grupos $\mathrm{Ta}-\mathrm{OH}$, sendo muito maior nas amostras tratadas quimicamente do que nas amostras não tratadas. Os tratamentos com solução de $\mathrm{NaOH}$ e posteriormente tratados termicamente à $300^{\circ} \mathrm{C}$, proporcionam uma fase amorfa em tântalo puro. A fase amorfa é o tantalato de sódio que acelera a formação de uma camada de apatita em SBF. Ambas as amostras, com e sem tratamento, formam apatita em suas superfícies devido ao SBF ser supersaturado em relação à hidroxiapatita. Porém, as amostras tratadas têm uma maior taxa de formação da apatita. O processo comum para ambas as amostras, sem tratamento e com tratamento químico, na formação de apatita em SBF é da seguinte maneira: 
- Grupos Ta-OH são formados na superfície do metal tântalo;

- Os grupos Ta-OH formados, se combinam primeiramente com pequenas quantidades de íons cálcio para formar o tantalato de cálcio;

- O tantalato de cálcio formado combina com íns fosfatos;

- Grandes quantidades de íons cálcio e fosfatos são adsorvidos na superfície do metal tântalo para formar apatita.

Nota-se que o metal tântalo forma apatita em sua superfície em SBF, não diretamente, mas através da formação do tantalato de cálcio. A taxa de formação dos grupos Ta-OH é muito maior nas amostras tratadas do que nas amostras não tratadas, devido à lenta formação de grupos Ta-OH, causado pela lenta hidratação da camada passiva de óxido de tântalo na superfície em SBF para amostras não tratadas. A formação do tantalato de sódio amorfo na superfície do metal para as amostras com tratamento, troca rapidamente seus íons sódio com os íons $\mathrm{H}_{3} \mathrm{O}^{+}$do $\mathrm{SBF}$, como resultado, grupos Ta-OH são rapidamente formados, onde se combinam com íons cálcio e depois com íons fosfatos para formar apatita. Conclui-se que, a nucleação da apatita na superfície do metal ocorre via formação de grupos Ta-OH em SBF, que se combina com ions cálcio formando o tantalato de cálcio e seguidamente se combinam com íons fosfatos para a formação da apatita.

Simples tratamentos químicos, os quais formam rapidamente grupos funcionais efetivos para a nucleação da apatita na superfície do material, tem altos potenciais para novos biomateriais com habilidade de se ligar ao osso. Muller, Helebrant, et.al. (2004), imergiram discos de titânio puro em uma solução aquosa de $10 \mathrm{M}$ de $\mathrm{NaOH}$ a $60^{\circ} \mathrm{C}$ por 24 horas. Essas amostras foram nomeadas de A. As amostras B foram atacadas em $\mathrm{HCl}$ sob atmosfera inerte de $\mathrm{CO}_{2}$ por 2 horas e então imersas em solução aquosa de $10 \mathrm{M}$ de $\mathrm{NaOH}$ a $60^{\circ} \mathrm{C}$ por 24 horas. Após os tratamentos, as amostras foram imersas em SBF por $2,5,10,14$ e 20 dias.

Por MEV, é visto que a superfície do titânio tratado com $\mathrm{NaOH}$ e posterior imersão em SBF por 2 dias permaneceu inalterada. A habilidade do titânio tratado em induzir a formação de hidroxiapatita foi avaliada por análise gravimétrica. Um aumento 
de massa na amostra indica a formação de uma camada na superfície. Um notável aumento de massa na amostra A, 1 e $1,5 \mathrm{mg}$ foi medido após 10 e 14 dias em SBF respectivamente. Os resultados correspondem ao decréscimo de concentração de $\left(\mathrm{PO}_{4}\right)^{3-}$ na solução. Pode se supor que a massa da camada do precipitado deve aumentar com o tempo, entretanto, a massa do precipitado após 20 dias foi de 0,6mg. Partículas esféricas isoladas, que são típicas de apatita cristalizada, foram observadas por MEV em amostras que foram imersas por 10 diạs em SBF. Após 14 dias em SBF, uma camada de apatita não homogênea foi formada nas superfícies das amostras $\mathrm{A}$. Duas áreas foram analisadas por DRX nessas amostras, a primeira área foi confirmada a formação de hidroxiapatita, já na segunda área somente o titânio foi detectado. Esses resultados indicam que a reprodutibilidade da apatita em titânio tratado com $\mathrm{NaOH}$ é baixa. A diferente habilidade do metal tratado com $\mathrm{NaOH}$ em induzir apatita, pode ser devido a diferenças na superfície do titânio, que dependem de seu processamento. A superfície do titânio é recoberta com uma camada passiva de óxido, cuja espessura depende da temperatura máxima de oxidação, entre $770-870^{\circ} \mathrm{C}$, além do mais, a camada passiva não é uniforme. Os resultados indicam que o tratamento do titânio com $\mathrm{NaOH}$, não é suficiente para a completa dissolução da camada passiva de óxido. Em exposição ao $\mathrm{NaOH}$, essa camada passiva se dissolve parcialmente para formar $\mathrm{HTiO}_{3}^{-}$. Simultaneamente, o titânio é hidratado para formar $\mathrm{HTiO}_{3}^{-} \cdot \mathrm{n} \mathrm{H}_{2} \mathrm{O}$. Esses grupos negativos reagem com a carga positiva dos íons alcalinos para produzir uma camada hidrogel de titanato na superfície do titânio. $\mathrm{O}$ ataque ácido do titânio em $\mathrm{HCl}$ sob atmosfera inerte, foi avaliado como uma alternativa de pré-tratamento para obter uma superfície uniforme do titânio antes do tratamento alcalino. Nenhuma mudança foi observada nas superfícies das amostras B após 2 dias de imersão em SBF. Pela análise de EDX, foi revelado cálcio, magnésio, sódio e fósforo na superfície do material. O sódio provavelmente é proveniente do tratamento alcalino, além disso, não houve diminuição na concentração de cálcio e fósforo no SBF e não foi observado aumento de massa na amostra. Após 5 dias em SBF, apareceram partículas esféricas isoladas em torno de $5 \mu \mathrm{m}$ de diâmetro nas superfícies das amostras B. Cálcio, magnésio e fósforo faziam parte da composição dessas partículas. Após 10, 14 e 20 dias em SBF, uma camada compacta e homogênea foi formada na superfície do material, onde foi identificada por DRX como hidroxiapatita. Com 2 e 5 dias de imersão em SBF, as mudanças nas concentrações de cálcio e fósforo foram desprezíveis. Uma notável diminuição na concentração de $\left(\mathrm{PO}_{4}{ }^{3-}\right)$ foi medida após 10 dias em SBF, indicando a 
deposição de uma camada rica em fósforo na superficie, além disso, a massa da amostra B após 10 dias, aumentou para $2 \mathrm{mg}$ e continuou aumentando com o tempo de exposição em SBF.

Pode se entender que:

- O metal titânio é passivado por um óxido que se forma espontaneamente;

- Durante o ataque ácido em $\mathrm{HCl}$, a camada de óxido se degrada:

$$
\mathrm{TiO}_{2}+4 \mathrm{HCl} \rightarrow \mathrm{TiCl}_{4}+2 \mathrm{H}_{2} \mathrm{O}
$$

Simultaneamente, o titânio reage com $\mathrm{HCl}$ para formar $\mathrm{TiCl}_{3}$ e $\mathrm{H}_{2}$ :

$$
2 \mathrm{Ti}+6 \mathrm{HCl} \rightarrow 2 \mathrm{TiCl}_{3}+3 \mathrm{H}_{2}
$$

$\mathrm{TiH}_{2}$ que foi detectado por DRX, pode ser formado por: $\mathrm{Ti}+\mathrm{H}_{2} \rightarrow \mathrm{TiH}_{2}$ Em exposição ao ataque ácido, a camada passiva de óxido de titânio em $\mathrm{NaOH}$ dissolve para formar uma camada de titânia amorfa contendo íons $\mathrm{Na}^{+}$.

$$
\mathrm{TiO}_{2}+\mathrm{NaOH} \rightarrow \mathrm{HTiO}_{3}{ }^{-}+\mathrm{Na}^{+}
$$

Imediatamente após a imersão em SBF, os íons sódio da camada amorfa, são trocados pelo $\mathrm{H}_{3} \mathrm{O}^{+}$da solução do $\mathrm{SBF}$, formando grupos Ti-OH que induzem a formação da apatita. Conclui-se que o titânio tratado em $\mathrm{NaOH}$, pode formar apatita após a exposição em SBF. A hidroxiapatita, no entanto, não é homogênea e nem uniforme, mesmo após 20 dias em SBF. O ataque ácido no titânio em $\mathrm{HCl}$ sob atmosfera inerte, leva a formação de uma superfície micro rugosa uniforme que favorece a condição para a formação in situ da hidroxiapatita. 


\section{FUNDAMENTOS TEÓRICOS}

\section{IV.1. BIOCERÂMICAS}

É essencial reconhecer que nenhum biomaterial é apropriado para todas as aplicações biomédicas. Como classe de biomateriais, cerâmicas, vidros e vitrocerâmicas são geralmente utilizadas para reparar ou substituir os tecidos. O sucesso desses materiais depende de uma fixação estável ao tecido conectivo. O mecanismo da fixação no tecido está diretamente ligado ao tipo de resposta do tecido na interface implante-tecido.

Nenhum material implantado em tecido vivo é totalmente inerte, pois todos os materiais emitem uma resposta ao organismo. Há quatro tipos de respostas ao tecido: 1) Se o material é tóxico, o tecido em torno do material morre. 2) Se o material não é tóxico e é inerte, um tecido fibroso de espessura variada é formado. 3) Se o matèrial não é tóxico e é biologicamente ativo, uma ligação interfacial é formada. 4) Se o material não é tóxico e é solúvel no meio, uma substituição de tecido ocorre. (HOFFMAN et.al., 1996).

\section{1.1. CLASSIFICAÇÃO DAS BIOCERÂMICAS}

Dentre as classes de biomateriais, as biocerâmicas utilizadas para implantes podem ser classificadas quanto ao seu comportamento no organismo como inertes ou toleráveis, ativas e reabsorvíveis.

\section{1.1.1. BIOCERÂMICAS INERTES OU TOLERÁVEIS}

São biocerâmicas que tem pouca ou nenhuma variação química durante longos períodos de exposição ao meio fisiológico. Não há resposta negativa do organismo, porém há a formação de um tecido fibroso, encapsulamento, em torno do material implantado. Esse encapsulamento é fino, menor que $5 \mu \mathrm{m}$ para que haja irrigação sanguínea no tecido.

Devido aos materiais inertes não possiuirem ligações químicas e nem biológicas com o tecido, ocorrem micromovimentos além do encapsulamento. A presença de micromovimentos na interface biomaterial-tecido eventualmente conduz a deterioração em função do implante ou do tecido na interface, ou ambos (HOFFMAN et.al., 1996).

A alumina $\left(\mathrm{Al}_{2} \mathrm{O}_{3}\right)$ e zircônia $\left(\mathrm{ZrO}_{2}\right)$ são biocerâmicas inertes que, por suas qualidades mecânicas, podem exercer uma função estrutural. A utilização desses 
materiais também pode ser na forma de compósitos, denominados ZTA (zirconia toughened alumina), com maior tenacidade, resistência em ambientes com pH agressivo e maior resistência ao desgaste. Porém, pelo fato de serem materiais bioinertes ou biotoleráveis, não sendo capazes de se ligar ao tecido ósseo, é necessário realizar um recobrimento eficaz e que garanta a formação de uma camada de biocerâmica que atenda as exigências do setor médico-odontológico (PICONI et.al.,1999). Dentre as diversas técnicas estudadas e propostas para este fim, o recobrimento biomimético se destaca pela otimizada ligação formada entre o substrato e a biocerâmica que o recobre, além da possibilidade de formação de camada bioativa sobre diversos materiais (RIGO et.al., 1999; KOKUBO et.al., 1997; ABE et.al., 1990).

\section{1.1.2. BIOCERÂMICAS ATIVAS}

Materiais bioativos são os materiais com características intermediárias, entre os reabsorvíveis e os bioinertes (HOFFMAN et.al., 1996).

O material bioativo apresenta uma resposta biológica especifica na interface do material, resultando na formação de uma ligação entre o tecido e o material (HOFFMAN et.al., 1996). Por fim, a bioatividade é definida como a habilidade de formar ligações com os tecidos moles e duros.

Biovidro, vitro-cerâmicas, fosfatos como hidroxiapatita e seus recobrimentos são classificados como cerâmicas bioativas.

Os vidros bioativos promovem reparação tecidual, não são tóxicos, não induzem respostas alérgicas ou carcinogênicas, como confirmado por meio de testes in vitro e "in vivo". O biovidro é geralmente composto por $\mathrm{SiO}_{2}, \mathrm{Na}_{2} \mathrm{O}, \mathrm{CaO}, \mathrm{P}_{2} \mathrm{O}_{5}, \mathrm{CaF}_{2}$.

Em soluções físiológicas simuladas, e em contato com tecidos vivos, ocorre a troca iônica entre a superfície dos vidros bioativos e o meio $\left(\mathrm{Na}^{+}\right.$e $\mathrm{Ca}^{+}$por $\left.\mathrm{H}_{3} \mathrm{O}^{+}\right)$, o process̉o de dissolução estimula a deposição de uma camada de Ca e P (hidroxiapatita carbonatada) sobre a superfície dos vidros, similar à fase mineral da apatita biológica do osso.

Vitro-cerâmicas são microcristais que se precipitam sobre a matriz vítrea durante um tratamento térmico, de forma espontânea ou germinada (adições de $\mathrm{Pt}, \mathrm{ZrO}_{2}$ ).

Biocerâmicas à base de fosfalos de cálcio (hidroxiapatita) têm sido utilizadas na medicina e odontologia à cerca de 35 anos (LEGEROS AND LEGEROS, 1993). 
Diferentes fases de cerâmicas de fosfato de cálcio são utilizadas, dependendo do material desejado, podendo ser um material bioativo ou um material reabsorvível. As fases estáveis de fosfato de cálcio dependem consideravelmente da temperatura e da presença de água, mesmo durante o processamento ou em uso ambiente do material (HOFFMAN et.al., 1996).

A hidroxiapatita (HA) tem um importante papel no processo de mineralização óssea e tem a seguinte fórmula química, $\mathrm{Ca}_{10}\left(\mathrm{PO}_{4}\right)_{6}(\mathrm{OH})_{2}$.

Suas principais vantagens são:

- Alta biocompatibilidade;

- Osteocondutibilidade, ou seja, conduz a formação de tecido ósseo em células ósseas.

Suas principais desvantagens são:

- Baixa resistência mecânica;

- Quando de origem animal, há problemas com impurezas e contaminações.

\section{1.1.3. BIOCERÂMICAS REABSORVIVEIS}

Os biomateriais reabsorvíveis sofrem degradação gradual em um período de tempo, sendo substituídos por tecido natural. Isso leva a uma fina ou inexistente espessura interfacial entre material-tecido.

O desenvolvimento de biocerâmicas reabsorvíveis pode apresentar dificuldades tais como:

- Manutenção da resistência e da estabilidade da interface durante o período de degradação e substituição por tecido natural;

- Controle de taxas de reabsorção para o reparo de tecido corpóreo (Alguns materiais dissolvem muito rapidamente outros lentamente);

Por causa da grande quantidade de material que pode ser substituido, é essencial que o biomaterial reabsorvível consista somente de substâncias aceitáveis ao metabolismo. 
Alguns materiais cerâmicos porosos ou fosfatos de cálcio como o fosfato tricálcico (TCP) são materiais reabsorvíveis (HOFFMAN et.al., 1996).

\section{2. CERÂMICAS À BASE DE FOSFATO DE CÁlCIO}

Muitos compostos à base de fosfato de cálcio são atualmente empregados na área médica, sobretudo, na ortopedia e odontologia, sendo os mais utilizados: hidroxiapatita e o fosfato-tricálcico, por isso alguns aspectos serão abordados (LEGEROS, 1991; HENCH, 1991).

O termo apatita é utilizado para descrever uma família de compostos com estrutura similar, mas não necessariamente de composições idênticas (ELLIOT, 1994).

As fases estáveis de cerâmicas de fosfato de cálcio dependem da temperatura e quantidade de água presente após o processo de obtenção ou no meio onde se encontram (HENCH, 1998).

A razão $\mathrm{Ca} / \mathrm{P}$ da hidroxiapatita estequiométrica estabelecida por difração de raios $\mathrm{X}$ e de nêutrons é de 1,67, no entanto, as hidroxiapatitas deficientes em cálcio (até $10 \%$ ) são as de maior interesse biológico, porque a razão $\mathrm{Ca} / \mathrm{P}$ no osso é mais próxima de 1,5 (HENCH, 1993).

Outra cerâmica pertencente a esta classe de material é o fosfato tricálcico (TCP), composição nominal $\mathrm{Ca}_{3}\left(\mathrm{PO}_{4}\right)_{2}$ e razão $\mathrm{Ca} / \mathrm{P}$ de 1,5 . O TCP pode ocorrer em duas estruturas cristalinas: monoclínica ( $\alpha$-TCP) e romboédrica $(\beta-\mathrm{TCP})$, sendo esta a mais estável. O $\beta$-TCP, apresenta um papel importante no processo de biomineralização óssea, sendo o precursor direto da apatita biológica (ELLIOT, 1994).

Cristalograficamente, a hidroxiapatita é mais similar ao osso natural do que o $\beta$ TCP, porém, a razão de reabsorção da hidroxiapatita é extremamente baixa comparada com a do $\beta$-TCP, a velocidade de dissolução do $\beta$-TCP é de 3 a 12 vezes mais rápida do que para a hidroxiapatita estequiométrica e um implante ósseo constituído de hidroxiapatita permanecerá mesmo depois de 3 ou 4 anos de implantação. O TCP, por outro lado, sendo reabsorvível, desaparecerá parcialmente, em períodos de 6 a 15 semanas dependendo da estequiometria e porosidade. Foi avaliada, em estudos comparativos, a reabsorção dos implantes "in vivo" em função da composição, sendo observado um comportamento de reabsorção da seguinte forma: $\mathrm{HAp}<\beta-\mathrm{TCP}<\alpha-\mathrm{TCP}$, embora esta tendência também seja influenciada pela densidade, distribuição de tamanho de poros e área de superfície específica (GROOT, 1985; KEVOR, 1998; RENOO, 1985). 


\section{3. RECOBRIMENTO BIOMIMÉTICO}

Existem muitos métodos de recobrimentos, como o CVD (chemical vapor deposition), deposição por plasma, imersão em soluções particuladas, deposição eletroquímica, biomimético, entre outros.

O recobrimento biomimético é caracterizado pela imersão dos materiais em uma solução sintética que simula o plasma sanguíneo (SBF), para geração dos núcleos que proporcionarão o crescimento apropriado de uma camada de apatita in vitro. Para os materiais bioinertes ou biotoleráveis é necessário fazer um pré tratamento químico com $\mathrm{H}_{3} \mathrm{PO}_{4}$ e $\mathrm{NaOH}$, com o objetivo de formar na superficie do material grupos hidroxila $\left(\mathrm{OH}^{-}\right)$. Essas cargas negativas facilitam a deposição da hidroxiapatita que crescem consumindo íons Ca e $\mathrm{P}$ da solução de SBF. Um outro método que segue o mesmo mecanismo do tratamento químico, é a utilização de um agente nucleante como o silicato de sódio, formando na superfície do material $\mathrm{Si}_{-}-\mathrm{OH}^{-}$. Além do tratamento químico e da utilização de um agente nucleante pode ser feito a deposição desses materiais em SBF na presença de vidros bioativos, onde a dissolução desses vidros ocasiona a supersaturação da solução, estimulando a nucleação de apatita (UCHIDA et.al., 2002; MIYAJI et.al., 1999).

\section{IV.4. DIAGRAMA DE FASES DO SISTEMA $\mathrm{ZrO}_{2}-\mathrm{Y}_{2} \mathrm{O}_{3}$}

$\mathrm{O}$ diagrama de fases do sistema $\mathrm{ZrO}_{2}-\mathrm{Y}_{2} \mathrm{O}_{3}$ tem sido estudado por muitos pesquisadores (LANTERI, et.al.,1984; RÜHLE, et.al.,1984). O diagrama proposto por Scott é apresentado na Figura 2.

De acordo com a Figura 2, observa-se que a zircônia estabilizada com $3 \mathrm{~mol} \%$ de ítria, na temperatura de $1500^{\circ} \mathrm{C}$, apresenta duas fases em sua microestrutura, a fase tetragonal e a fase cúbica.

Outro aspecto importante observado neste diagrama é o abaixamento da temperatura de transição entre as fases cúbica $\rightarrow$ tetragonal e tetragonal $\rightarrow$ monoclínica. determinantes na retenção destes à temperatura ambiente. 


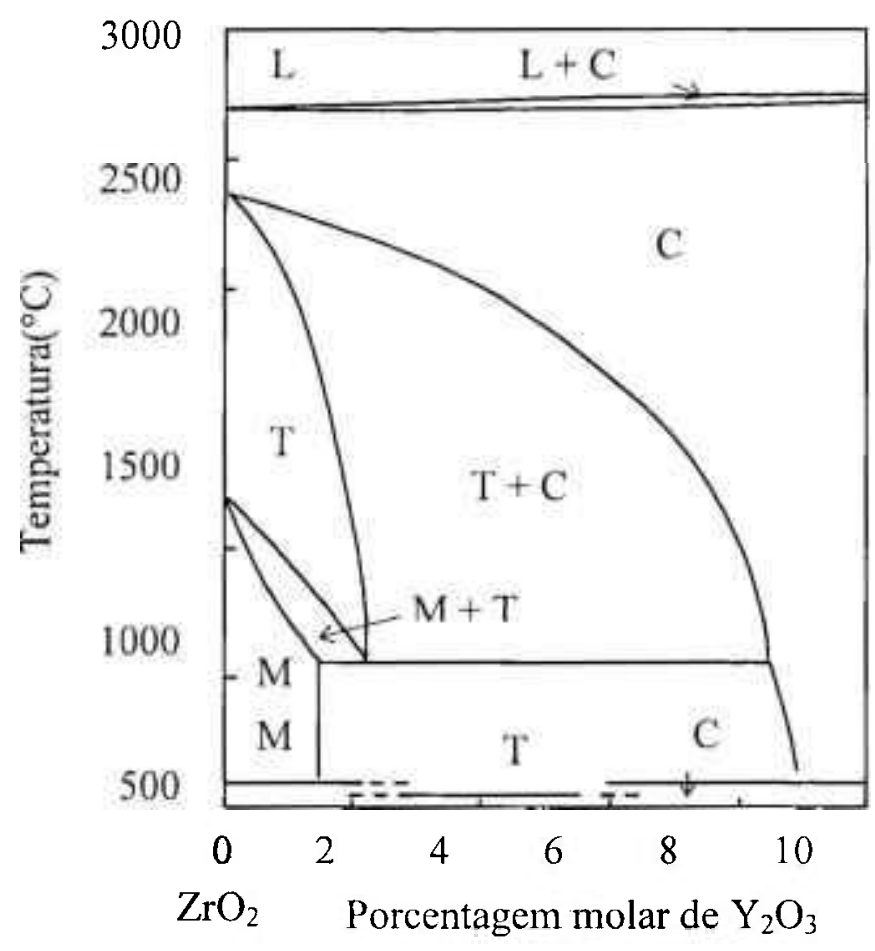

Figura 2: Diagrama de fases proposto por Scott do sistema zircônia-ítria na região rica em zircônio, onde $\mathrm{M}, \mathrm{T}$ e C representam as fases monoclínica, tetragonal e cúbica, respectivamente.

\section{5. DIFRAÇÃO DE RAIOS X}

Raios X são ondas eletromagnéticas que possuem comprimentos de onda de $10^{-}$ ${ }^{10}$ a $10^{-8} \mathrm{~m}$.

Os comprimentos de onda de raios X utilizados em difração estão na faixa de 0.5 a $2.5 \AA$. Como radiação eletromagnética, os raios $\mathrm{X}$ têm propriedades de ondas e partículas (PADILHA; AMBRÓSIO, 1985).

Os tubos de raios $\mathrm{X}$ utilizam um feixe de elétrons de alta energia $(\sim 50 \mathrm{kV})$ direcionados a um alvo metálico refrigerado.A maior parte da energia do feixe é perdida em colisões que colocam os átomos em movimento e produzem calor (PADILHA; AMBRÓSIO, 1985).

Parte da energia dos elétrons interage com o campo elétrico do átomo e quando us elétrons são desacelerados é reemitida como raios X (PADILHA; AMBRÓsIO, 1985).

Esta radiação policromática, também denominada "bremsstrahlung" ou radiação "branca", produz um espectro contínuo. 
Uma porção menor, porém significativa do feixe de elétrons colide com os elétrons dos átomos do alvo. Alguns elétrons são removidos de seus orbitais, levando os átomos a um estado excitado. Este estado excitado é breve, e a energia armazenada é emitida quando elétrons de outros orbitais preenchem o orbital vazio.Estes elétrons de transição têm energia quantizada, e a radiação emitida tem comprimentos de onda específicos. Este tipo de radiação é denominado radiação característica. Portanto, os raios $\mathrm{X}$ que deixam o alvo têm comprimentos de onda específicos superpostos a radiação branca (PADILHA; AMBRÓSIO, 1985).

A difração pode ser definida como um fenômeno de espalhamento de radiação eletromagnética por um arranjo periódico de centros de espalhamento, com espaçamento da mesma ordem de magnitude do comprimento de onda da radiação incidente.

Um feixe de raios $\mathrm{X}$ ao ser difratado por uma amostra contém informações sobre os tipos de átomos que constituem o material, arranjo atômico e geometria cristalina.

A unidade básica de uma amostra cristalina é a célula unitária. A rede cristalina define a forma e o tamanho da célula unitária e o arranjo periódico no espaço.

As arestas da célula unitária para a maioria dos sólidos inorgânicos apresentam medidas de 3 a $20 \AA$.

Os centros de espalhamento encontram-se em uma rede tridimensional, e poucas direções podem difratar. A difração ocorre somente quando o feixe incidente forma um ângulo apropriado em relação ao cristal.

A interferência construtiva ocorre quando o ângulo de incidência e o ângulo de difração, $\theta$, satisfaz a condição de Bragg:

$$
\mathrm{n} \lambda=2 \cdot \mathrm{d} \cdot \operatorname{sen} \theta \quad \text { (Eq 1) }
$$

onde $\lambda$ é o comprimento de onda da radiação e d é o espaçamento perpendicular entre os planos da rede. 


\section{5.1. INTENSIDADE DO FEIXE DIFRATADO}

A intensidade integrada de raios $X$ difratados, medida em um difratômetro de raios $\mathrm{X}$ acoplado a um monocromador, por uma amostra policristalina, com espessura infinita, pode ser escrita para uma determinada reflexão (ISHIKAWA et.al.,1993; MERRY et.al.,1998):

$$
I_{l k k l}=\left\{\frac{I_{0} A \lambda^{3} \mu_{0}^{2} e^{4}\left[F^{2} p\left(\frac{1+\cos ^{2} 2 \theta}{\operatorname{sen}^{2} \theta \cos \theta}\right)\right] e^{-2 M}}{32 \pi r(4 \pi)^{2} m^{2} c^{4} 2 \mu V^{2}}\right\}_{l k k l}
$$

$I_{0}=$ intensidade do feixe incidente;

$r$ raio do difratômetro ( distância da amostra ao detector );

$\lambda=$ comprimento de onda da radiação $\mathrm{X}$;

$c$ = velocidade da luz;

e e $m_{e}=$ carga e massa do elétron;

$e^{-2 M}=$ fator temperatura;

$p=$ fator de multiplicidade;

$V=$ volume da célula unitária da fase;

$\left(1+\cos ^{2} 2 \theta\right)$

$$
\left(\operatorname{sen}^{2} \theta \cos \theta\right)
$$

$\mu=$ coeficiente de absorção linear;

$2 \theta_{m}=$ ângulo de difração do monocromador;

\section{5.2. FATOR DE ESTRUTURA}

As intensidades dos feixes difratados dependem dos tipos de átomos que constituem o cristal e seu arranjo na célula unitária.

O espalhamento causado pelos elétrons na célula unitária resulta em uma função de interferência complexa. A amplitude total do feixe espalhado é a soma das contribuições de todos os elétrons, ou seja, é proporcional a $Z$ (número atômico).

Estes valores de espalhamento são a amplitude normalizada do número de elétrons envolvidos para o ângulo $\theta=0$, e são os fatores de espalhamento atômico. 
Para os feixes espalhados na direção da incidência, $\theta=0$, os raios estão em fase e a amplitude é somada. Quando o ângulo $\theta$ é diferente de zero as trajetórias dos raios espalhados são diferentes e a diferença de fase resulta em interferência.

A medida desta diferença de fase é contida em um fator exponencial que define a mudança de amplitude em função das posições dos átomos.

A combinação deste fator de fase e do fator de espalhamento atômico resulta o fator de estrutura (CINI, 1975; ISHIKAWA et.al., 1993):

$$
F_{h k l}=\sum f_{n} e^{\left(2 \pi i\left(h x_{n}+k y_{n}+l z_{w}\right)\right)}
$$

onde $\mathrm{f}_{\mathrm{n}}$ é o fator de espalhamento para o átomo $\mathrm{n}$;

h, k, 1 são os índices de Miller;

$\mathrm{x}_{\mathrm{n}}, \mathrm{y}_{\mathrm{n}}, \mathrm{z}_{\mathrm{n}}$ são as coordenadas de posição do n-ésimo átomo;

$$
f_{n}=f_{0} e^{\left(\frac{-B \operatorname{sen}^{2} \theta}{\lambda}\right)}
$$

onde $f_{n}$ é o fator de espalhamento a temperatura do zero absoluto; $B$ é a amplitude média de vibração normal à direção de difração;

A amplitude total do feixe difratado é a soma das contribuições de cada célula unitária nas direções de difração permitidas pela geometria da rede.

O cálculo da intensidade total do feixe difratado além do fator de estrutura deve incluir correções em função da técnica experimental e da amostra analisada.

A intensidade medida é proporcional ao fator de estrutura vezes seu complexo conjugado. 
O fator de Lorentz é devido à divergência do feixe de raios X incidente e a monocromatização parcial.

Estas características podem favorecer a reflexão de um determinado plano. Para um difratômetro de pó (MERRY et.al., 1998):

$$
L=\frac{1}{\operatorname{sen} 2 \theta \operatorname{sen} \theta}=\operatorname{cossec} 2 \theta \operatorname{cossec} \theta
$$

(Eq 5)

\section{5.4. FATOR DE POLARIZAÇÃO}

Os raios $\mathrm{X}$ característicos ao serem difratados apresentam certa quantidade de polarização, que depende do ậngulo de Bragg:

$$
P=\frac{1}{2}\left(1+\cos ^{2} 2 \theta\right)
$$

(Eq 6)

Combinando os dois efeitos:

$$
L P=\frac{\left(1+\cos ^{2} 2 \theta\right)}{\left(\operatorname{sen}^{2} \theta \cos \theta\right)}
$$

\section{5.5. TÉCNICAS DE DIFRAÇÃO DE RAIOS $X$}

As amostras a serem analisadas por difração de raios $\mathrm{X}$ podem estar na forma de monocristais ou policristais.

As amostras policristalinas são utilizadas na técnica conhecida como método do pó (KLUG;ALEXANDER,1974), onde utiliza-se um pó fino constituído por cristalitos 
orientados aleatoriamente. A incidência de um feixe de radiação monocromática na amostra irá produzir um padrão de círculos concêntricos.

As primeiras técnicas para aplicação do método do pó foram desenvolvolvidas a partir de 1920 (KLUG;ALEXANDER,1974).As técnicas mais conhecidas e utilizadas até hoje são a câmara de Debye-Scherrer e câmara de Guinier. A característica comum destas técnicas é a utilização de um filme para a coleta dos dados.

Os difratômetros de raios $\mathrm{X}$ foram desenvolvidos um pouco mais tarde, entre 1950 e 1960, sendo automatizados em 1980 (WARREN,1959). Estes equipamentos apresentam muitas vantagens, como: rapidez e precisão na coleta de dados por um detector de raios $\mathrm{X}$ e facilidade na preparação e posicionamento das amostras.

A geometria mais utilizada para os difratômetros é a de Bragg-Brentano, onde um feixe de radiação monocromática incide em uma amostra na forma de pó compactado, rotacionada em um ângulo 0, enquanto os dados são coletados por um detector que se move em $2 \theta$ (CULLITY,2001).

O padrão de difração obtido por contagens de um detector é um gráfico da intensidade, medida em contagens por segundo, em função da posição angular.

A posição angular do feixe difratado depende dos espaçamentos entre os planos de átomos na amostra e do comprimento de onda da radiação. A posição das linhas de difração contém dados para identificação de fases, determinação do parâmetro de célula, mudanças de fase (polimorfismo) e os valores da distância interplanar (d).

As equações básicas da difração de raios $\mathrm{X}$ são as mesmas que regem a difração de nêutrons (PADILHA; AMBRÓSIO,1985), exceto pelo efeito de espalhamento do feixe. O feixe de neutrons pode ser obtido de um reator ou fontes de neutrons emitidos por pulsação. Os dados podem ser obtidos por comprimento de onda fixo ou ângulo fixo. Os dados do feixe difratado são coletados por um detector movél com fendas de colimação.

A fonte de neutrons mais utilizada é a fonte de neutrons pulsada para difratometria do pó com emissão sincronizada TOF("time of flight"). No caso de difração TOF em uma fonte de reator, um pulsador produz um feixe de neutrons policromático e o padrão de difração da amostra, é obtido por um conjunto de detectores de foco regulado em função da difração TOF. 


\section{5.6. DIFRATÔMETRO DE RAIOS X}

Os primeiros equipamentos desenvolvidos para a aplicação da técnica de difração de raios $\mathrm{X}$ foram às câmaras com filmes para detecção do feixe difratado.

Entretanto, as câmaras de pó apresentam algumas desvantagens. Os tempos de exposição são relativamente longos e os dados obtidos não tem boa precisão estatística.

A substituição de filmes por detectores de fótons levou ao desenvolvimento de vários tipos de geometria para os difratômetros. A geometria mais utilizada nos difratômetros comerciais é a geometria de Bragg-Brentano (CULLITY, 2001).

\section{5.7. GEOMETRIA DE BRAGG-BRENTANO}

$\mathrm{O}$ difratômetro é constituído basicamente por um tubo de raios $\mathrm{X}$, um porta amostra onde incide a radiação e um detector móvel, geralmente de cintilação.

A Figura 3 mostra de maneira esquemática o funcionamento de um difratômetro.

$\mathrm{O}$ feixe de raios $\mathrm{X}$ é gerado pela fonte $\mathrm{S}$, passa pelo colimador $\mathrm{A}$ e incide na amostra C, a qual está sobre um suporte H. A amostra sofre rotação sobre o eixo O, perpendicular ao plano da Figura. O feixe difratado passa pelos colimadores $\mathrm{B}$ e $\mathrm{F}$ e incide no detector $\mathrm{G}$, que está sobre o suporte $\mathrm{E}$.

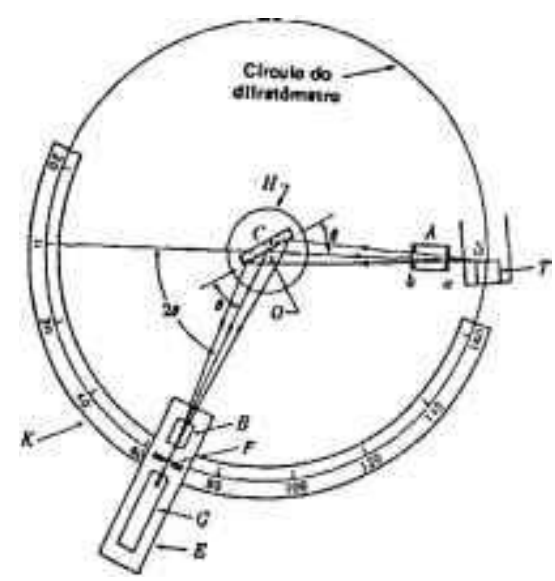

Figura 3: Difratômetro de raios X esquemático (PADILHA; AMBRÓSIO, 1985).

Os suportes E e H estão acoplados mecanicamente de modo que o movimento $2 \theta$ graus do detector é acompanhado pela rotação $\theta$ graus da amostra. Este acoplamento assegura que o ângulo de incidência e o de reflexão serão iguais à metade do ângulo de difração.Um feixe divergente de radiação proveniente do foco linear $\mathrm{L}$ do tubo de raios 
$\mathrm{X}$ passa através dos colimadores de placas paralelas (fendas Soller) $\mathrm{G}$ e uma unidade de fendas de divergência B e irradia a superfície plana da amostra $C$.

Os raios difratados pelos cristalitos na amostra a um ângulo $2 \theta$ convergem para uma linha na fenda de recepção D. Tanto atrás comó adiante da fenda de recepção pode ser instalado um segundo conjunto de colimadores de placas paralelas $\mathrm{E}$, e uma fenda de espalhamento F.

Um monocromador para o feixe difratado pode ser colocado atrás da fenda de recepção na posição da fenda de espalhamento.

Os eixos do foco linear e da fenda de recepção estão a distâncias iguais do eixo do goniômetro.

Os raios X são detectados por um detector de radiação $G$, normalmente um detector de cintilação ou contador proporcional.

A superfície da amostra permanece tangenciando o círculo focal $\mathrm{K}$. O propósito dos colimadores de placas paralelas é limitar a divergência axial do feixe, controlando parcialmente a forma do perfil da linha difratada. O centro da superfície da amostra deve estar no eixo do goniômetro.

O eixo do goniômetro deve estar paralelo ao eixo do foco linear, fenda de divergência e fenda de recepção. Alguns dos requisitos mecânicos da geometria são preenchidos pela própria construção do goniômetro, enquanto que outros são definidos no procedimento de alinhamento, como o ângulo de emissão $\alpha$ do feixe, que é o ângulo entre a superfície do ânodo e o centro do feixe primário.

A geometria parafocal origina dois círculos: o círculo focal, indicado pela linha pontilhada K, na Figura 4, e círculo do goniômetro, indicado pela linha pontilhada H. A fonte $\mathrm{L}$, a amostra $\mathrm{P}$, e a fenda de recepção $\mathrm{D}$, estão contidos no círculo focal, que tem raio variável. A amostra se situa no centro do círculo do goniômetro, que tem raio fixo.

No alinhamento do difratômetro deve-se ter atenção especial na determinação dos movimentos do zero do goniômetro e $\theta / 2 \theta$. Os erros nestes ajjustes podem levàr a erros nos valores observados de $2 \theta$. No método de Rietveld pode-se corrigir pequenos desvios 0/20 e na posição da amostra C. 


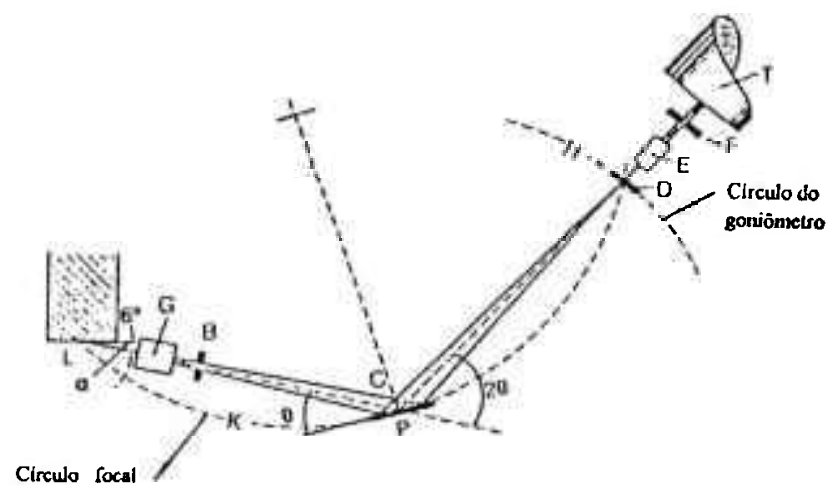

Figura 4: Arranjo geométrico do difratômetro de Bragg-Brentano

(KLUG;ALEXANDER, 1974).

\section{5.8. ANÁLISE QUANTITATIVA DE FASES - MÉTODO DE RIETVELD}

O desenvolvimento de métodos computacionais aplicados a difratometria de pó tem posșibilitado a análise estrutural de padrões de difração digitalizados. O método de Rietveld (RIETVELD, 1969) é uma aplicação dos princípios básicos de física da difração e de parâmetros cristalográficos fundamentais, como parâmetros de rede, estados de oxidação e posições de ocupação na célula unitária para o cálculo das intensidades do padrão de difração.

O método de Rietveld é baseado na construção de um padrão de difração calculado, de acordo com o modelo estrutural. O padrão calculado é obtido pela introdução direta dos dados cristalográficos, como:

a) simetria do grupo espacial

b) posições atômicas

c) posições de ocupação

d) parâmetros de rede

O padrão calculado ao se ajustar ao padrão observado fornece dados dos parâmetros estruturais do material e parâmetros do perfil de difração. O termo refinamento no método de Rietveld refere-se ao processo de ajuste do modelo de parâmetros utilizados no cálculo de um padrão de difração, que seja o mais próximo do 
observado. O refinamento é conduzido pela minimização da soma das diferenças entre as intensidades calculadas e observadas, a cada passo angular do padrão de difração.

Os parâmetros, específicos de cada fase, que variam durante o refinamento são (YOUNG, 1995):

a) estruturais: posições atômicas, parâmetros da célula unitária, fatores de ocupação, fator de escala, parâmetros de vibração térmica (isotrópicos e anisotrópicos) e parâmetro térmico isotrópico geral.

b) não estruturais: parâmetros da largura à meia altura $(U, V, W)$, assimetria, $2 \theta$ zero, orientação preferencial e coeficientes da radiação de fundo.

O método de Rietveld é aplicado ao intervalo angular total do padrão de difração, aumentando a precisão dos dados obtidos. O problema de sobreposição de picos é minimizado, permitindo o máximo de extração de informações do padrão de difração.

Os requisitos básicos para o refinamento pelo método de Rietveld são (HILL; MADSEN, 1987):

a) medidas precisas de intensidades dadas em intervalos 20 ;

b) um modelo inicial próximo à estrutura real do cristal;

c) um modelo que descreva a forma, largura e erros sistemáticos nas posições dos picos de Bragg;

O método de Rietveld pode ser aplicado na análise quantitativa de fases, ajuste de parâmetros de célula e estudos estruturais como: determinação de tamanho de cristalitos, distribuição de cátions, incorporação de átomos e formação de vacâncias, posições atômicas e posições de ocupação.

A partir de métodos matemáticos é possível a construção de um padrão de difração teórico. O padrão calculado é comparado ao padrão observado experimentalmente e as diferenças nas intensidades são minimizadas pelo método de mínimos quadrados (TUFEKCI; BRANTLEY et.al., 1999):

$$
Q_{v}=\sum_{i} w_{i}\left(y_{\text {icalc }}-y_{\text {iobs }}\right)^{2}
$$

onde $\mathrm{y}_{\mathrm{i}}=$ intensidade da i-ésimà posição $2 \theta$ e $\mathrm{w}_{\mathrm{i}}=1 / \mathrm{y}$

O método parte de um modelo estrutural que descreve o espalhamento pelo fator de estrutura (BOHNER, 2000): 


$$
F_{h k l}=\sum N_{j} f_{j} e^{\left[2 \pi i\left(h x_{j}+k y_{j}+l z_{j}\right)\right]\left[-B_{j}\left(\frac{\operatorname{sen}^{2} \theta}{\lambda^{2}}\right)\right]}
$$

Onde $F_{h k l}$ é o fator de estrutura; $N_{j}$ é o fator de ocupação do j-ésimo átomo; $f_{j}$ é fator de espalhamento; $h, k$ e 1 são os índices de Miller; $\mathrm{x}_{\mathrm{j}}, \mathrm{y}_{\mathrm{j}}$ e $\mathrm{z}_{\mathrm{j}}$ são as coordenadas atômicas; $B_{\mathrm{j}}$ é o fator de temperatura isotrópico; $\theta$ é o ângulo de difração; $\lambda$ é o comprimento de onda utilizado na difração de raios X.

A intensidade calculada $\mathrm{y}_{\text {calc }}$ é combinada com as possíveis reflexões hkl e com base no modelo estrutural, constantes físicas e variáveis instrumentais é definida:

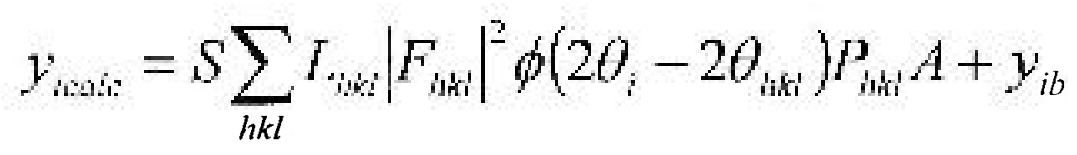

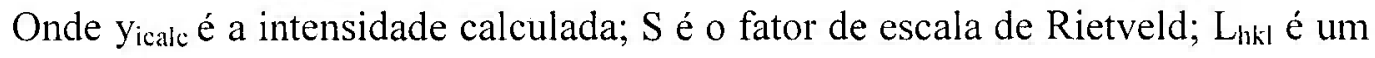
fator que contém os fätores de Lorentz, polarização e multiplicidade ; $\phi$ é a intensidade analítica da função de perfil escolhida; $\mathrm{P}_{\mathrm{hkl}} \mathrm{e}$ a função de orientação preferencial; $\mathrm{A}$ é o fator de absorção instrumental; $\mathrm{y}_{\mathrm{b}}$ é a intensidade da radiação de fundo no i-ésimo passo.

Quando $\mathrm{S}$ é combinado com o número de fórmulas por célula unitária, $Z, M$ massa da fórmula unitária e $\mathrm{V}$, volume da célula unitária, a fração em peso $\mathrm{W}_{\mathrm{p}}$ da fase $\mathrm{p}$ em uma mistura de $\mathrm{n}$ fases é determinada por:

$$
w_{p}=\frac{S_{p}(Z M V)_{p}}{\sum_{i=1}(Z M V)_{i}}
$$

(Eq 11)

Portanto, além da determinação de estruturas cristalográficas a partir de padrões de difração experimentais, é possível determinar a concentração de cada fase em uma mistura.

A quantificação de fases não depende de padrões internos ou externos ou curvas de calibração.

O ajuste do padrão de difração calculado ao padrão observado é baseado na aplicação de um método estatístico que minimize os erros durante os ciclos do refinamento. O método aplicado é o método dos mínimos quadrados. Este método 
apresenta algumas vantagens como rapidez de resolução e determinação dos erros estatísticos em cada ciclo do refinamento. Entretanto, devido à grande correlação das variáveis envolvidas, o método pode levar a divergência dos valores durante os ciclos do refinamento. A aplicação deste método no programa é feita pelo algoritmo de Newton-Raphson.

O refinamento inclui os parâmetros estruturais e não estruturais durante a execução dos ciclos, o que pode levar à divergência ou falso mínimo quando o padrão observado apresenta sobrepósição ou alargamento de picos.

Os programas LHPMRietica ${ }^{(1)}, \operatorname{GSAS}^{(1)}, \operatorname{RIETAN}^{(1)}$, FULLPROF $^{(1)}$ e outros têm como opção a aplicação do método de Le Bail ${ }^{(1)}$ no refinamento. A utilização deste método permite que o refinamento dos parâmetros de perfil e estrutura sejam refinados em duas etapas distintas, o que pode facilitar o refinamento de padrões que apresentam sobreposição de picos. Por este método é possível estimar com precisão e rapidez os parâmetros de rede, o que facilita a identificação das fases contidas no padrão.

\section{5.9. AVALIAÇÃO DO REFINAMENTO}

\section{5.9.1. RESÍDUOS}

As quantidades utilizadas para avaliar o progresso do refinamento e a concordância entre o perfil observado e calculado são os resíduos obtidos a partir das diferenças das intensidades observadas e calculadas.

O residuo $R_{P}$ é estimado a partir da seguinte expressão (YOUNG, 1995):

$$
P_{p}=\frac{\sum_{i}\left|y_{i o}-y_{i c}\right|}{\sum_{i} y_{i o}}
$$

onde $i$ é o i-ésimo passo

\footnotetext{
${ }^{1}$ http://www.ccp14.ac.uk/.
} 
$O$ resíduo $R_{W P}$ considera o erro associado a cada valor da intensidade uma função do número de contagens, utilizando o fator de ponderação $w(2 \theta)$ :

$$
R_{w p}=\sqrt{\frac{\sum_{i} w_{i}\left(2 \theta_{i}\right)\left(y_{i}-y_{i}\right)^{2}}{\sum_{i} w\left(20_{1}\right) y_{i b}^{2}}}
$$

onde $w\left(2 \theta_{\mathrm{i}}\right)=1 /\left[\right.$ variança de $\left.y_{i o}\right]=1 / y_{i o}$

O efeito do fator de ponderação é reduzir a contribuição do erro devido ao desajuste na parte superior dos picos, portanto as regiões mais próximas da borda inferior dos picos devem ser observadas.

Os valores para $R_{W P}$ para bons resultados é de $2-10 \%$, enquanto que os valores típicos obtidos variam de $10-20 \%$. Para avaliar a qualidade do ajuste compara-se o valor final de $R_{W P}$ com o valor do erro esperado. O erro esperado $\left(\mathrm{R}_{\exp }\right)$ é derivado do erro estatístico associado às intensidades medidas:

$$
R_{E X P}=\sqrt{\frac{(N-P)}{\sum_{i} w\left(2 \theta_{i}\right) y_{i 0}^{2}}}
$$

$\mathrm{N}=$ número de observações

$\mathrm{P}=$ número de parâmetros variáveis

O denominador contém a soma das intensidades observadas, e quanto maior a intensidade no intervalo menor será o resíduo. Estes resíduos dependem da intensidade da radiação de fundo: o aumento da intensidade da radiação de fundo implica a redução dos valores de $\mathrm{R}$. 


\section{6. ÍNDICE DE QUALIDADE DO REFINAMENTO ("GOODNESS OF FIT"- GOF)}

O cálculo do parâmetro Gof inclui o número de variáveis sob refinamento. Através deste parâmetro pode se avaliar se uma mudança no número de parâmetros pode diminuir o erro residual.

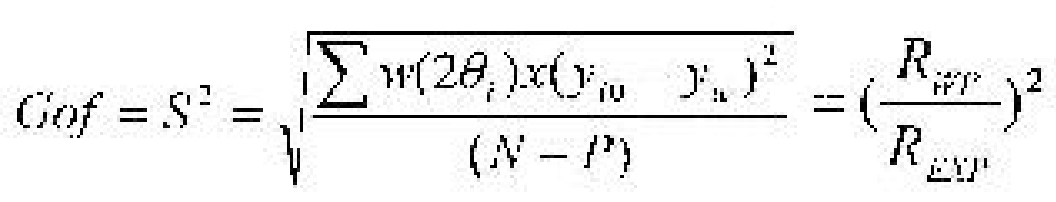

Os valores dos desvios padrão são calculados a partir da expressão:

$$
\sigma_{m}^{2}=A_{m m}^{-1} S^{2}
$$

onde $A_{m m}{ }^{-1}$ é o elemento diagonal da inversa da matriz normal no procedimento de minimização por mínimos quadrados. Se $S^{2}$ é diferente da unidade e/ou varia com as condições experimentais, pode se concluir que os fatores de ponderação não são apropriados (a estatística de contagem não é a fonte primária do erro), ou os modelos teóricos para a estrutura ou picos de difração estão incompletos ou incorretos.

$O$ resíduo $R_{B}$ é uma medida da concordância entre as intensidades de Bragg medidas e calculadas. As intensidades observadas estão ligadas ao modelo estrutural e $R_{B}$ é um indicador do ajuste dos parâmetros estruturais.

$$
R_{B}=\frac{\sum_{K} I\left|I_{K O}-I_{K C}\right|}{\sum_{K} I_{K O}}
$$

onde $I_{k o}$ e $I_{k c}$ são as intensidades observada e calculada, respectivamente para as reflexões de Bragg.

$R_{W P}$ é o indicador estatístico que melhor representa a aproximação já que o numerador é o resíduo minimizado no procedimento de mínimos quadrados. Os fatores que modificam $R_{W P}$ são as diferenças na forma dos picos (como a largura) e a estatística da radiação de fundo. $R_{B}$ é menos afetado pela estatística da radiação de fundo, sendo 
também um indicador importante principalmente da aproximação entre o modelo estrutural calculado e a estrutura real.

\section{7. FLUORESCÊNCIA DE RAIOS X POR DISPERSÃO DE COMPRIMENTO DE ONDA (WDXRF)}

A Fluorescência de raios $\mathrm{X}$ por dispersão de comprimento de onda (WDXRF) consiste em incidir um feixe de raios $\mathrm{X}$ em uma amostra e produzir radiações fluorescentes (transições eletrônicas dos elétrons das camadas mais internas dos átomos), que são características para cada elemento químico. Estas radiações são difratadas por um cristal analisador (de acordo com a lei de Bragg) e captadas por um detector.

A técnica WDXRF é aplicada para a determinação qualitativa e quantitativa de maiores e menores constituintes e traços em diversos tipos de materiais.

\section{7.1. MÉTODO DE PARÂMETROS FUNDAMENTAIS (FP)}

\section{7.1.1. CÁlCULO DA INTENSIDADE TEÓRICA}

O método de parâmetros fundamentais (FP) consiste em calcular a intensidade teórica dos elementos químicos por meio de amostras de composição química conhecida, (próxima ou não da amostra) submetida aos parâmetros instrumentais bem definidos, como excitação do tubo de raios $\mathrm{X}$ e geometria óptica.

Relacionando-se a intensidade fluorescente teórica calculada e a medida para cada elemento químico, pode se obter uma curva de sensibilidade do equipamento e assim, determinar a composição química e as impurezas de amostras desconhecidas.

O método foi apresentado em 1955 por Sherman, passando por modificações em 1966 por Shiraiwa e Fujino. Nestes últimos algoritmos foi introduzida uma correção para a radiação fluorescente secundária, graças ao advento dos modernos computadores, que possibilitaram cálculos mais refinados. Em 1968, Criss e Birks conseguiram quantificar matematicamente a intensidade fluorescente em termos de parâmetros fisicos fundamentais e parâmetros instrumentais, que são as bases para as correções do efeito de matriz. As maiores dificuldades encontradas referem-se às expressões que constavam de integrais múltiplas, laboriosas de serem resolvidas na prática. Outra dificuldade consistia também na obtenção do espectro primário do tubo de raios X com 
precisão. A partir de 1977, o método começou a ser utilizado para filmes finos e atualmente é utilizado para qualquer tipo de amostra.

Os cálculos teóricos para a intensidade fluorescente de raios $\mathrm{X}$ baseiam-se nos seguintes critérios (KATAOKA, 1989):

- Todos os elementos devem estar uniformemente distribuídos na amostra;

- A intensidade fluorescente característica é proporcional à concentração do elemento medido;

- Os efeitos de intensificação e ou absorção da matriz podem ser calculados usando-se as constantes físicas, isto é, coeficiente de absorção de massa, rendimento de fluorescência, etc;

- A intensidade fluorescente de raios $X$ proveniente da amostra é dependente da configuração do equipamento e das condições de medida. 


\section{PROCEDIMENTO EXPERIMENTAL}

O procedimento experimental, adotado para síntese, processamento $\mathrm{e}$ caracterização de cerâmicas de alumina e zircônia estabilizada com 3mol\% de itria e compósitos zircônia-alumina, é apresentado no fluxograma da Figura 5, detalhado nos itens a seguir:

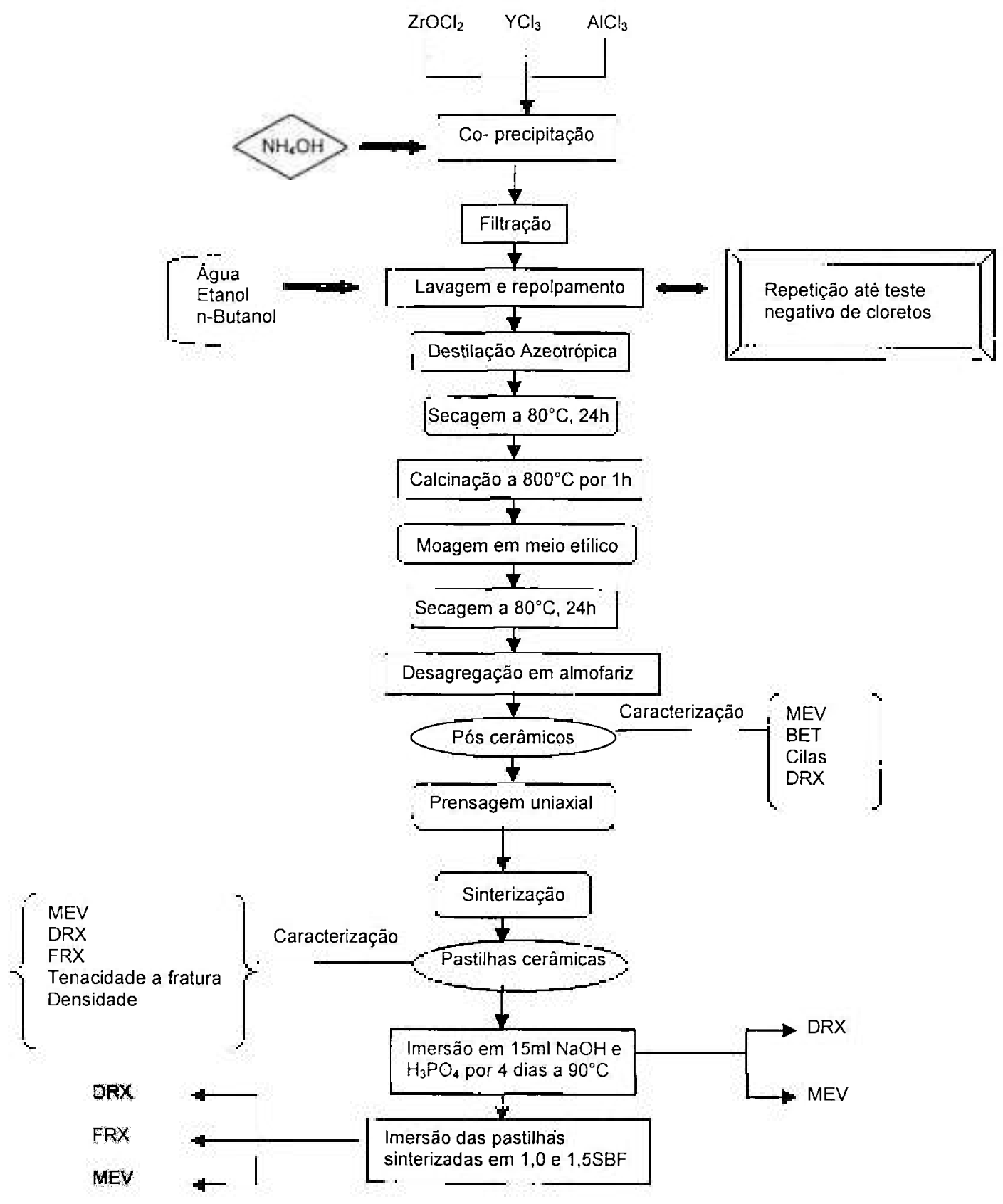

Figura 5: Fluxograma esquemático da metodologia adotada para sintese, processamento e caracterização de cerâmicas de alumina e zircônia estabilizada. 
Matérias-primas: Os pós de alumina, zircônia estabilizada e compósitos foram preparados pela rota de co-precipitação de hidróxidos em meio amoniacal, partindo de oxicloreto de zircônio de pureza 99,5\% em $\mathrm{ZrO}_{2}$ e $\mathrm{HfO}_{2}$ (IPEN, Brasil), cloreto de alumínio 99,9\% em massa (Synth, Brasil) e cloreto de ítrio, preparado pela dissolução do óxido de ítrio $99,9 \%$ em massa (Aldrich ,USA).

\section{V.1. SÍNTESE DOS PÓS}

A co-precipitação de hidróxidos de alumínio, zircônio e ítrio e respectivos compósitos, foi realizada com hidróxido de amônio, fixando-se a concentração de óxidos, na solução de partida, em $35 \mathrm{gL}^{-1}$.

Os precipitados obtidos foram filtrados e lavados com água destilada até a eliminação de íons cloreto (teste realizado com nitrato de prata). Em seguida, os precipitados foram submetidos a tratamentos com líquidos orgânicos visando minimizar, após secagem, a formação de aglomerados fortes, decorrentes de forças capilares, pontes de hidrogênio ou cargas eletrostáticas existentes entre as partículas hidratadas (KALISZEWSKI et.al., 1990; MARCOS et.al., 2001). Esse procedimento consiste na lavagem do gel com etanol e posterior tratamento, com butanol por destilação azeotrópica. Neste último caso, a remoção da água residual do precipitado inicia-se a $92,25^{\circ} \mathrm{C}$, quando ocorre a formação da mistura azeotrópica butanol-água. Como o ponto de ebulição do butanol é elevado $\left(117,5^{\circ} \mathrm{C}\right)$, a água é totalmente removida do precipitado antes que todo o solvente seja evaporado (USSUI et.al., 1996).

Os grânulos obtidos foram então desagregados em almofariz de ágata e mantidos em estufa a $80^{\circ} \mathrm{C}$ por 24 horas.

As amostras de zircônia e alumina foram calcinadas a $800^{\circ} \mathrm{C}$, por 1 hora e submetidas à moagem em etanol por 16 horas. A secagem dos pós moídos foi realizada em estufa a $80^{\circ} \mathrm{C}$, por 24 horas, finalmente foi feita a desagregação dos pós em almofariz de ágata.

As amostras de alumina foram designadas A e de zircônia estabilizada com 3 mol\% de ítria como TZP. Assim sendo, foram sintetizados pós contendo 80 e $20 \% \mathrm{em}$ massa de alumina em zircônia estabilizada com 3 mol\% de ítria (amostras 80A20TZP e 20A80TZP), 100\% em massa de alumina (100A) e 100\% de zircônia estabilizada com 3 mol\% de ítria (100TZP). 


\section{V.2. PROCESSAMENTO CERÂMICO}

Os pós cerâmicos foram conformados por prensagem uniaxial, utilizando-se pressões de compactação de $76,4 \mathrm{MPa}$ para matrizes cilindricas de diâmetro $10 \mathrm{~mm}$ e $85 \mathrm{MPa}$ para matrizes cilíndricas de diâmetro de $15 \mathrm{~mm}$.

A sinterização foi realizada ao ar, em forno elétrico tipo caixa (Lindberg), a temperaturas de $1500^{\circ} \mathrm{C}$ por 1 hora para a amostra de zircônia estabilizada (100TZP), $1650^{\circ} \mathrm{C}$ por 1 hora (amostras $80 \mathrm{~A} 20 \mathrm{TZP}$ e $\left.20 \mathrm{~A} 80 \mathrm{TZP}\right)$ e $1600^{\circ} \mathrm{C}$ por 3 horas (amostra 100A). A taxa de aquecimento empregada foi de $10^{\circ} \mathrm{C} \cdot \mathrm{min}^{-1}$ até $800^{\circ} \mathrm{C}$ e $5^{\circ} \mathrm{C} \cdot \mathrm{min}^{-1}$ até a temperatura de sinterização.

\section{V.3. PREPARAÇÃO SUPERFICIAL DAS AMOSTRAS SINTERIZADAS}

Para a realização do ataque químico superficial, os substratos cerâmicos foram imersos em $15 \mathrm{~mL}$ de solução de $5 \mathrm{M} \mathrm{H}_{3} \mathrm{PO}_{4}$ e $15 \mathrm{M} \mathrm{NaOH}$, sendo mantidos em potes de polietileno de alta densidade a temperatura de $90^{\circ} \mathrm{C}$ por 4 dias em banho termostático. Para manter a concentração do ácido ou base constantes, evitando a evaporação destes solventes, foi feito um sistema de refluxo, descartando a necessidade de reposição da solução.

\section{V.4. RECOBRIMENTO BIOMIMÉTICO}

O recobrimento biomimético foi realizado imergindo as amostras sinterizadas em uma solução sintética de composição iônica semelhante a do plasma sangüíneo, simulated body fluid (SBF), com concentrações de 1,0 e 1,5M.

As concentrações iônicas das soluções de 1,0 SBF e 1,5SBF estão relacionadas na Tabela 1 .

Tabela 1: Concentrações iônicas das soluções empregadas $\left(\mathrm{mmol} \cdot \mathrm{dm}^{-3}\right)$.

\begin{tabular}{|c|c|c|c|c|c|c|c|c|}
\cline { 2 - 8 } \multicolumn{1}{c|}{} & $\mathbf{N a}^{+}$ & $\mathbf{K}^{+}$ & $\mathbf{C a}^{2+}$ & $\mathbf{M g}^{2+}$ & $\mathbf{H C O}_{3}{ }^{2-}$ & $\mathbf{C l}^{-}$ & $\mathbf{H P O}_{4}{ }^{2-}$ & $\mathbf{S O}_{4}{ }^{2-}$ \\
\hline $\mathbf{S B F}$ & 142,0 & 5,0 & 2,5 & 1,5 & 4,2 & 148,0 & 1,0 & 0,5 \\
\hline $\begin{array}{c}\mathbf{1 , 5} \\
\mathbf{S B F}\end{array}$ & 213,0 & 7,5 & 3,8 & 2,3 & 6,3 & 223,0 & 1,5 & 0,75 \\
\hline
\end{tabular}

As soluções foram preparadas dissolvendo-se $\mathrm{NaCl}, \mathrm{KCl}, \mathrm{K}_{2} \mathrm{HPO}_{4}, \mathrm{CaCl}_{2} .2 \mathrm{H}_{2} \mathrm{O}$, $\mathrm{MgCl}_{2} \cdot 6 \mathrm{H}_{2} \mathrm{O}, \mathrm{NaHCO}_{3}, \mathrm{Na}_{2} \mathrm{SO}_{4}$ e $\left(\mathrm{Na}_{2} \mathrm{O}\right)_{0,28} \cdot \mathrm{SiO}_{2}$ de grau analítico em água destilada e 
deionizada. $\mathrm{O}$ pH de todas as soluções foram ajustados a 7,25 a $37^{\circ} \mathrm{C} \operatorname{com~} \mathrm{HCl} 0,1 \mathrm{M} \mathrm{e}$ tris(hidroximetil)aminometano $\left(\mathrm{CH}_{2} \mathrm{OH}\right)_{3} \mathrm{CNH}_{2} \quad 0,05 \mathrm{M}$, guardadas em frascos fechados de polipropileno.

Na Tabela 2 são apresentadas as quantidades necessárias de cada reagente para o preparo de 1 litro de SBF e 1,5SBF.

Tabela 2: Quantidade de reagentes para o preparo de SBF e 1,5 SBF

\begin{tabular}{|l|r|r|}
\hline \multicolumn{1}{|c|}{ Reagentes } & SBF (g) & \multicolumn{1}{c|}{ 1,5SBF (g) } \\
\hline$\left(\mathrm{Na}_{2} \mathrm{O}_{0.28} \cdot \mathrm{SiO}_{2}\right.$ & 7,9946 & 11,9919 \\
\hline $\mathrm{NaCl}$ & 0,2236 & 0,3354 \\
\hline $\mathrm{KCl}$ & 0,1742 & 0,2613 \\
\hline $\mathrm{K}_{2} \mathrm{H} \mathrm{PPO}_{4}$ & 0,3676 & 0,5514 \\
\hline $\mathrm{CaCl}_{2} \cdot 2 \mathrm{H}_{2} \mathrm{O}$ & 0,3050 & 0,4575 \\
\hline $\mathrm{MgCl}_{2} \cdot 6 \mathrm{H}_{2} \mathrm{O}$ & 0,3528 & 0,5292 \\
\hline $\mathrm{NaHCO}_{3}$ & 0,0701 & 0,1065 \\
\hline $\mathrm{Na}_{2} \mathrm{SO}_{4}$ & & $15 \mathrm{~mL}$ \\
\hline $\mathrm{HCl} 0,1 \mathrm{M}$ & $10 \mathrm{~mL}$ & até $\mathrm{pH}=7,25$ \\
\hline Tris $0,05 \mathrm{M}$ & até $\mathrm{pH}=7,25$ & \\
\hline
\end{tabular}

\section{V.5. CARACTERIZAÇÃO DOS PÓS}

Os pós cerâmicos obtidos foram caracterizados pelas seguintes técnicas:

- Difração de raios X (DMAX 2000, Rigaku), para identificação das fases cristalinas presentes. As análises foram realizadas com radiação $\mathrm{Cu}-\mathrm{K} \alpha$, monocromador de grafite, passo $0,02^{\circ}$ e tempo de 6 segundos de contagem. Não foi empregado o método de Rietveld, devido aos pós cerâmicos apresentarem baixa cristalinidade.

- Microscopia eletrônica de varredura (XL30, Philips), para observação da forma das partículas e aglomerados.

- Adsorção gasosa (BET Quantachrome, Nova 1200), para medidas de área de superfície específica.

- Difração a laser (Cilas granulometer), para determinação da distribuição granulométrica das partículas ou aglomerados. 


\section{V.6. CARACTERIZAÇÃO DAS AMOSTRAS SINTERIZADAS}

As técnicas utilizadas para a caracterização das amostras sinterizadas foram:

- Determinação da densidade aparente pelo método de Archimedes, utilizando-se a equação 18 :

$$
\rho_{\text {amostra }}=\frac{M s}{(M u-M i)}
$$

Sendo:

$\rho=$ densidade $\left(\mathrm{g} . \mathrm{cm}^{-3}\right)$;

Ms, Mu e Mi = Massa seca, massa úmida e massa imersa, respectivamente $(\mathrm{g})$.

Para determinação da densidade teórica dos compósitos de zircônia-alumina, utilizou-se a regra das misturas:

$$
\rho_{\text {composito }}=\left(\rho a^{*} X a\right)+\left(\rho b^{*} X b\right)
$$

Sendo:

$\rho \mathrm{a}=$ densidade teórica do óxido A $\left(6,1 \mathrm{~g} / \mathrm{cm}^{3}\right.$ para zircônia estabilizada com 3 mol\% de ítria);

$\rho b=$ densidade teórica do compósito $B\left(3,98 \mathrm{~g} / \mathrm{cm}^{3}\right.$ para a alumina);

$\mathrm{Xa}=$ fração volumétrica do óxido $\mathrm{A}$;

$\mathrm{Xb}=$ fração volumétrica do óxido $\mathrm{B}$.

- Difração de raios X (DMAX 2000, Rigaku), para identificação e quantifịcação das fases cristalinas presentes pelo método de Rietveld, utilizando os seguintes parâmetros: radiação $\mathrm{Cu}-\mathrm{K} \alpha$, monocromador de grafite, passo $0,02^{\circ}$ e tempo de 6 segundos de contagem. As fendas utilizadas foram: de divergência $12^{\circ}$, de espalhamento $1 / 2^{\circ}$, de recepção $0,3 \mathrm{~mm}$. A miliamperagem e a voltagem utilizadas foram $20 \mathrm{~mA}$ e $40 \mathrm{Kv}$ respectivamente.

- Análise microestrutural, por microscopia eletrônica de varredura (XL, Philips), observando-se a superfície de fratura, a superficie após os tratamentos químicos com $\mathrm{H}_{3} \mathrm{PO}_{4}$ e $\mathrm{NaOH}$ e a superfície onde ocorreu a deposição de hidroxiapatita através do processo biomimético nas amostras sinterizadas. 
- Fluorescência de raios X (modelo RIX-3000 da Rigaku), para a observação da espessura da camada formada de hidroxiapatita decorrente do recobrimento biomimético.

- Avaliação das propriedades mecânicas das amostras de alumina, zircônia estabilizada com $3 \mathrm{~mol} \%$ de ítria e compósitos, pela determinação da dureza e tenacidade à fratura, empregando-se o ensaio de impressão Vickers (durômetro VMT-7, Buehler). Para esta finalidade, as amostras foram cortadas, na direção do eixo longitudinal com disco diamantado, embutidas em baquelite e polidas com pasta de diamante de granulometria de 15,6 e $1 \mu \mathrm{m}$ para a observação da trinca por microscopia óptica. A força aplicada pelo identador nas amostras de alumina-zircônia foi à faixa de 10 a $500 \mathrm{~N}$. As imagens das impressões e das trincas foram obtidas por microscopia óptica (microscópio PMG3, Olympus).

A dureza do material foi calculada de acordo com a seguinte equação:

$$
H v=\frac{a^{*} P}{d^{2}}
$$

Sendo:

$\mathrm{a}=$ constante;

$\mathrm{Hv}=$ dureza Vickers $(\mathrm{GPa})$;

$\mathrm{P}=$ força aplicada $(\mathrm{N})$;

$\mathrm{d}=$ comprimento da diagonal da impressão (m).

A determinação da tenacidade à fratura $\left(\mathrm{K}_{\mathrm{IC}}\right)$ pode ser realizada empregando-se um grande número de equações. Foi utilizada a equação de Casellas (MORAES et al.,2004) ao invés da equação de Anstis (MORAES et al.,2004) ou Niihara (MORAES et al.,2004), devido a essas últimas equações apresentarem valores de $K_{\mathrm{IC}}$ que são de 40 a $50 \%$ superiores para o mesmo material quando comparada com os valores obtidos da equação de Casellas.

A equação de Casellas é dada pela seguinte fórmula:

$$
K_{\digamma C}=0,024 *\left(\frac{E}{H}\right)^{\frac{1}{2}} *\left(\frac{P}{C}\right)^{\frac{3}{2}}
$$


Onde:

$\mathrm{K}_{\mathrm{IC}}=$ tenacidade à fratura $\left(\mathrm{MPa} \cdot \mathrm{m}^{1 / 2}\right)$;

$\mathrm{P}=$ carga aplicada $(\mathrm{N})$;

$\mathrm{E}=$ módulo de Young;

$\mathrm{H}=$ dureza $(\mathrm{GPa})$;

$a=$ metade do comprimento da diagonal da impressão vickers (m);

$\mathrm{l}=$ comprimento da trinca $(\mathrm{m})$;

$\mathrm{c}=1+\mathrm{a}(\mathrm{m})$.

Nesse trabalho, o módulo de Young utilizado foi o obtido pela regra das misturas, sendo 210GPa (PICONI et al.,1999), (HANNINK, 2000), (BRAVO-LEON et al., 2002) para a zircônia e 380 GPa (PICONI et al.,1999), (HANNINK, 2000) para a alumina. 


\section{RESULTADOS E DISCUSSÕES}

\section{VI.1. CARACTERIZAÇÃo DOS PÓS SINTETIZADOS}

As micrografias obtidas por microscopia eletrônica de varredura das amostras 100A, 80A20TZP, 20A80TZP e 100TZP, apresentadas na Figura 6, indicam que os pós apresentam-se na forma de aglomerados, sendo que as partículas que compõe esses aglomerados apresentam dimensões nanométricas (GARCIA et.al., 2006; GARCIA et.al., 2005). Este fato é evidenciado pelos elevados valores de área superficial específica relacionado na Tabela 3.

Tabela 3: Valores de área superficial específica dos pós sintetizados: 100A, 80A20TZP, 20A80TZP e 100TZP.

\begin{tabular}{|c|c|}
\hline Amostras & Sw $\left(\mathbf{~ m}^{2} / \mathbf{g}\right)$ \\
\hline $100 \mathrm{~A}$ & $179,9 \pm 1,0$ \\
\hline $80 \mathrm{~A} 20 \mathrm{TZP}$ & $118,9 \pm 1,3$ \\
\hline $20 \mathrm{~A} 80 \mathrm{TZP}$ & $119,4 \pm 0,3$ \\
\hline $100 \mathrm{TZP}$ & $32,62 \pm 0,1$ \\
\hline
\end{tabular}
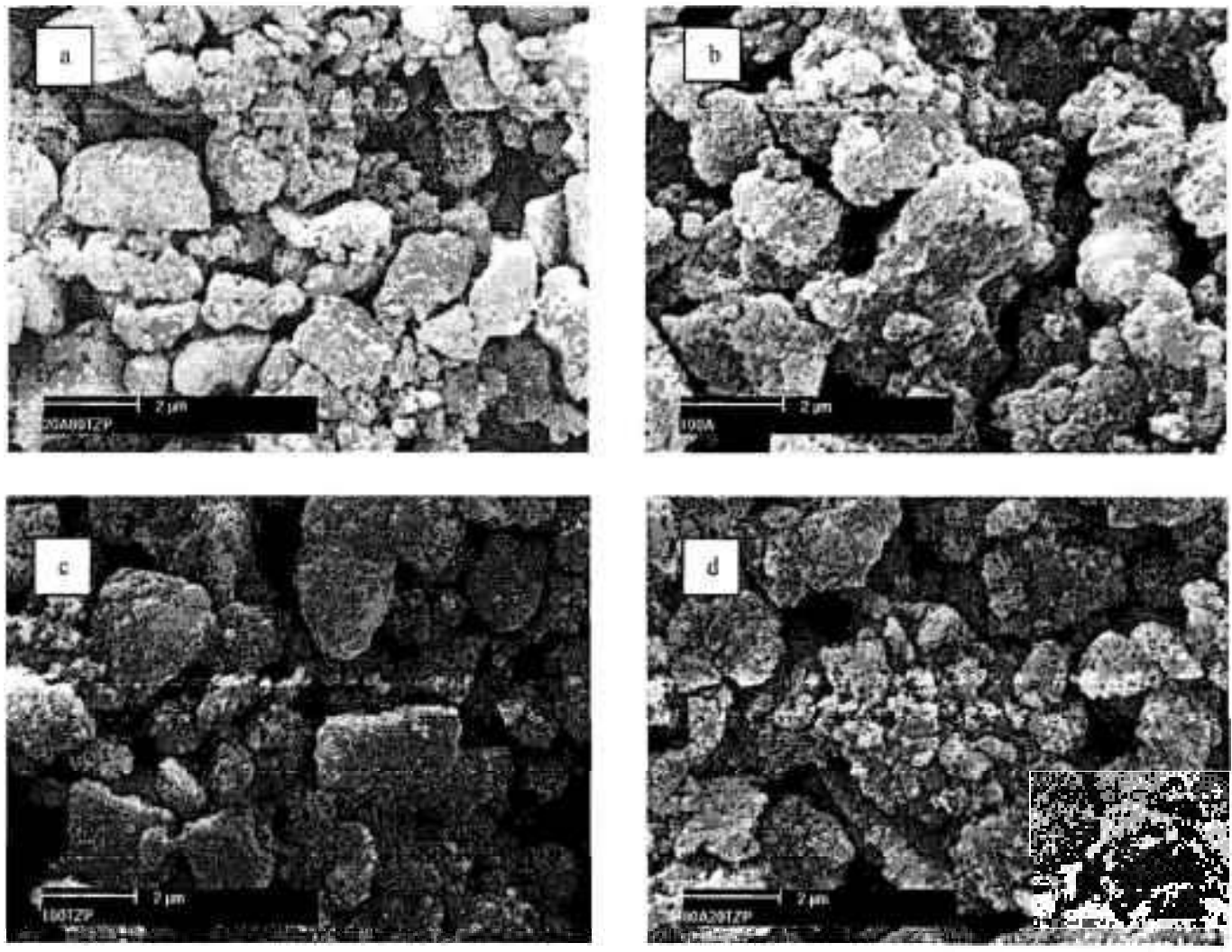

Figura 6: Micrografias obtidas por microscopia eletrônica de varredura dos pós cerâmicos sintetizados. a) 20A80TZP ; b)100A ;c)100TZP e d) $80 \mathrm{~A} 20 \mathrm{TZP}$ 
Os resultados de distribuição granulométrica, apresentados nas Figuras 7 a 10 , mostram que a alumina pura (100A) apresenta uma distribuição bimodal, com tamanhos médios de aglomerados de 4.6 e $23 \mu \mathrm{m}$.

Para a zircônia estabilizada (100TZP), a distribuição é praticamente monomodal, com tamanho médio de aglomerados de 1,6 $\mu \mathrm{m}$.

As amostras (80A20TZP e 20A80TZP) apresentam distribuição granulométrica semelhante aos pós 100A e 100TZP respectivamente, com tamanhos médios de aglomerados de 4 e $18 \mu \mathrm{m}$ para a mistura $80 \mathrm{~A} 20 \mathrm{TZP}$ e 2,4 e $8,5 \mu \mathrm{m}$ para a mistura 20A80TZP.

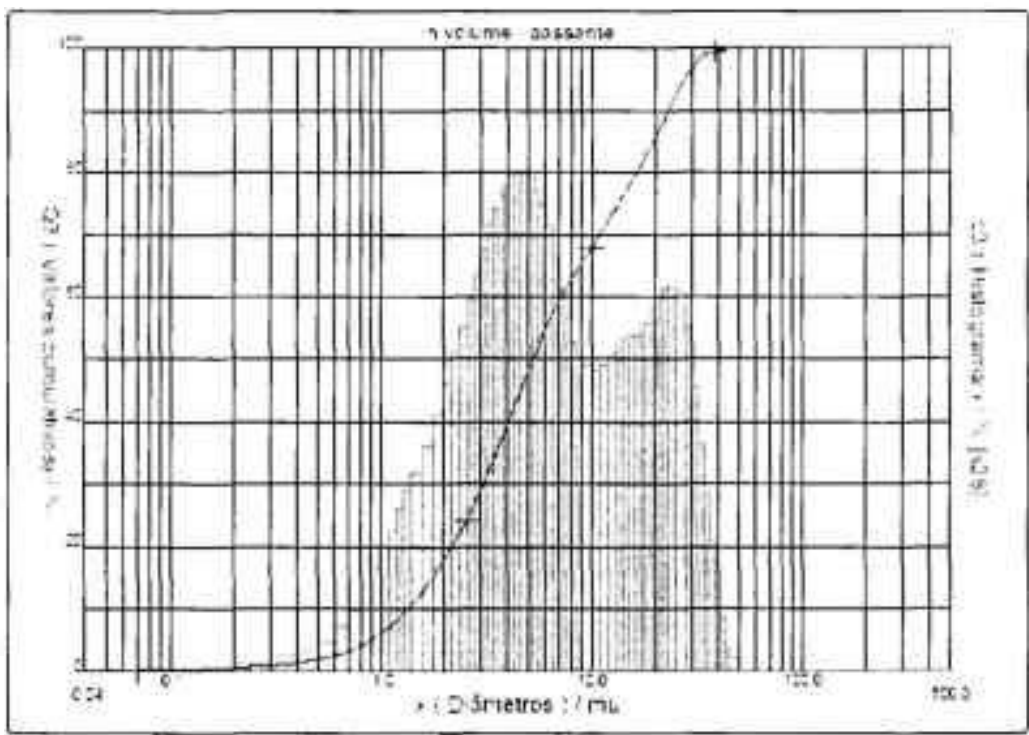

Figura 7: Distribuição granulométrica do pó sintetizado (100A)

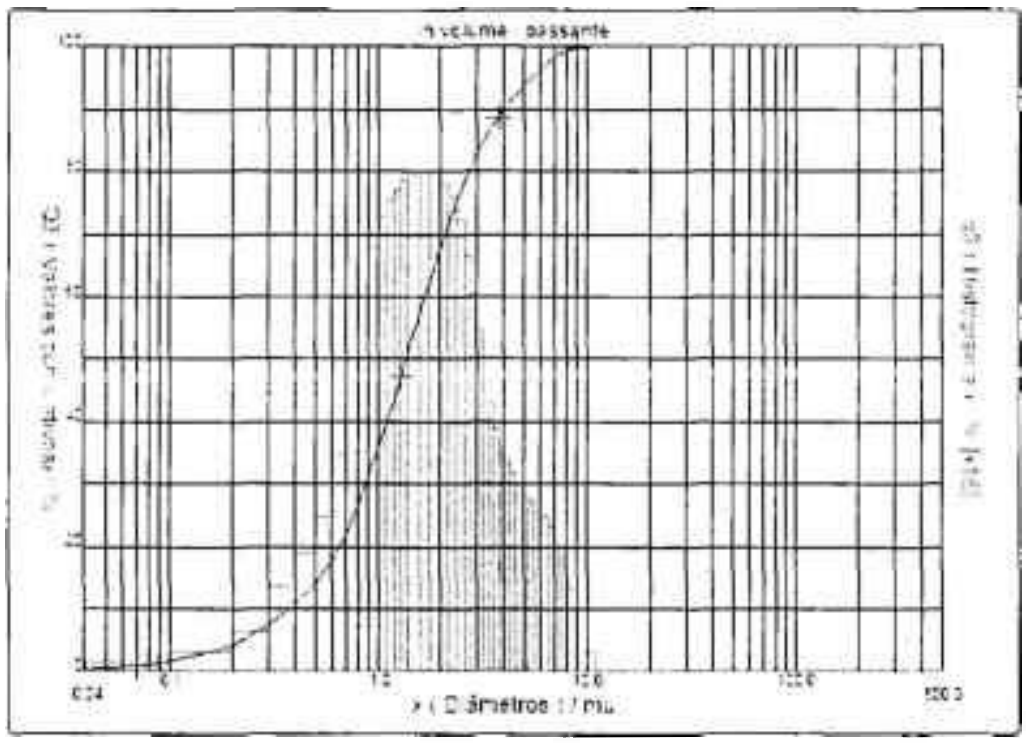

Figura 8: Distribuição granulométrica do pó sintetizado (100TZP) 


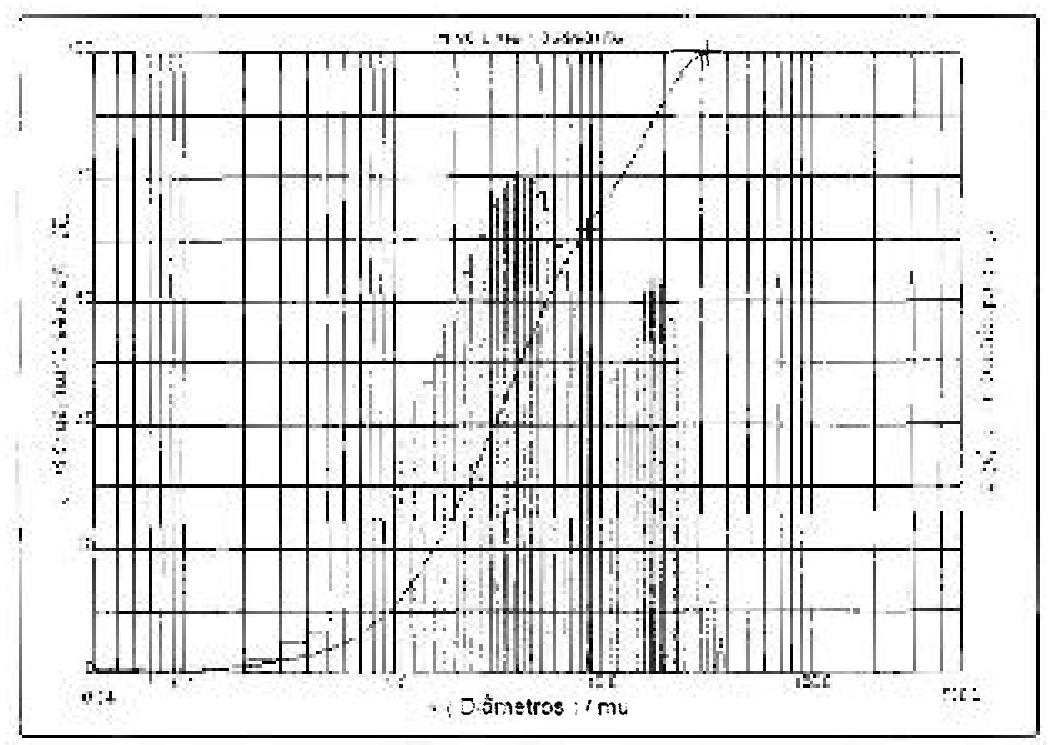

Figura 9: Distribuição granulométrica do pó sintetizado (80A20TZP)

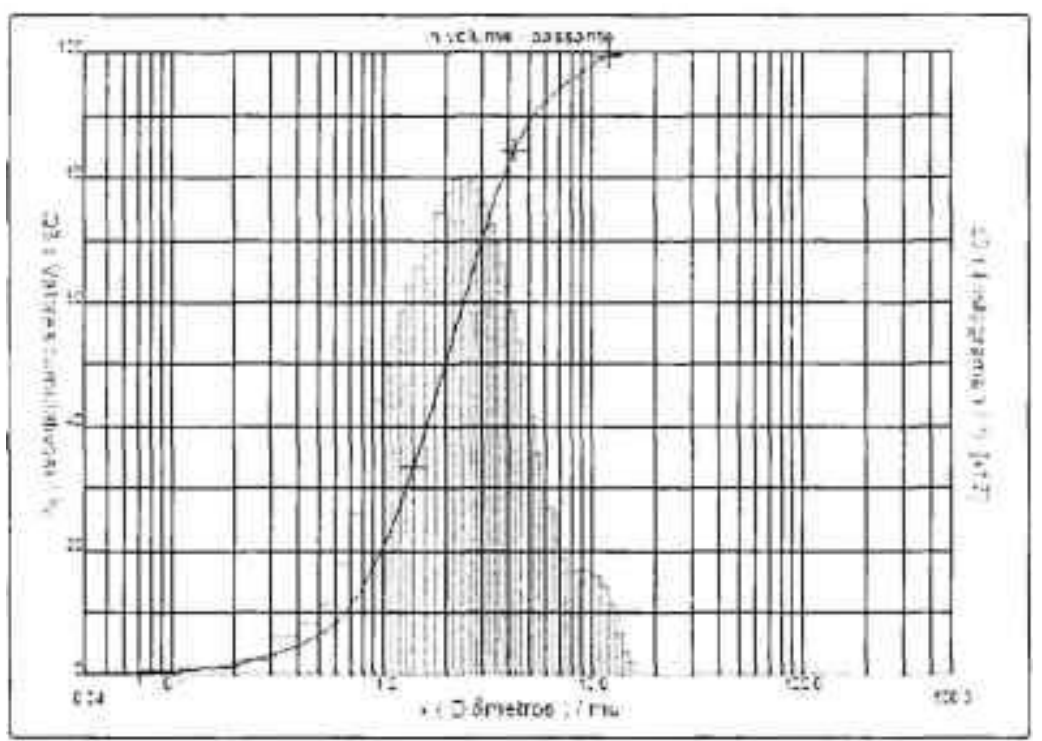

Figura 10: Distribuição granulométrica do pó sintetizado (20A80TZP)

Os difratogramas dos pós calcinados a $800^{\circ} \mathrm{C}$ por 1 hora. são apresentados nas Figuras 11 a 14.

Considerando que o alargamento do perfil de DRX indica o grau de cristalinidade, pode-se afirmar que a amostra 100A apresenta-se pouco cristalina, enquanto a amostra 100 TZP apresenta cristalinidade. 
Observou-se que quanto maior o teor de alumina, menos cristalina é a amostra, inibindo a cristalização da zircônia, como verificado nos difratogramas das Figuras 11 a 14.

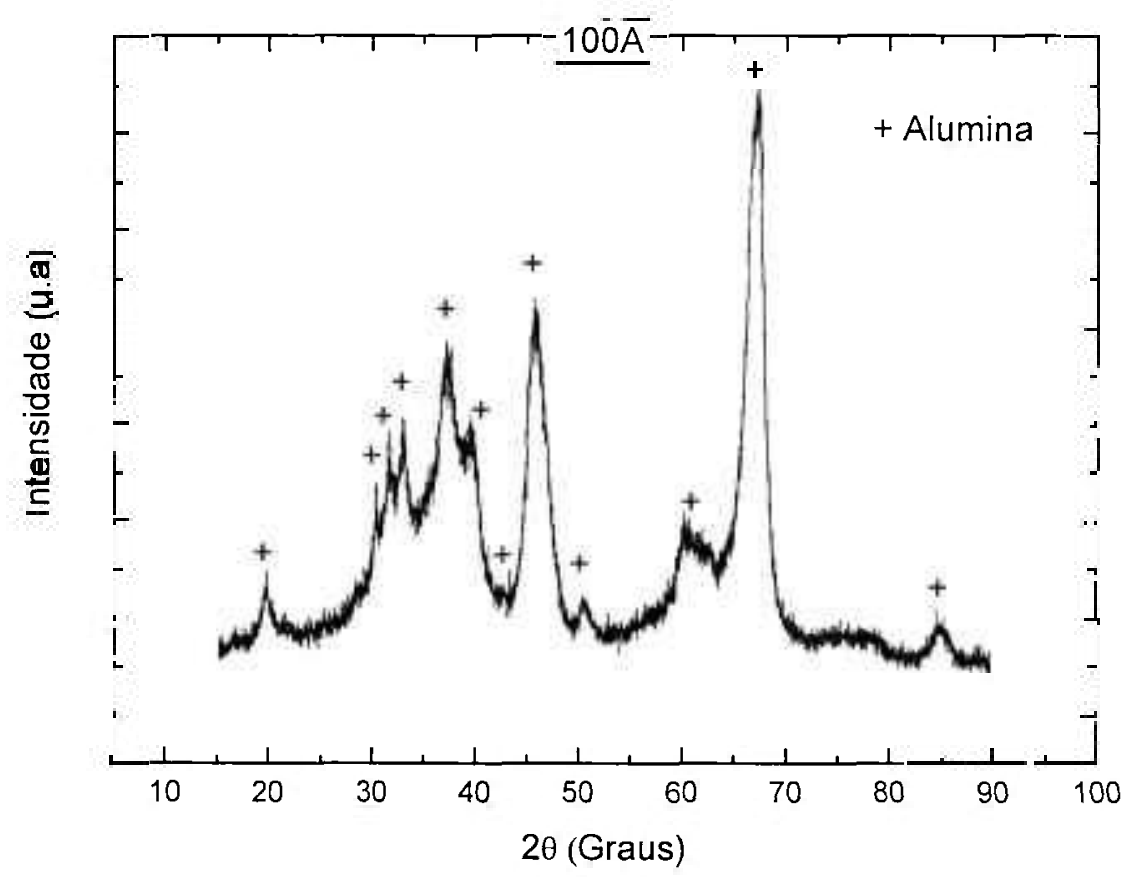

Figura 11: Difratograma do pó sintetizado (100A)

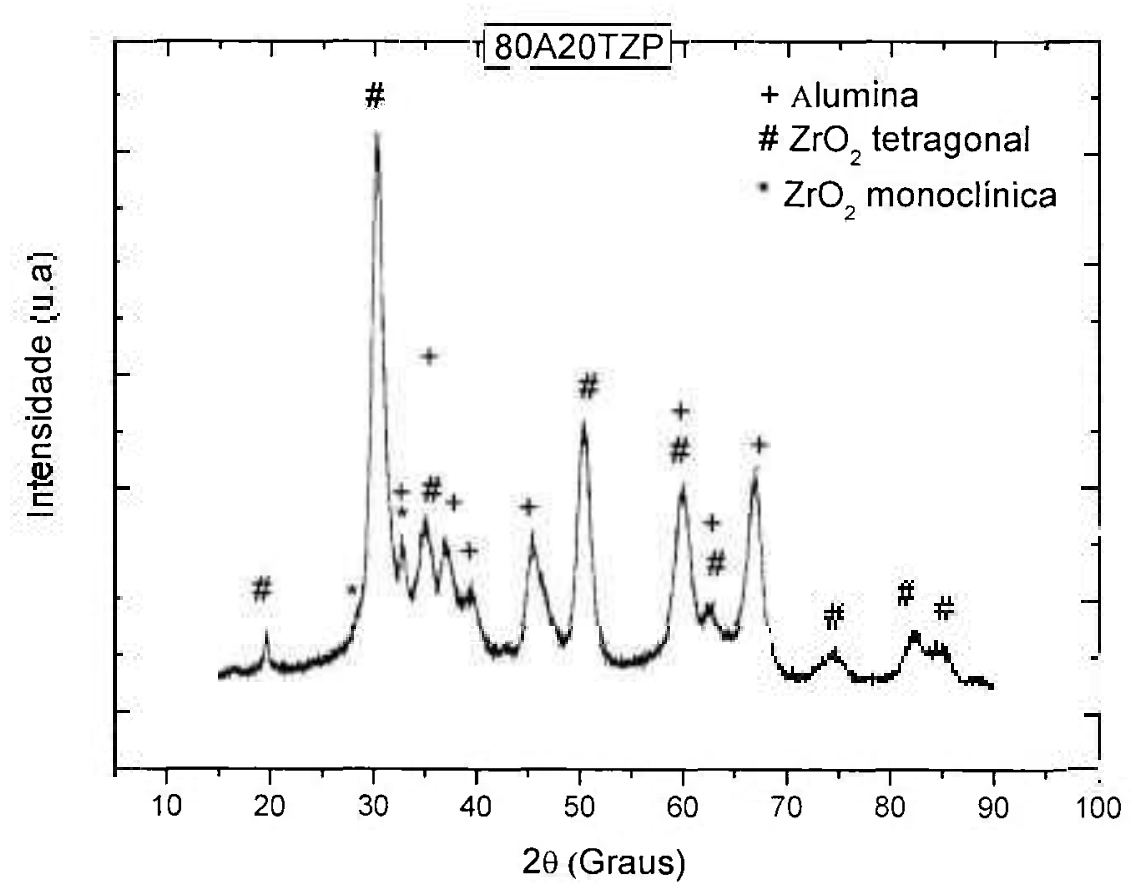

Figura 12: Difratograma do pó sintetizado (80A20TZP) 


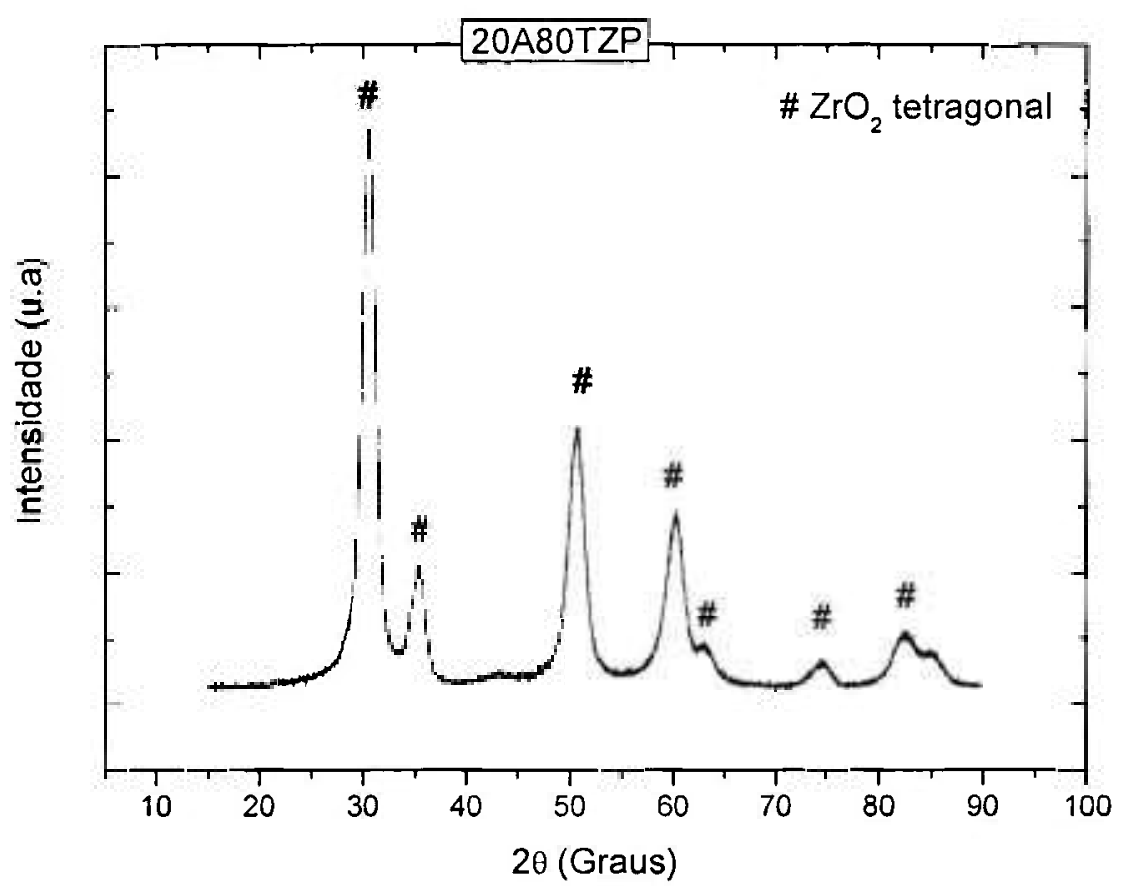

Figura 13: Difratograma do pó sintetizado (20A80TZP)

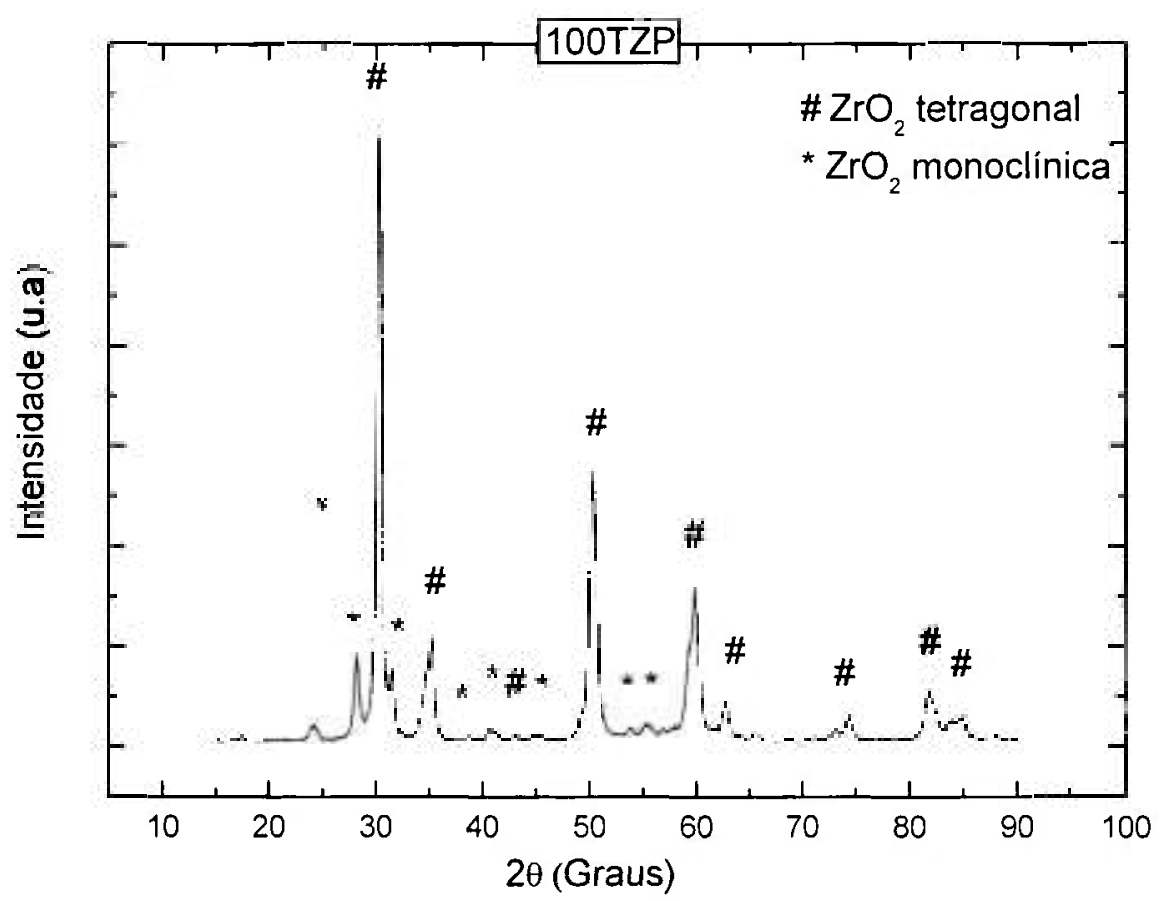

Figura 14: Difratograma do pó sintetizado (100TZP) 
Para o difratograma da Figura 13, observa-se que não foi verificada a fase da alumina, devido à baixa cristalinidade.

\section{VI.2. CARACTERIZAÇÃO DAS CERÂMICAS APÓS SINTERIZAÇÃO}

Após a sinterização, as pastilhas foram analisadas por MEV, DRX, determinação da dureza, tenacidade à fratura e densidade.

As micrografias obtidas por microscopia eletrônica de varredura apresentadas na Figura 15, indicam as superfícies de fratura das amostras sinterizadas: 20A80TZP; 80A20TZP; 100TZP e 100A. Nota-se que a estabilização com $3 \mathrm{~mol} \%$ de ítria permite a obtenção de cerâmicas constituídas por grãos com tamanho estimado entre 0.6 a $1,0 \mu \mathrm{m}$, com fratura e porosidade intergranular. A amostra contendo $100 \%$ alumina é formada por grãos maiores, em torno de 1,6 $\mathrm{m}$ com porosidade intergranular e intraganular.
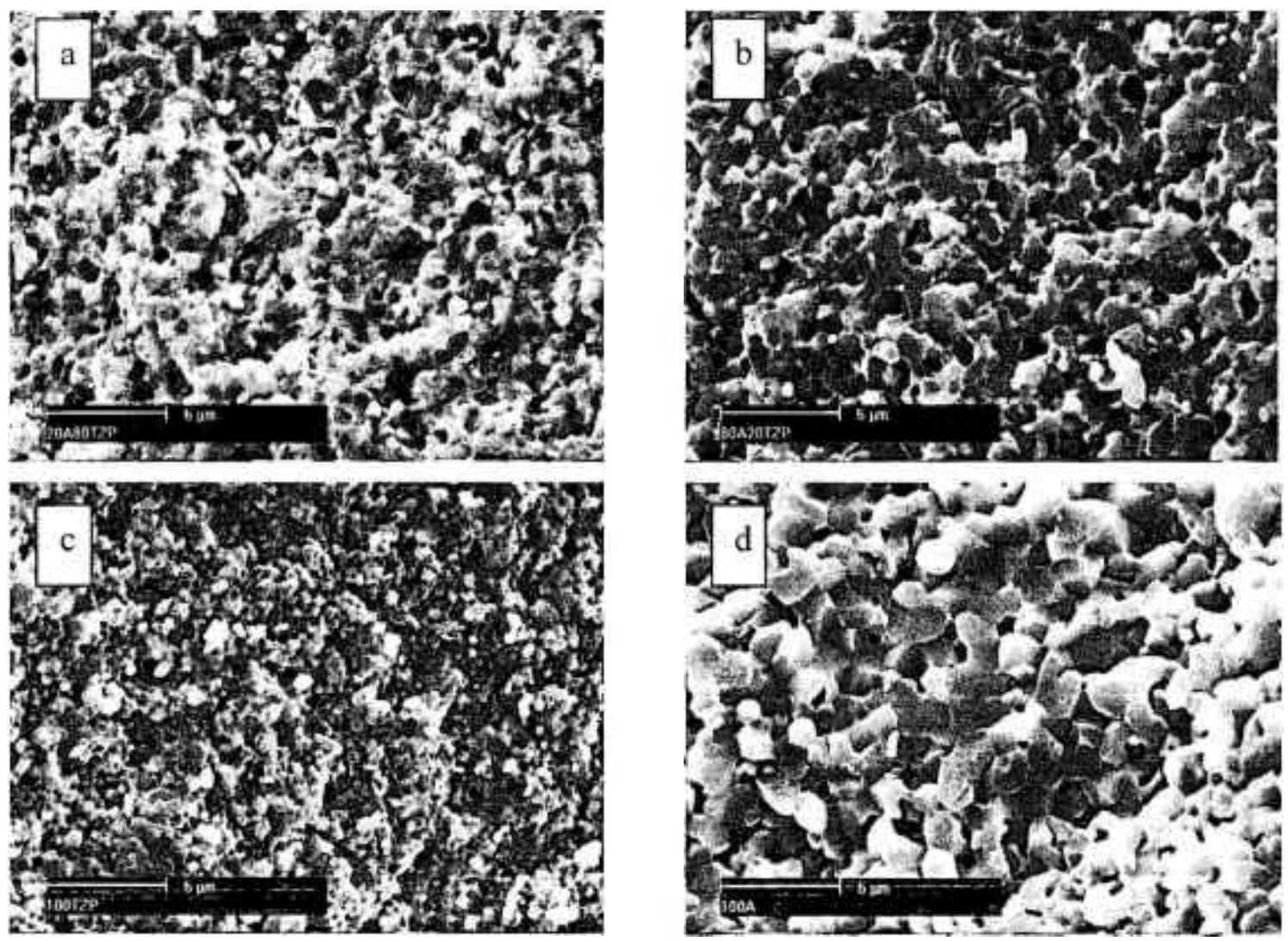

Figura 15: Micrografias obtidas por microscopia eletrônica de varredura de superfícies de fratura das amostras sinterizadas. a) 20A80TZP; b)80A20TZP; c)100TZP e d) 100A 
De acordo com os difratogramas das Figuras 16 e 17, obtidos para as amostras sinterizadas foram observadas as fase alfa da alumina, as fases tetragonal, monoclínica e cúbica da zircônia. Para cada composição foram quantificadas as fases pelo método de Rietveld (YOUNG, 1995; YOUNG et.al., 1982), conforme apresentado na Tabela 4.

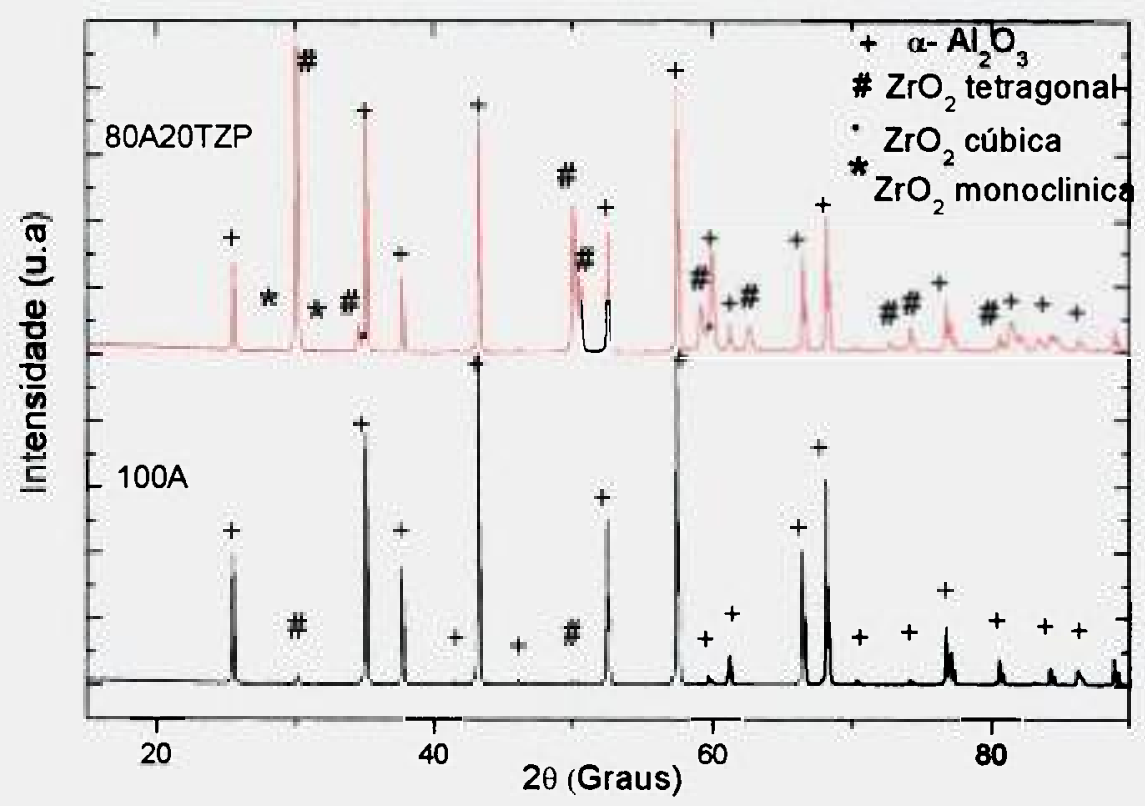

Figura 16: Difratogramas das cerâmicas sem tratamento químico de superfície com as seguintes composições: 80A20TZP e 100A

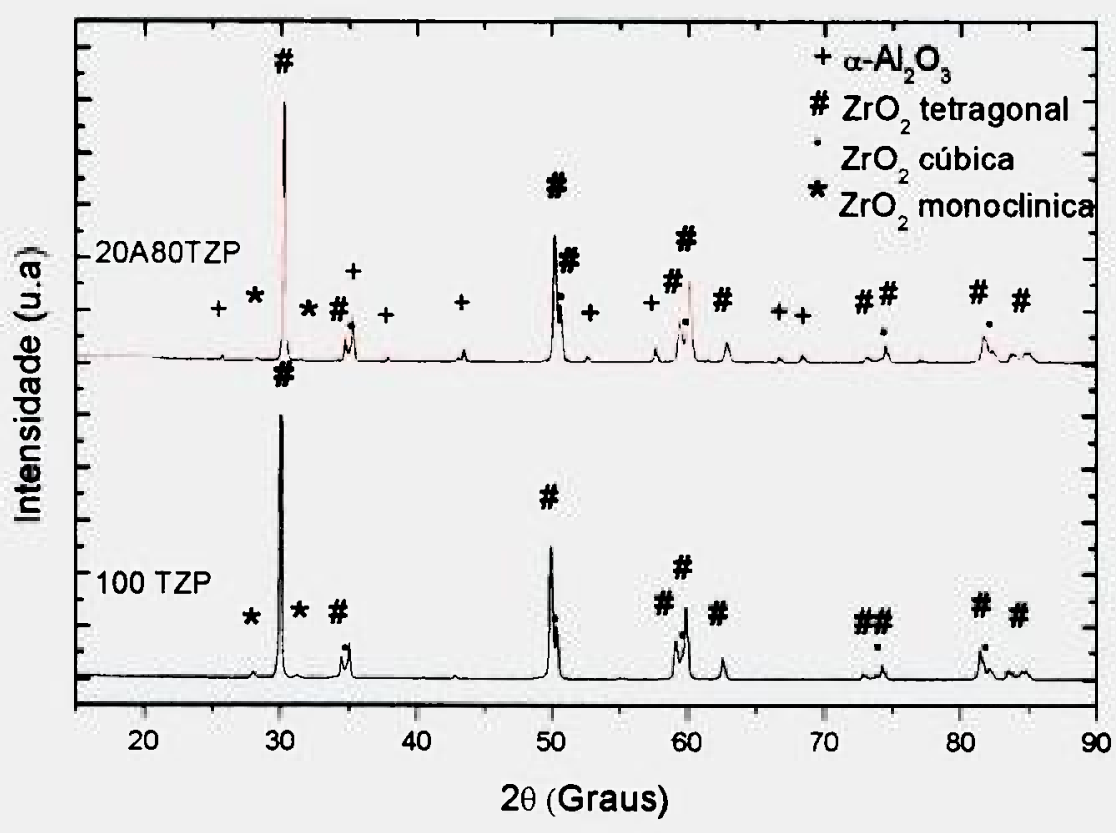

Figura 17: Difratogramas das cerâmicas sem tratamento químico de superficie com as seguintes composições: 20A80TZP e 100TZP 
A Tabela 4 mostra a quantificação das fases das amostras sem tratamento químico.

Tabela 4: Quantificação de fases das cerâmicas à base de alumina e zircônia, sem tratamento químico de superfície.

\begin{tabular}{|c|c|c|c|c|}
\hline \multirow{2}{*}{ Amostras } & \multicolumn{4}{|c|}{ Composição das fases (\%em massa) } \\
\cline { 2 - 5 } & $\alpha$-alumina & $\begin{array}{c}\text { Tetragonal da } \\
\text { Zircônia }\end{array}$ & $\begin{array}{c}\text { Monoclínica } \\
\text { da Zircônia }\end{array}$ & $\begin{array}{c}\text { Cúbica da } \\
\text { Zircônia }\end{array}$ \\
\hline 80A20TZP & 80 & 16 & 0,6 & 3 \\
\hline $20 \mathrm{~A} 80 \mathrm{TZP}$ & 21 & 62 & 2,0 & 15 \\
\hline $100 \mathrm{~A}$ & 99 & 0,6 & $\cdots$ & 32,1 \\
\hline 100TZP & $-\cdots---$ & 59,2 & $\mathbf{8 , 7}$ & \\
\hline
\end{tabular}

Da análise da Tabela 4, podemos destacar:

- A mistura $\mathrm{Al}_{2} \mathrm{O}_{3} / \mathrm{ZrO}_{2}$ apresenta as proporções de acordo com o esperado;

- O aparecimento da fase cúbica na amostra 100TZP também foi observado por outro autor (Chevalier 2004). A análise do diagrama de fase de $\mathrm{Y}_{2} \mathrm{O}_{3}-\mathrm{ZrO}_{2}$ mostra que na temperatura de sinterização da amostra $100 \mathrm{TZP}\left(1500^{\circ} \mathrm{C}\right.$ por 1 hora), deve apresentar duas fases: uma fase cúbica, rica em ítria e outra tetragonal com concentração menor ou igual a 3 mol\% de ítria. Matsui (2006), mostra em seu trabalho que a fase cúbica começa a se formar em $1300^{\circ} \mathrm{C}$ para amostras com $2,9 \mathrm{~mol} \%$ de ítria. Esse fato está relacionado com a segregação de íons $\mathrm{Y}^{3+}$ nos contornos de grãos, mostrando que a transformação se inicia nos contornos de grãos.

Segundo a Tabela 5, a maior densificação foi atingida para o compósito 20A80TZP. Para a alumina pura e com $20 \%$ de zircônia estabilizada, a densidade do compósito aumenta com a adição de zircônia, uma vez que a densificação da zircônia ocorre em temperaturas mais baixas. Outro aspecto relevante refere-se à inibição da cristalização da zircônia na presença de alumina, exigindo elevada temperatura de sinterização para densificação e homogeneização da microestrutura (GARCIA et.al., 2006).

Conforme aumenta o teor de zircônia, a dureza do compósito diminui. Maiores valores de dureza implicam em melhor resistência ao desgaste e ao risco. A quantidade de carga pode afetar o tamanho da indentação e o comprimento da trinca, sendo dependentes da dimensão da amostra e da microestrutura do material.

O módulo de elasticidade, empregado na equação de Casellas (MORAES et.al., 2004), para determinação da tenacidade à fratura $\left(\mathrm{K}_{\mathrm{IC}}\right)$ foi obtido pela regra das misturas 
sendo 210GPa para a Y-TZP e 380 GPa para alumina (MORAES et.al., 2004) e a carga utilizada foi $100 \mathrm{~N}$. Os maiores valores de tenacidade do compósito contendo alumina, em relação à zircônia estabilizada, são consequiência da presença de maior concentração de fase cúbica e monoclínica nesta última amostra. Nos compósitos com matriz de alumina ou mesmo com alta porcentagem de alumina, com a carga utilizada de $100 \mathrm{~N}$ e $300 \mathrm{~N}$ não foi possível determinar a tenacidade à fratura, pois a natureza frágil desta cerâmica, não permite a visualização e a medição das trincas.

Tabela 5: Propriedades das cerâmicas à base de alumina e zircônia sem tratamento químico de superfície

\begin{tabular}{|c|c|c|c|c|c|}
\hline Composições & $\begin{array}{c}\text { Densidade } \\
\text { aparente } \\
\left(\mathrm{g} / \mathrm{cm}^{3}\right)\end{array}$ & $\begin{array}{c}\text { Densidade } \\
\text { teórica } \\
\left(\mathrm{g} / \mathrm{cm}^{3}\right)\end{array}$ & $\begin{array}{c}\text { Densidade } \\
\text { da pastilha } \\
\text { sinterizada } \\
(\% \rho t)\end{array}$ & $\begin{array}{c}\text { K }_{\mathrm{IC}} \\
\left(\mathrm{MPa.m}^{1 / 2}\right)\end{array}$ & $\begin{array}{c}\text { Hv } \\
(\mathbf{G P a})\end{array}$ \\
\hline $100 \mathrm{~A}$ & $3,75 \pm 0,01$ & 3,98 & 94,2 & $-\infty \ldots$ & $17,0 \pm 0,8$ \\
\hline 80A20TZP & $4,22 \pm 0,01$ & 4,28 & 98,6 & -..- & $17,1 \pm 0,5$ \\
\hline 20A80TZP & $5,40 \pm 0,01$ & 5,47 & 98,7 & $8,6 \pm 0,5$ & $12,4 \pm 0,7$ \\
\hline 100TZP & $5,97 \pm 0,05$ & 6,10 & 97,9 & $7,0 \pm 0,9$ & $9,6 \pm 0,7$ \\
\hline
\end{tabular}

Amostras com porosidade residual que tenham aplicações em biomateriais, como as obtidas neste trabalho, não oferecem grandes problemas, considerando seu melhor desempenho mecânico comparado às demais cerâmicas, também utilizadas como biomateriais (LEGEROS, 1991). Sabe-se que a porosidade aberta pode auxiliar na drenagem de líquidos, fornecendo nutrientes para sobrevivência do tecido na interface com o material (RIBEIRO, 2003).

\section{VI.3. CARACTERIZAÇÃO DAS CERÂMICAS SUBMETIDAS A ATAQUE QUÍMICO}

Para as composições submetidas a tratamentos químicos superficiais $\left(5 \mathrm{M} \mathrm{H}_{3} \mathrm{PO}_{4}\right.$ e $15 \mathrm{M} \mathrm{NaOH}$ ) observou-se, pelos difratogramas das Figuras 18, 19, 20 e 21, que houve um aumento da concentração de fase monoclínica, para a grande maioria das amostras, em relação as composições que não foram submetidas a tratamentos.

A Tabela 6 mostra a quantificação das fases pelo método de Rietveld das amostras tratadas quimicamente com ácido e base. 


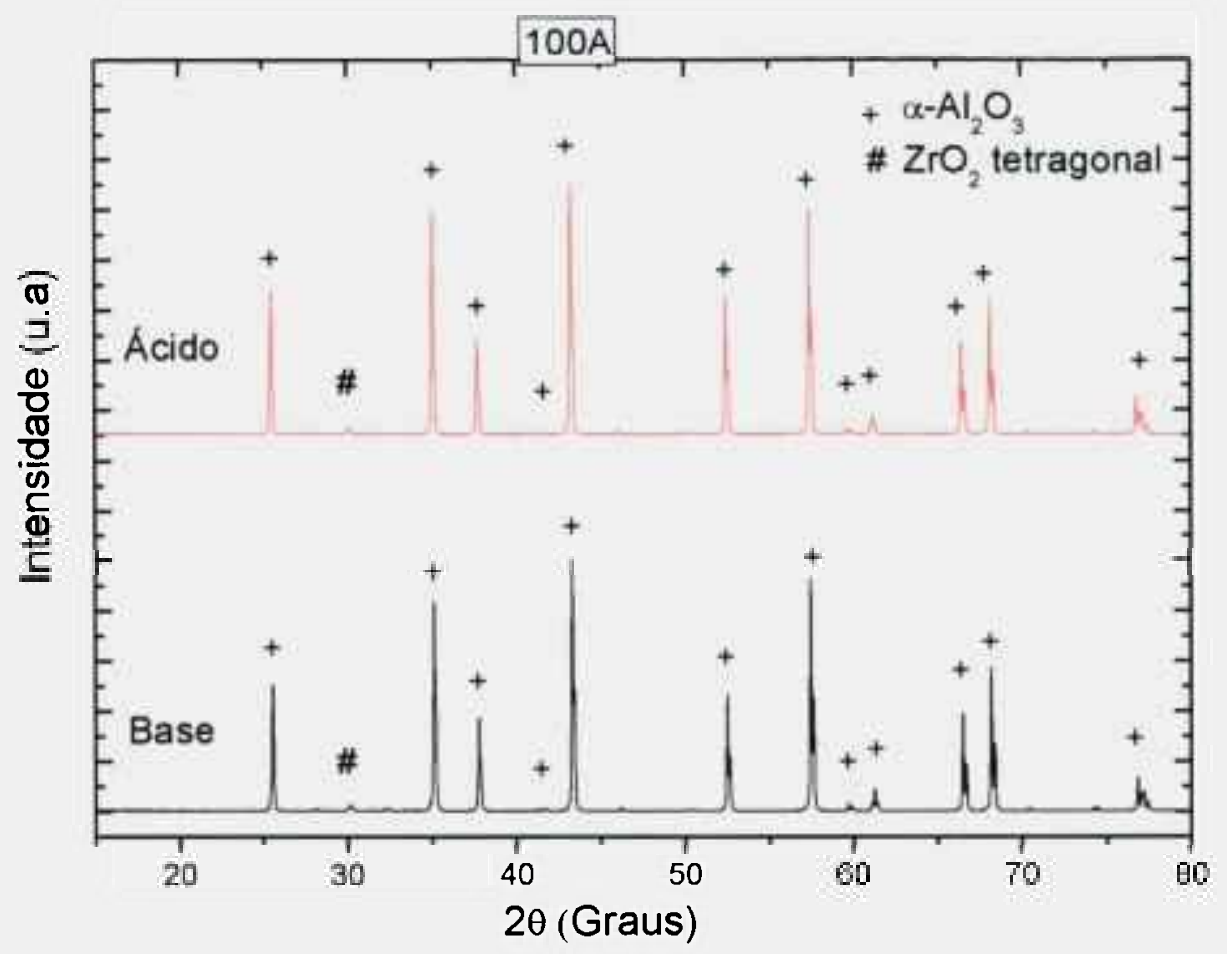

Figura 18: Difratograma da cerâmica $(100 \mathrm{~A})$ com tratamento químico de superficie com ácido $\left(\mathrm{H}_{3} \mathrm{PO}_{4}\right)$ e base $(\mathrm{NaOH})$

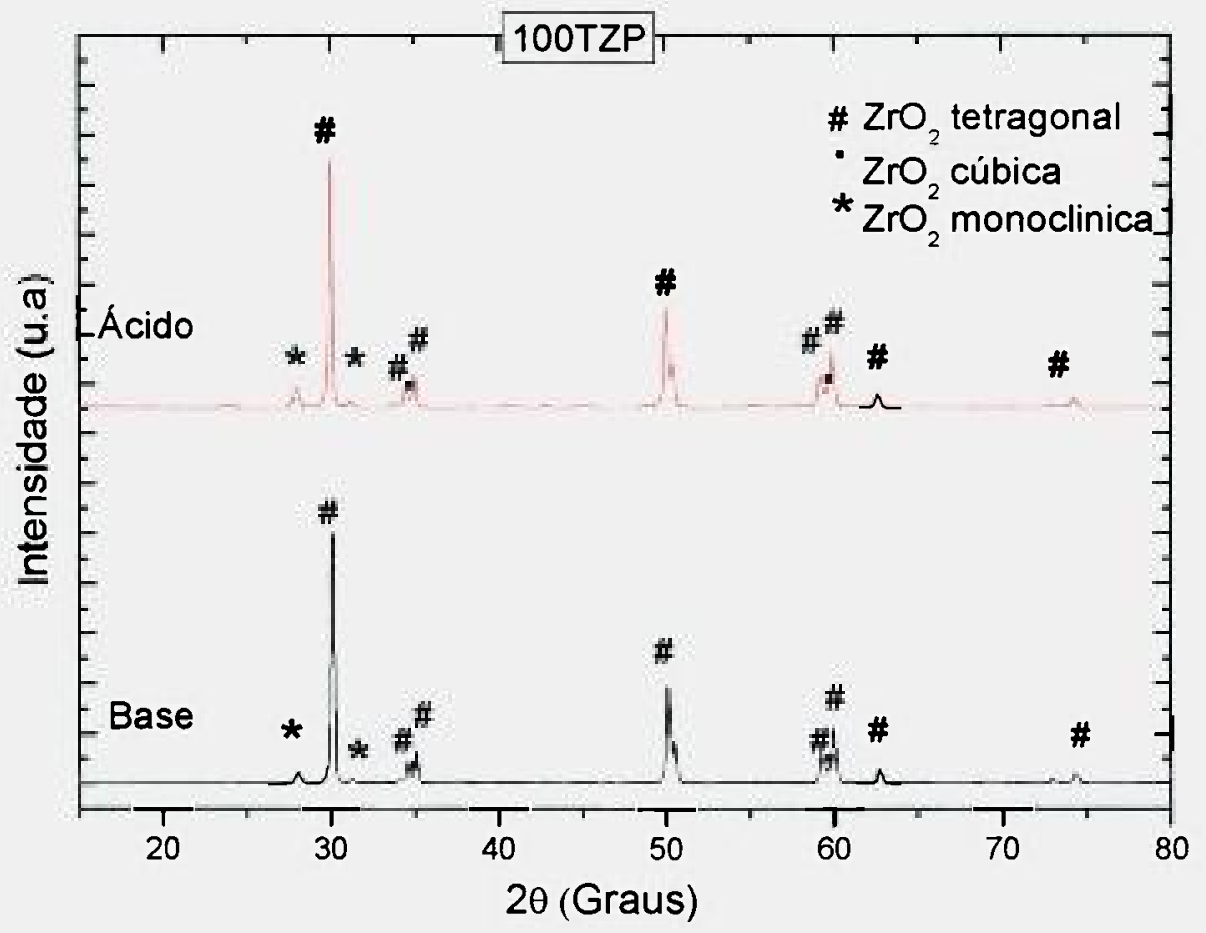

Figura 19: Difratograma da cerâmica (100TZP) com tratamento químico de superficie com ácido $\left(\mathrm{H}_{3} \mathrm{PO}_{4}\right)$ e base $(\mathrm{NaOH})$ 


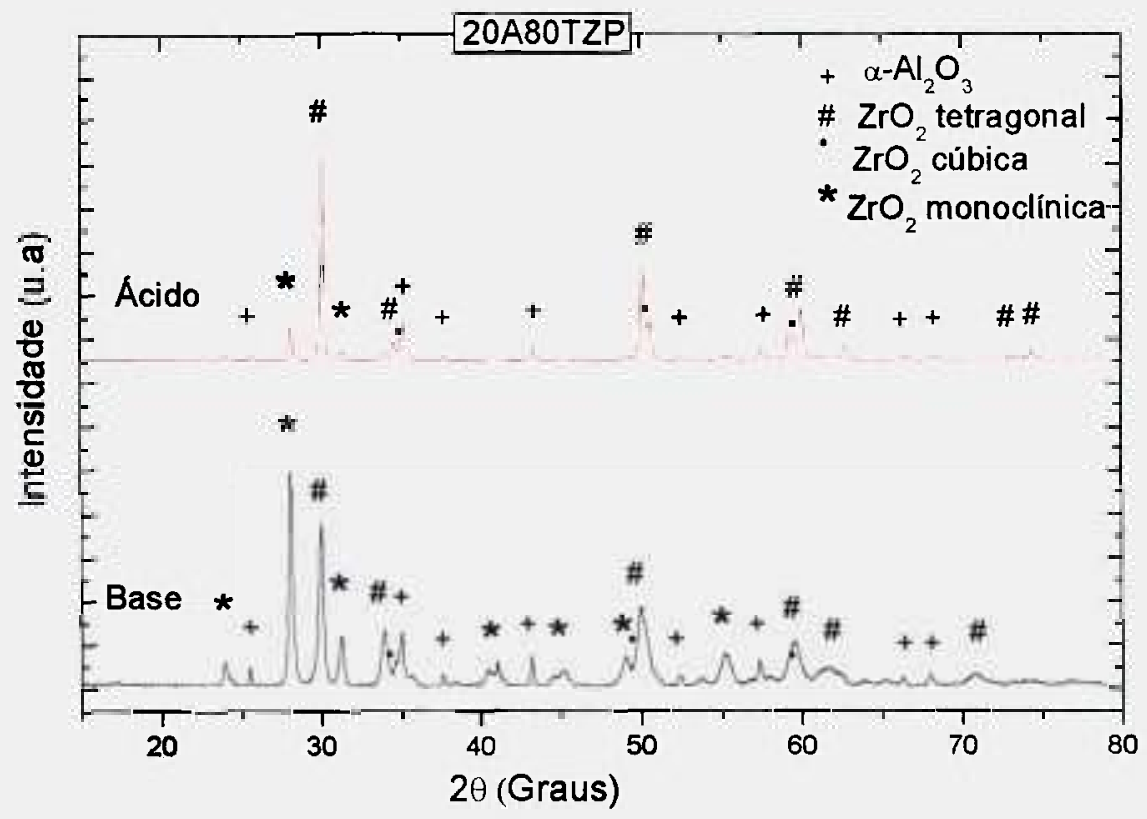

Figura 20: Difratograma da cerâmica (20A80TZP) com tratamento químico de superficie com ácido $\left(\mathrm{H}_{3} \mathrm{PO}_{4}\right)$ e base $(\mathrm{NaOH})$

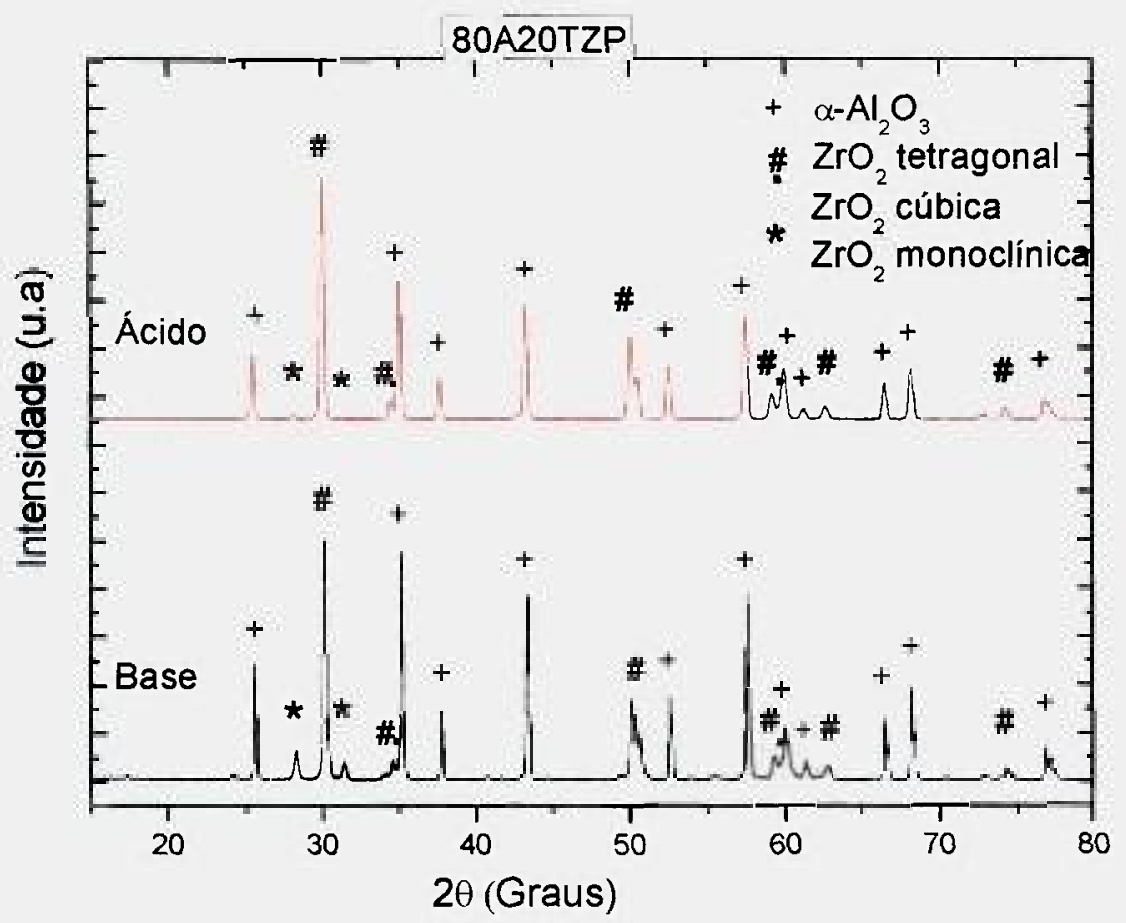

Figura 21: Difratograma da cerâmica (80A20TZP) com tratamento químico de superficie com ácido $\left(\mathrm{H}_{3} \mathrm{PO}_{4}\right)$ e base $(\mathrm{NaOH})$ 
Tabela 6: Quantificação de fases das cerâmicas à base de alumina e zircônia, após tratamento químico de superfície com $\mathrm{H}_{3} \mathrm{PO}_{4} \mathrm{e} \mathrm{NaOH}$.

\begin{tabular}{|c|c|c|c|c|}
\hline \multirow[b]{2}{*}{ Amostras } & \multicolumn{4}{|c|}{ Composição das fases (\%em massa) } \\
\hline & $\alpha$-alumina & $\begin{array}{l}\text { Tetragonal } \\
\text { da Zircônia }\end{array}$ & $\begin{array}{l}\text { Monoclínica } \\
\text { da Zircônia }\end{array}$ & $\begin{array}{c}\text { Cúbica da } \\
\text { Zircônia }\end{array}$ \\
\hline $80 \mathrm{~A} 20 \mathrm{TZP}\left(\mathrm{H}_{3} \mathrm{PO}_{4}\right)$ & 79,1 & 20,3 & 0,5 & $\ldots$ \\
\hline $80 \mathrm{~A} 20 \mathrm{TZP}(\mathrm{NaOH})$ & 80,5 & 13,8 & 5,6 & $\ldots$ \\
\hline $20 \mathrm{~A} 80 \mathrm{TZP}\left(\mathrm{H}_{3} \mathrm{PO}_{4}\right)$ & 24 & 51 & 18 & 6 \\
\hline $20 \mathrm{~A} 80 \mathrm{TZP}(\mathrm{NaOH})$ & 23 & 25 & 48 & 3,1 \\
\hline $100 \mathrm{~A}\left(\mathrm{H}_{3} \mathrm{PO}_{4}\right)$ & 99,4 & 0,32 & 0,27 & 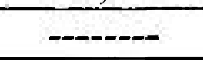 \\
\hline $100 \mathrm{~A}(\mathrm{NaOH})$ & 99,5 & 0,15 & 0,47 & - \\
\hline $100 \mathrm{TZP}\left(\mathrm{H}_{3} \mathrm{PO}_{4}\right)$ & --.-- & 68,8 & 22,8 & 8,3 \\
\hline $100 \mathrm{TZP}(\mathrm{NaOH})$ & --.---- & 70 & 14 & 15 \\
\hline
\end{tabular}

De acordo com as Tabelas 4 e 6, nota-se uma pequena quantidade de zircônia na amostra 100A, isso se deve ao fato da utilização do meio de moagem de zircônia.

A Tabela 7, mostra os resultados de refinamento das amostras sem tratamento químico e com tratamento de $\mathrm{H}_{3} \mathrm{PO}_{4}$ e $\mathrm{NaOH}$.

Segundo Young, 1995, valores típicos de S (raiz quadrada do indice de qualidade do refinamento) menores que 2 e valores de Resíduos (Rwp) em torno de 10, são aceitos como bons resultados.

Tabela 7: Resultado de refinamento das cerâmicas à base de alumina e zircônia sem tratamento químico e após tratamento químico de superfície com $\mathrm{H}_{3} \mathrm{PO}_{4} \mathrm{e} \mathrm{NaOH}$.

\begin{tabular}{|c|c|c|}
\hline Amostras & $\mathbf{S}$ & $\mathbf{R}_{\mathbf{w p}}$ \\
\hline $100 \mathrm{~A}$ & 1,95 & 8,44 \\
\hline $100 \mathrm{~A}\left(\mathrm{H}_{3} \mathrm{PO}_{4}\right)$ & 1,95 & 12 \\
\hline $100 \mathrm{~A}(\mathrm{NaOH})$ & 2,09 & 11,09 \\
\hline $80 \mathrm{~A} 20 \mathrm{TZP}$ & 1,88 & 7,86 \\
\hline $80 \mathrm{~A}_{20 \mathrm{TZP}}\left(\mathrm{H}_{3} \mathrm{PO}_{4}\right)$ & 2,04 & 11,80 \\
\hline $80 \mathrm{~A} 20 \mathrm{TZP}(\mathrm{NaOH})$ & 1,95 & 9,0 \\
\hline 20A80TZP & 2,18 & 9,91 \\
\hline $20 \mathrm{~A} 80 \mathrm{TZP}\left(\mathrm{H}_{3} \mathrm{PO}_{4}\right)$ & 1,61 & 9,20 \\
\hline $20 \mathrm{~A} 80 \mathrm{TZP}(\mathrm{NaOH})$ & 1,88 & 11,9 \\
\hline 100TZP & 2,05 & 9,26 \\
\hline $100 \mathrm{TZP}\left(\mathrm{H}_{3} \mathrm{PO}_{4}\right)$ & 1,93 & 10,70 \\
\hline $100 \mathrm{TZP}(\mathrm{NaOH})$ & 1,81 & 9,25 \\
\hline
\end{tabular}


Pela análise da Tabela 6, verifica-se que houve um aumento da fase alumina na superfície do compósito, atingindo valores de 23 e 24\% para a amostra 20A80TZP tratada quimicamente com base e com ácido respectivamente. Este fato também foi verificado por Uchida (2002) em amostras de $10 \% \mathrm{Ce}-\mathrm{TZP} / \mathrm{Al}_{2} \mathrm{O}_{3}$, tratadas com as mesmas soluções de $\mathrm{H}_{3} \mathrm{PO}_{4}$ e $\mathrm{NaOH}$. Foi mostrado que o substrato libera grande quantidade de $\mathrm{Zr}$ e $\mathrm{Al}$ quando tratados com $5 \mathrm{M} \mathrm{H}_{3} \mathrm{PO}_{4}$ e pequena quantidade de $\mathrm{Zr}$ e $\mathrm{Al}$ em soluções ćom 15M NaOH. A razão atômica $\mathrm{Zr} / \mathrm{Al}$ se manteve praticamente a mesma para ambos tratamentos, mas menor do que a razão atômica para as amostras não tratadas quimicamente. Isto significa que a quantidade de alumina liberada é menor do que a de zircônia, em ambos os casos.

De acordo com os resultados de DRX apresentados na Tabela 6, foi observado maior transformação de fase tetrảgonal para monoclínica da zircônia para os materiais contendo alumina que sofreram tratamentos com $\mathrm{NaOH}$.

De acordo com as Figuras 22 e 23 , as pastilhas sinterizadas que foram submetidas ao tratamento químico com hidróxido de sódio $(\mathrm{NaOH})$, foram as menos atacadas, formando cristais de sódio na forma de agulhas em sua superfície. Estes fatos sugerem que a integridade da alumina contribui para a transformação da fase tetragonal da zircônia.

De acordo com Chevalier (2004), a transformação da fase tetragonal para a fase monoclínica resulta na formação de microtrincas. Uma vez iniciada a microtrinca, a degradação ocorre de um grão para outro. Se um grão se transforma e não há contato com outro grão de zircônia, o envelhecimento não terá continuidade.

A transformação da fase tetragonal para a fase monoclínica ocasiona em um aumento de $4 \%$ no volume do material a temperatura ambiente, resultando em tensões de compressão. Devido os grãos de alumina ter um alto módulo de elasticidade comparado com os grãos de zircônia, poderão ser formadas microtrincas nos grãos da zircônia vizinhos aos grãos da alumina. Esse efeito contribuirá para a transformação de fase.

Quanto mais baixa a quantidade de grãos de zircônia, mais baixa será a taxa de envelhecimento.

As amostras tratadas com $5 \mathrm{M} \mathrm{H}_{3} \mathrm{PO}_{4}$, têm uma menor transformação de fase do que as amostras tratadas com $15 \mathrm{M} \mathrm{NaOH}$ (Tabela 6). Tratamentos químicos com $\mathrm{H}_{3} \mathrm{PO}_{4}$ apresentam grandes depressões em suas superfícies, quando comparado com as amostras que não sofreram nenhum tratamento (Figuras 22 e 23). Esse tipo de 
tratamento químico libera uma maior quantidade de alumina e zircônia da superficie, aliviando as tensões entre os grãos e reduzindo a propagação das microtrincas.

A amostra 100TZP, apresentou grande quantidade de fase cúbica antes dos tratamentos químicos, aumentando a fase tetragonal e a fase monoclínica após os tratamentos (Tabelas 4 e 6 ).

Guo e He (2003), observaram na zircônia dopada com $8 \mathrm{~mol} \%$ de itria após a exposição em 2,6 x $10^{-2} \mathrm{~atm}, 250^{\circ} \mathrm{C}$ em vapor de água durante 2 anos, a presença de uma pequena quantidade de fase monoclínica. A explicação dada pelos autores, é que durante o envelhecimento, a fase cúbica da zircônia se transforma para a fase tetragonal da zircônia e finalmente para a fase monoclínica da zircônia devido à falta de vacâncias de oxigênio causadas pelos grupos $\mathrm{OH}^{*}$. Nesse trabalho, a quantidade de dopante é muito menor do que a utilizada pelo Guo e He, reduzindo a estabilidade da fase cúbica, além do tratamento químico garantir uma maior concentração de grupos $\mathrm{OH}^{-}$na superficie.

Esse fato sugere que ocorre a seguinte transformação: cúbica $>$ tetragonal $>$ monoclínica.

A literatura relata que irregularidades na superfície de materiais podem favorecer mecanismos de adsorção física. A exposição de espécies polares, decorrentes de grupos fosfatos, associados ao ataque ácido e grupos hidroxila ou oxigênio reativo, associado ao ataque alcalino, pode promover uma adsorção mais efetiva de caráter químico sobre a superfície dos materiais. A presença de defeitos, definidos em termos de heterogeneidade química, pela introdução de outros elementos (impurezas) ou porosidade na superfície, como a observada nas amostras, pode atuar como sítios iniciantes para nucleação e posterior crescimento de cristais. Características superficiais desta natureza são extremamente interessantes na garantia de uma adesão mais efetiva quando se idealiza um recobrimento superficial (DOROZHKIN, 2002; UCHIDA et.al., 2002). 

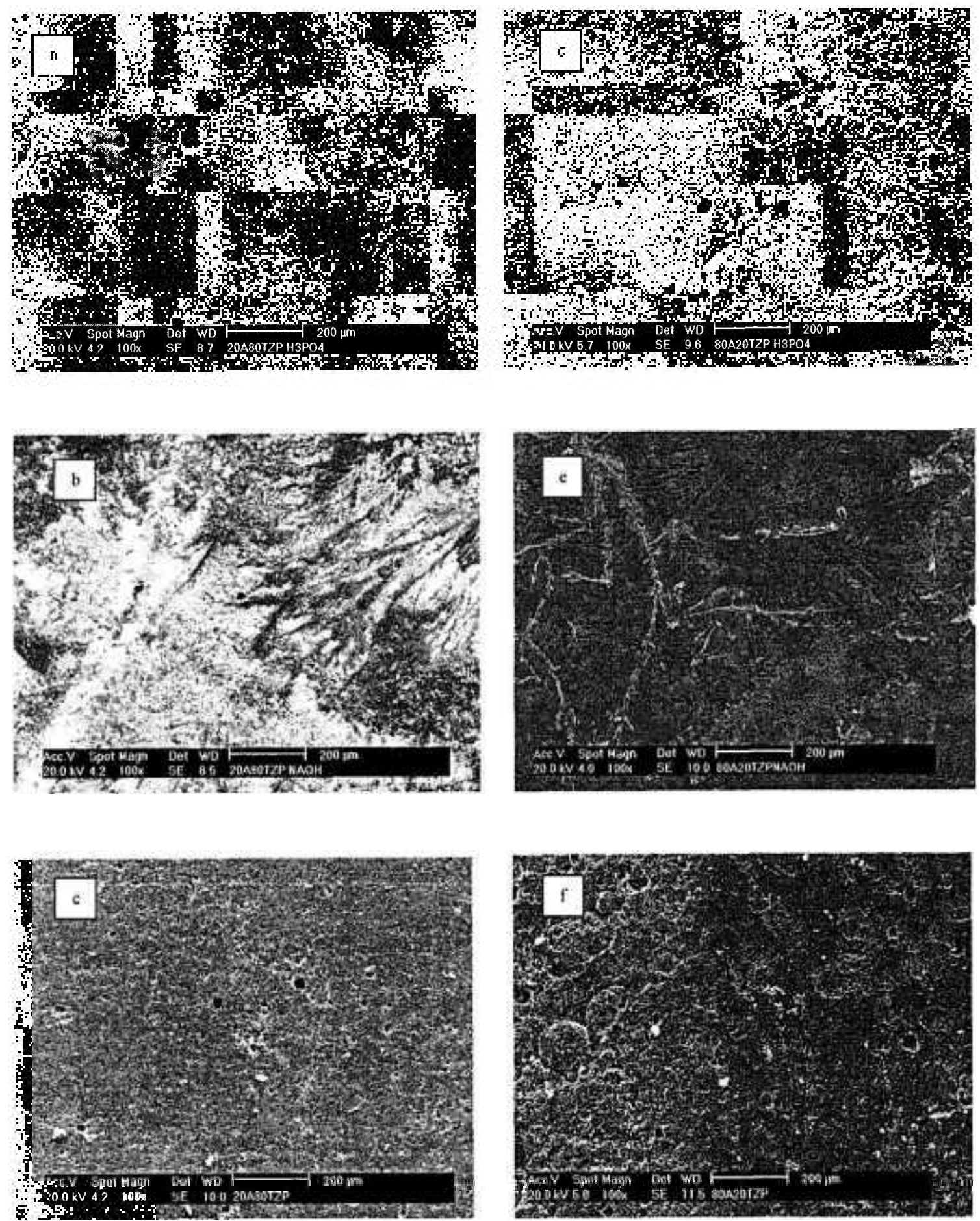

Figura 22: Micrografias obtidas por microscopia eletrônica de varredura das amostras sem tratamento e das amostras após tratamento químico superficial. a)20A80TZP $\left(\mathrm{H}_{3} \mathrm{PO}_{4}\right) ; \quad$ b)20A80TZP(NaOH); c)20A80TZP; d) $80 \mathrm{~A} 20 \mathrm{TZP}\left(\mathrm{H}_{3} \mathrm{PO}_{4}\right)$; $\quad$ e) $80 \mathrm{~A} 20 \mathrm{TZP}(\mathrm{NaOH})$ e f) $80 \mathrm{~A} 20 \mathrm{TZP}$ 

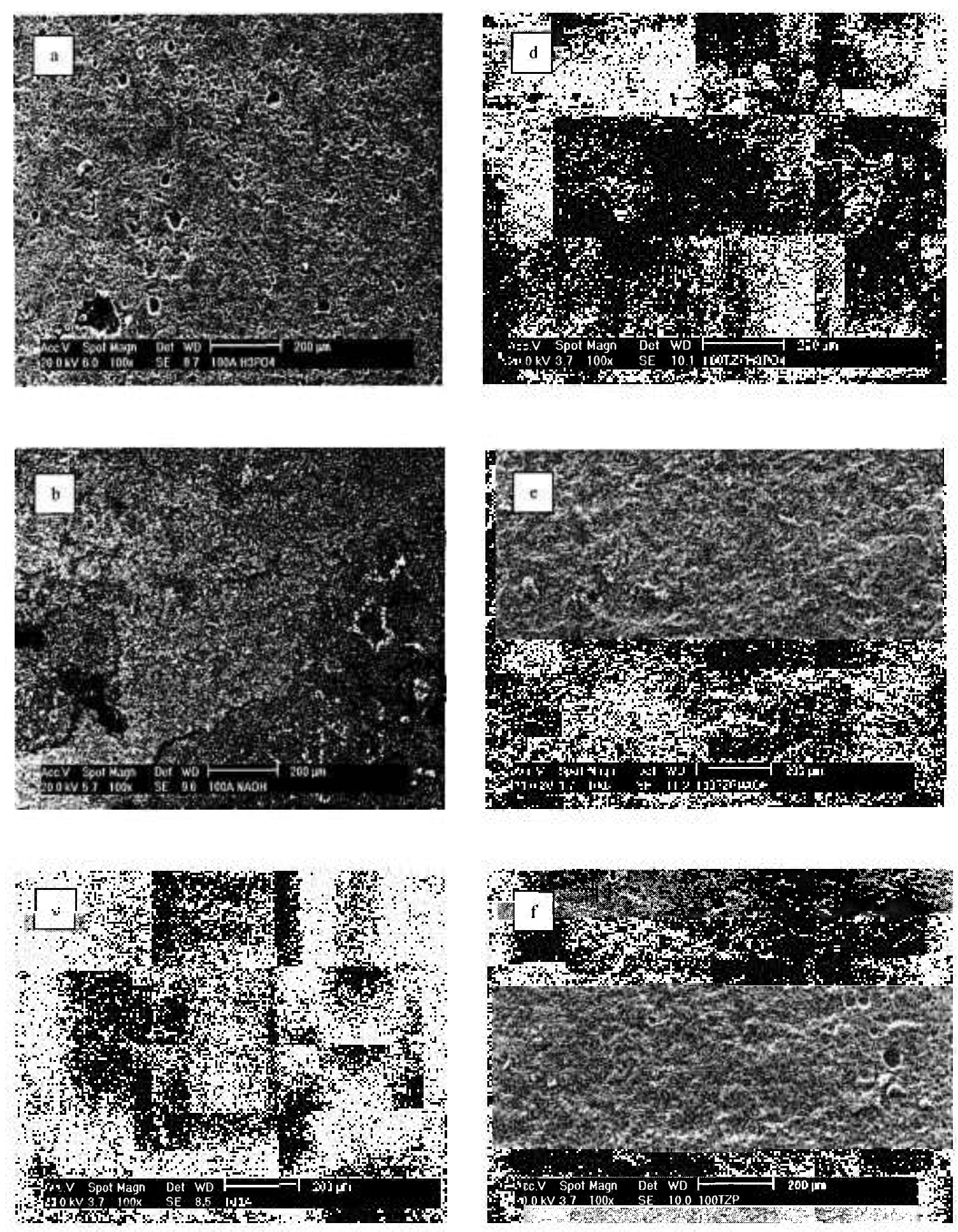

Figura 23: Micrografias obtidas por microscopia eletrônica de varredura das amostras sem tratamento e das amostras após tratamento químico superficial. a) $100 \mathrm{~A}\left(\mathrm{H}_{3} \mathrm{PO}_{4}\right) ;$ b) $100 \mathrm{~A}(\mathrm{NaOH}) ; c) 100 \mathrm{~A}$; d) $100 \mathrm{TZP}\left(\mathrm{H}_{3} \mathrm{PO}_{4}\right)$;e) $100 \mathrm{TZP}(\mathrm{NaOH})$ e f) $100 \mathrm{TZP}$ 


\section{VI.4. TESTES DE IMERSĀO EM SBF}

Não foram realizados ensaios com as amostras tratadas quimicamente com $\mathrm{NaOH}$, devido a mesma apresentar alta quantidade de zircônia monoclínica como visto por meio do método de Rietveld na Tabela 6, ocasionando a degradação da zircônia, ou seja, promovendo a formação de trincas e diminuindo a tenacidade, não sendo apropriado para uso estrutural, além da formação de compostos de $\mathrm{Na}$ nas superfícies das amostras.

Na Figura 24 são apresentadas as micrografias das amostras sem tratamento químico e com tratamento de $\mathrm{H}_{3} \mathrm{PO}_{4}$ da amostra 80A20TZP que foi imersa por 21 dias em SBF.
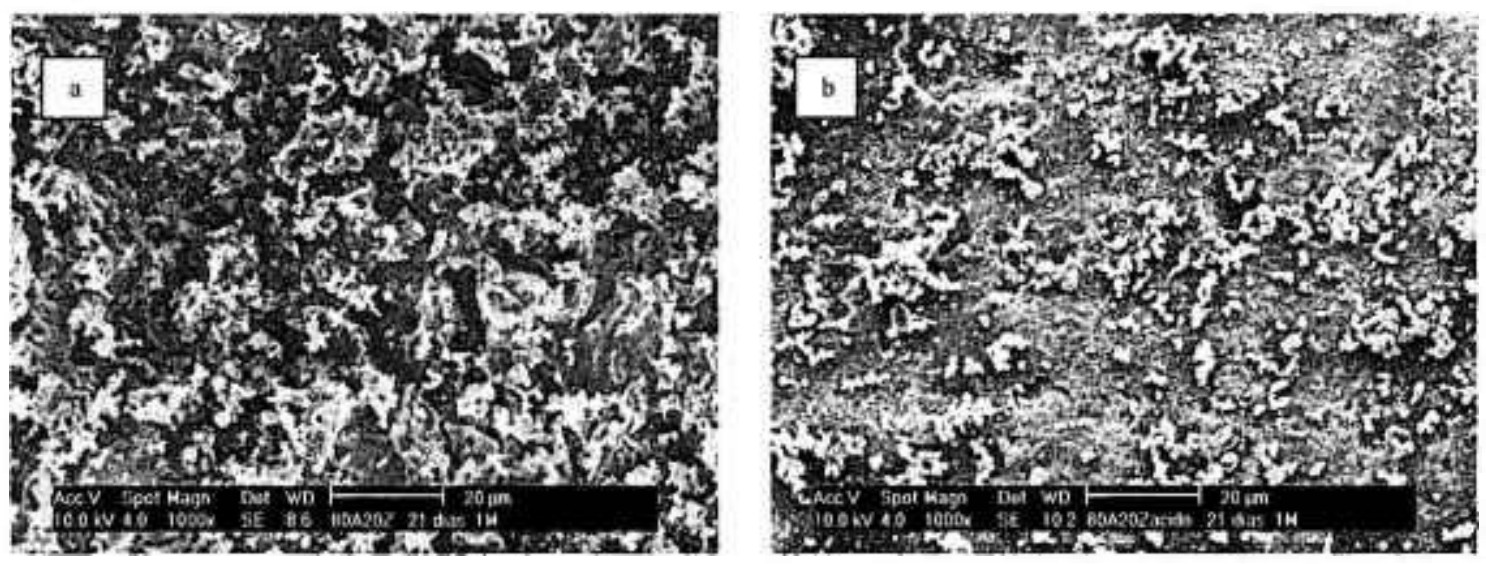

Figura 24: Micrografias obtidas por microscopia eletrônica de varredura da amostra sem tratamento e da amostra após tratamento químico superficial após a imersão em SBF por 21 dias. a) $80 \mathrm{~A} 20 \mathrm{TZP}$; b) $80 \mathrm{~A} 20 \mathrm{TZP}\left(\mathrm{H}_{3} \mathrm{PO}_{4}\right)$

Nota-se que, mesmo após 21 dias de imersão em SBF, houve uma pequena formação de partículas de apatita na superfície do material. Com a imersão dos substratos em uma solução 1,5 vez mais concentrada que a solução de SBF original, os núcleos das apatitas crescem espontaneamente pelo consumo dos íons cálcio e fosfato da solução, formando uma camada uniforme de apatita.

Abaixo são apresentados os resultados das amostras sem tratamento químico e com tratamento de $\mathrm{H}_{3} \mathrm{PO}_{4}$ que foram imersas em $1,5 \mathrm{SBF}$.

Os ensaios em 1,5SBF foram realizados no periodo de 3 dias, 6 dias, 15 dias e 21 dias com troca da solução de 3 em 3 dias.

De acordo com as micrografias obtidas por varredura das amostras imersas em $1,5 \mathrm{SBF}$ por 3 dias mostrada na Figura 25 , nota-se que para a amostra 20A80TZP sem tratamento químico (Fig 25a), há a formação de partículas e aglomerados de apatita com 
tamanhos estimados na faixa de 1 a $2 \mu \mathrm{m}$ e 4 a $5 \mu \mathrm{m}$ respectivamente, distribuídos de forma dispersa. Já para a amostra 20A80TZP com tratamento de $\mathrm{H}_{3} \mathrm{PO}_{4}$ (Fig 25b), notase também uma distribuição dispersa de apatita com aglomerados de tamanhos estimados entre 6 e $8 \mu \mathrm{m}$.

Para a amostra 80A20TZP sem tratamento químico (Fig 25c), percebe-se a dispersão de aglomerados de apatita com tamanhos estimados na faixa de 4 a $5 \mu \mathrm{m}$. A amostra 80A20TZP com tratamento químico (Fig 25d), apresenta uma distribuição mais homogênea de partículas de apatita com tamanhos estimados de 1,0 a 2,0 $\mu \mathrm{m}$.

Para a amostra 100A sem tratamento químico (Fig 25e), há a presença de grandes aglomerados de apatita com tamanhos estimados de 10 a $12 \mu \mathrm{m}$ distribuídos homogeneamente sobre toda a superfície em contraste com a amostra 100A tratada quimicamente (Fig 25f), onde há uma distribuição menos uniforme de aglomerados de apatita com tamanhos estimados entre 16 e $20 \mu \mathrm{m}$.

A amostra 100TZP sem tratamento químico (Fig 25g) apresenta aglomerados de apatita com tamanhos estimados de 10 a $12 \mu \mathrm{m}$ distribuidos de forma homogênea. A amostra 100TZP com tratamento químico (Fig 25h), não apresenta partículas e nem aglomerados de apatita em sua superfície, podendo ser explicado por problemas de manuseio da amostra, como conseqüência, a falta de aderência da apatita na superfície.

A avaliação dessas imagens junto com os dados de espessura equivalente, apresentadas na Tabela 8, mostram que, após 3 dias de imersão em 1,5SBF, foram identificadas em todas as amostras, exceto na amostra 100TZP tratada com ácido (Fig 25h), a formação de aglomerados de apatita, com densidade e tamanhos diferentes para cada amostra, além da espessura em torno de $0,2 \mu m$, não sendo percebido um crescimento preferencial para as amostras tratadas com ácido em relação às não tratadas.

A Figura 26 mostra as micrografias obtidas por varredura das amostras sem tratamento químico e com tratamento de $\mathrm{H}_{3} \mathrm{PO}_{4}$ que foram imersas em 1,5SBF por 6 dias. 

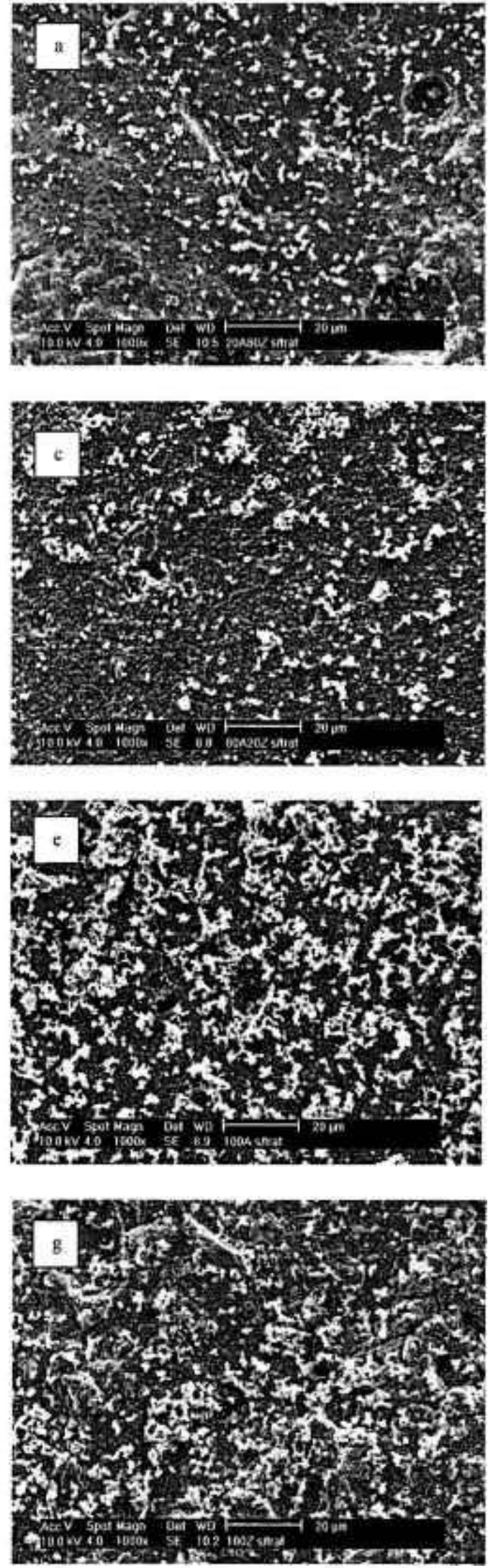
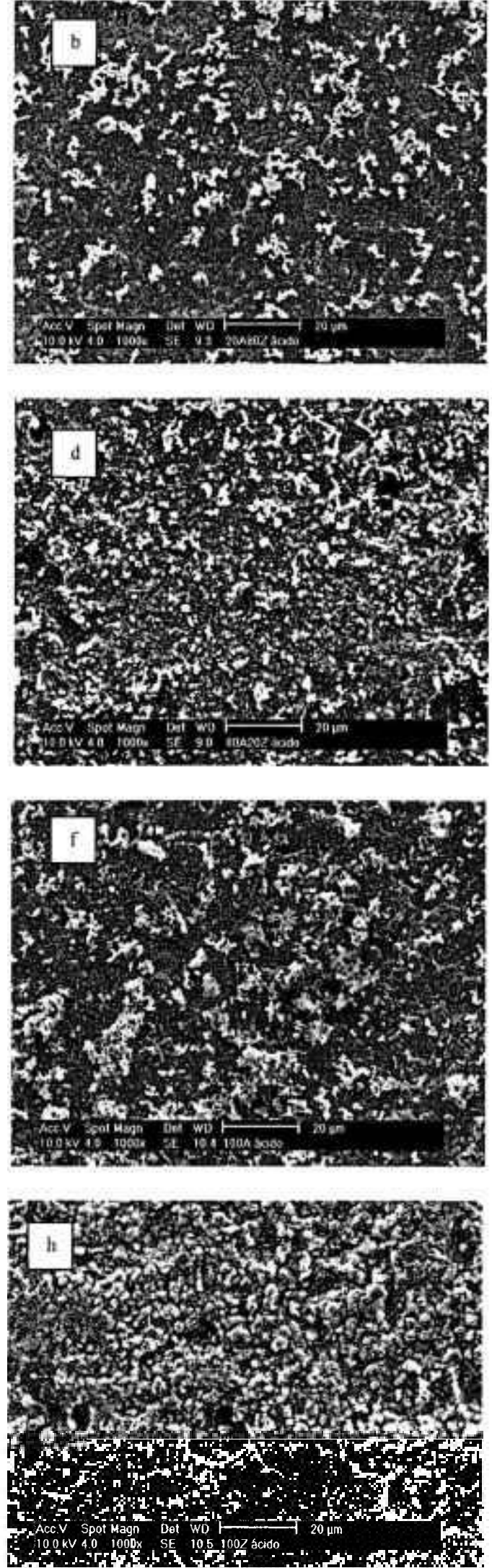

Figura 25: Micrografias obtidas por microscopia eletrônica de varredura das amostras sem tratamento e das amostras com tratamento químico superficial após a imersão em 1,5 SBF por 3 dias. a) $20 \mathrm{~A} 80 \mathrm{Z}$; b) $20 \mathrm{~A} 80 \mathrm{Z}\left(\mathrm{H}_{3} \mathrm{PO}_{4}\right)$; c) $80 \mathrm{~A} 20 \mathrm{Z}$; d) $80 \mathrm{~A} 20 \mathrm{Z}\left(\mathrm{H}_{3} \mathrm{PO}_{4}\right)$; e) $100 \mathrm{~A} ;$ f) $100 \mathrm{~A}\left(\mathrm{H}_{3} \mathrm{PO}_{4}\right) ;$ g) $100 \mathrm{TZP}$; h) $100 \mathrm{TZP}\left(\mathrm{H}_{3} \mathrm{PO}_{4}\right)$ 

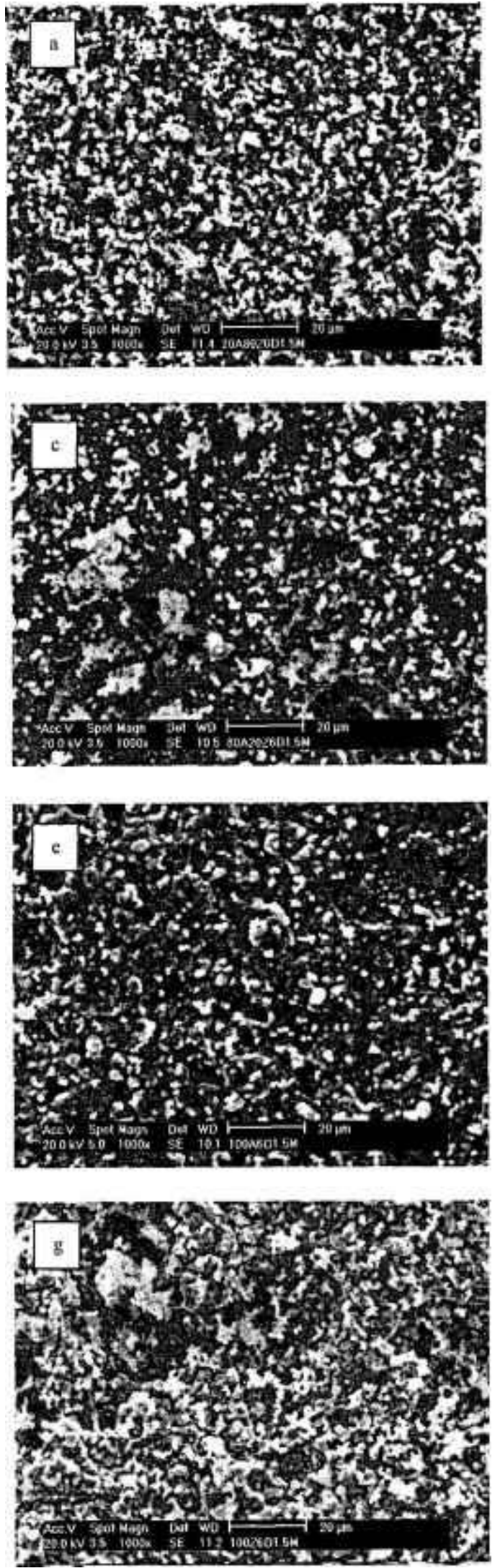
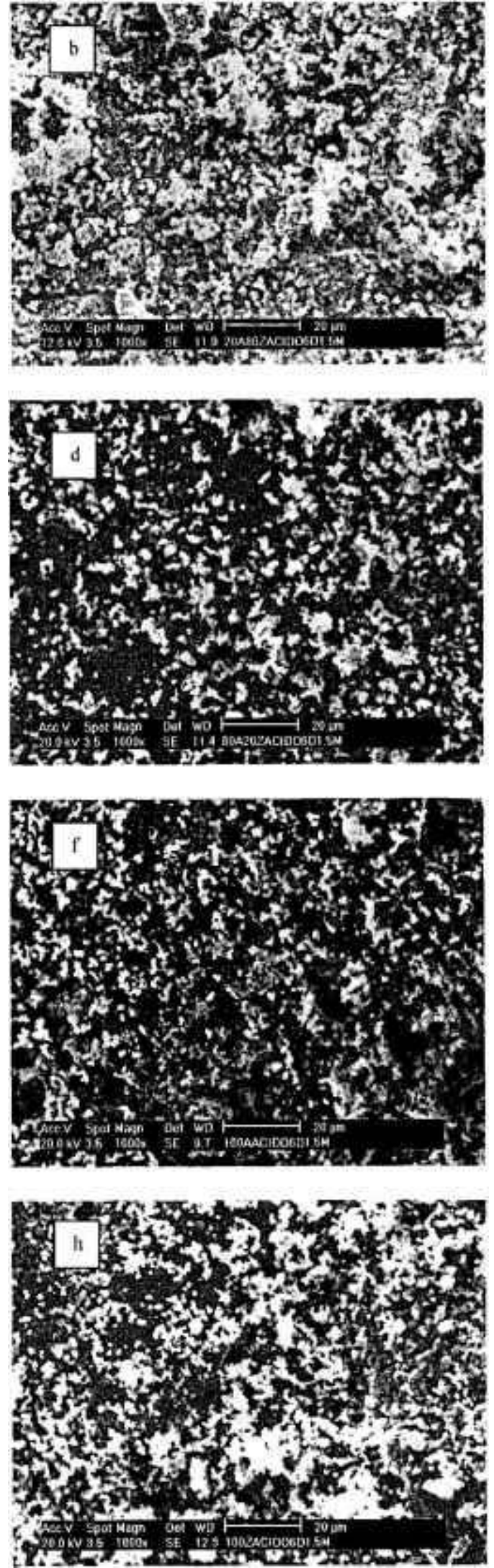

Figura 26: Micrografias obtidas por microscopia eletrônica de varredura das amostras sem tratamento e das amostras com tratamento químico superficial após a imersão em $1,5 \mathrm{SBF}$ por 6 dias. a) 20A80Z; b) $20 \mathrm{~A} 80 \mathrm{Z}\left(\mathrm{H}_{3} \mathrm{PO}_{4}\right)$; c) $80 \mathrm{~A} 20 \mathrm{TZP}$; d) 80A20TZP $\left(\mathrm{H}_{3} \mathrm{PO}_{4}\right)$; e) $100 \mathrm{~A}$; f) $\left.100 \mathrm{~A}\left(\mathrm{H}_{3} \mathrm{PO}_{4}\right) ; \mathrm{g}\right) 100 \mathrm{TZP}$; h) 100TZP $\left(\mathrm{H}_{3} \mathrm{PO}_{4}\right)$ 
Há a formação de mais aglomerados de apatita nas amostras imersas em SBF por 6 dias do que nas amostras imersas em 3 dias. Os pontos claros são as apatitas formadas e a região mais escura é o substrato.

Observa-se que para a amostra 20A80TZP sem tratamento químico (Fig 26a), há a formação de partículas e aglomerados de apatita com tamanhos estimados na faixa de 1 a $2 \mu \mathrm{m}$ e 6 a $10 \mu \mathrm{m}$ respectivamente, distribuídos de forma dispersa. Já para a amostra 20A80TZP com tratamento de $\mathrm{H}_{3} \mathrm{PO}_{4}$ (Fig 26b), nota-se uma distribuição mais homogênea de apatita com aglomerados de tamanhos estimados entre 16 e $20 \mu \mathrm{m}$.

Para a amostra 80A20TZP sem tratamento químico (Fig 26c), percebe-se a dispersão de partículas e aglomerados de apatita com tamanhos estimados na faixa de 1 a $2 \mu \mathrm{m}$ e 8 a $16 \mu \mathrm{m}$ respectivamente. A amostra 80A20TZP com tratamento químico (Fig 26d), apresenta uma distribuição de partículas e aglomerados de apatita com tamanhos estimados de 1,0 a $2,0 \mu \mathrm{m}$ e 6 a $8 \mu \mathrm{m}$ respectivamente.

Já para a amostra 100A sem tratamento químico (Fig 26e), há a presença de partículas dispersas de apatita com tamanhos estimados entre 2 e $4 \mu \mathrm{m}$ e para a amostra 100A tratada quimicamente (Fig 26f), há uma distribuição mais homogênea de partículas de apatita com tamanho estimado na faixa de $2 \mu \mathrm{m}$ e aglomerados de apatita com tamanhos estimados entre 10 e $12 \mu \mathrm{m}$.

A amostra 100TZP sem tratamento químico (Fig 26g) apresenta partículas de apatita com tamanhos estimados de 0,5 a $2 \mu \mathrm{m}$ dispersamente distribuídas. A amostra 100TZP com tratamento químico (Fig 26h), apresenta partículas de apatita com tamanhos estimados entre 1 e $2 \mu \mathrm{m}$ e aglomerados de apatita com tamanhos estimados na faixa de 6 e $8 \mu \mathrm{m}$ com uma distribuição mais homogênea.

Estes resultados estão de acordo com os resultados apresentados na Tabela 8, cuja espessura equivalente de apatita está em torno de $2 \pm 0,7 \mu \mathrm{m}$. Em relação à deposição de apatita nas amostras imersas por 3 dias, as amostras imersas em SBF por 6 dias, apresentaram um aumento da concentração de apatita depositada.

As amostras atacadas com ácido apresentam partículas e aglomerados de apatita, enquanto que as amostras sem ataque, além de apresentarem espessura equivalente menor de apatita, praticamente quase não apresentam aglomerados.

$\mathrm{Na}$ Figura 27, estão as micrografias das amostras sem tratamento químico e após tratamento com $\mathrm{H}_{3} \mathrm{PO}_{4}$, que foram imersas em 1,5SBF por 15 dias. 

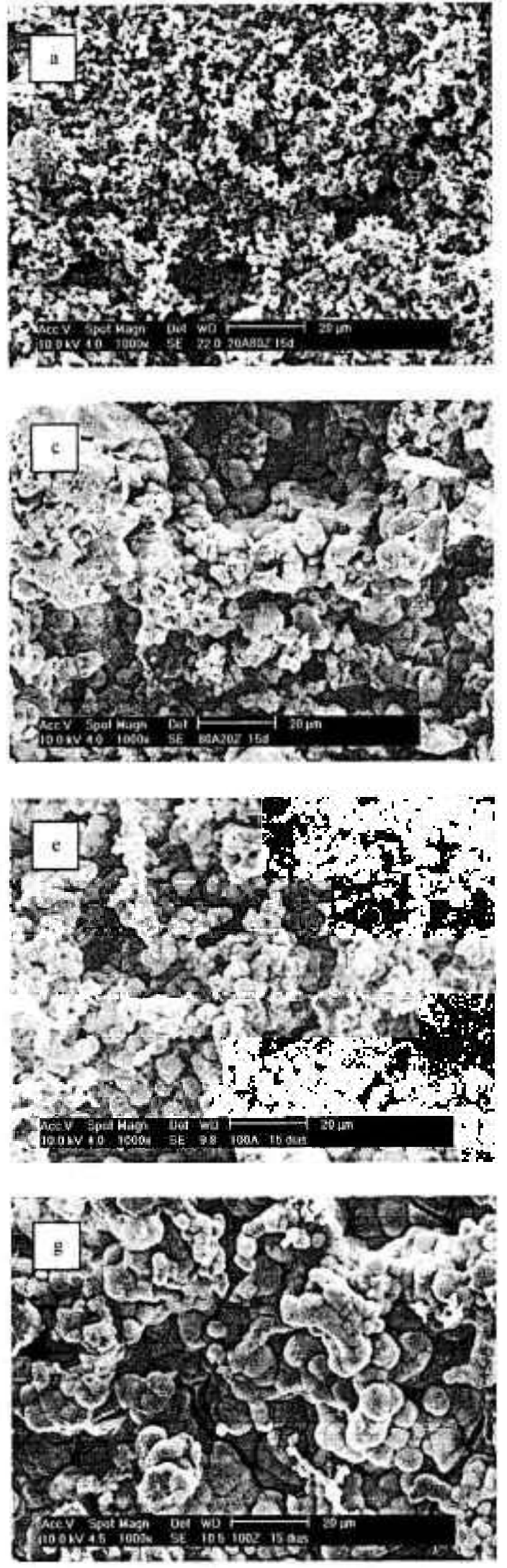
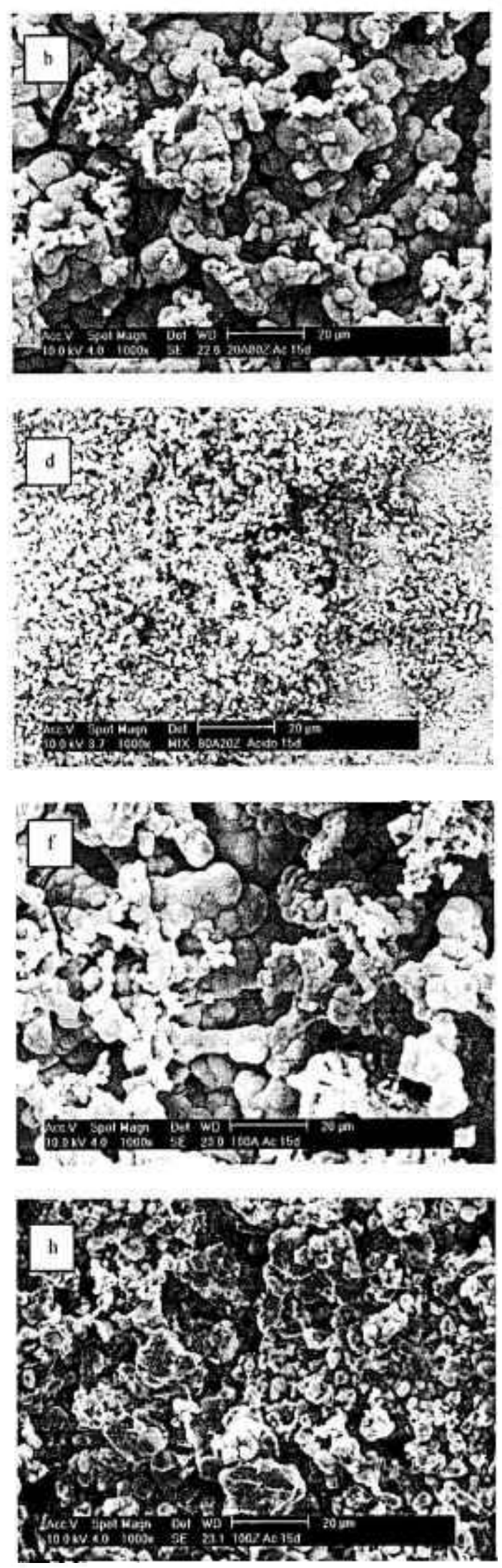

Figura 27: Micrografias obtidas por microscopia eletrônica de varredura das amostras sem tratamento e das amostras com tratamento químico superficial após a imersão em $1,5 \mathrm{SBF}$ por 15 dias. a) 20A80Z; b) $20 \mathrm{~A} 80 \mathrm{Z}\left(\mathrm{H}_{3} \mathrm{PO}_{4}\right)$; c) 80A20TZP; d) 80A20TZP $\left(\mathrm{H}_{3} \mathrm{PO}_{4}\right)$; e) $\left.\left.\left.100 \mathrm{~A} ; \mathrm{f}\right) 100 \mathrm{~A}\left(\mathrm{H}_{3} \mathrm{PO}_{4}\right) ; \mathrm{g}\right) 100 \mathrm{TZP} ; \mathrm{h}\right) 100 \mathrm{TZP}\left(\mathrm{H}_{3} \mathrm{PO}_{4}\right)$ 
Observa-se que tanto nas amostras sem tratamento, quanto nas amostras com tratamento químico após 15 dias de imersão em SBF, houve a formação de uma camada densa e uniforme de apatita, onde não se consegue distinguir o substrato.

Estes resultados estão de acordo com os resultados apresentados na Tabela 8, onde se verifica que a camada de apatita é bastante espessa, tanto para as amostras não tratadas quanto para as amostras tratadas quimicamente. A exceção ocorre para as amostras 20A80TZP sem tratamento (Fig 27a) e 80A20TZP com tratamento (Fig 27d), onde é possível verificar o substrato pelas micrografias e a espessura gira em torno de $6,5 \pm 1,5 \mu \mathrm{m}$, podendo ser explicado pela falha no manuseio das amostras.

A amostra 20A80TZP sem tratamento (Fig 27a) apresenta partículas esféricas e aglomerados com tamanho estimado na faixa de 2 a $3 \mu \mathrm{m}$ e 2 a $6 \mu \mathrm{m}$ respectivamente.

A amostra 20A80TZP com tratamento químico (Fig 27b) apresenta partículas esféricas de apatita com tamanhos estimados em torno de 2 a $6 \mu \mathrm{m}$ e menor quantidade de aglomerados.

Já a amostra 80A20TZP sem tratamento químico (Fig 27c), apresenta partículas esféricas com tamanho estimado na faixa de 6 a $10 \mu \mathrm{m}$, com tratamento químico (Fig 27d), as partículas estão na faixa de 2 a $3 \mu \mathrm{m}$.

A amostra 100A sem tratamento (Fig 27e) apresenta partículas esféricas com tamanho estimado médio de $5 \mu \mathrm{m}$ e a amostra $100 \mathrm{~A}$ com tratamento químico (Fig 27f), apresenta partículas esféricas com tamanho estimado na faixa de 3 a $8 \mu \mathrm{m}$ e em ambas as amostras ocorrem pouco aglomerados.

Para a amostra 100 TZP não tratada quimicamente (Fig 27g), são formadas partículas esféricas regulares superficiais, apresentando tamanho estimado na faixa de 3 a $10 \mu \mathrm{m}$ e poucos aglomerados.

Para a amostra 100 TZP tratada quimicamente (Fig 27h), tem-se uma mistura de partículas arredondadas com tamanho estimado entre 1 e $3 \mu \mathrm{m}$ e partículas maiores não regulares de tamanho estimado entre 8 e $20 \mu \mathrm{m}$.

A Figura 28 apresenta as micrografias das amostras sem tratamento químico e após tratamento com $\mathrm{H}_{3} \mathrm{PO}_{4}$, que foram imersas em 1,5SBF por 21 dias. 

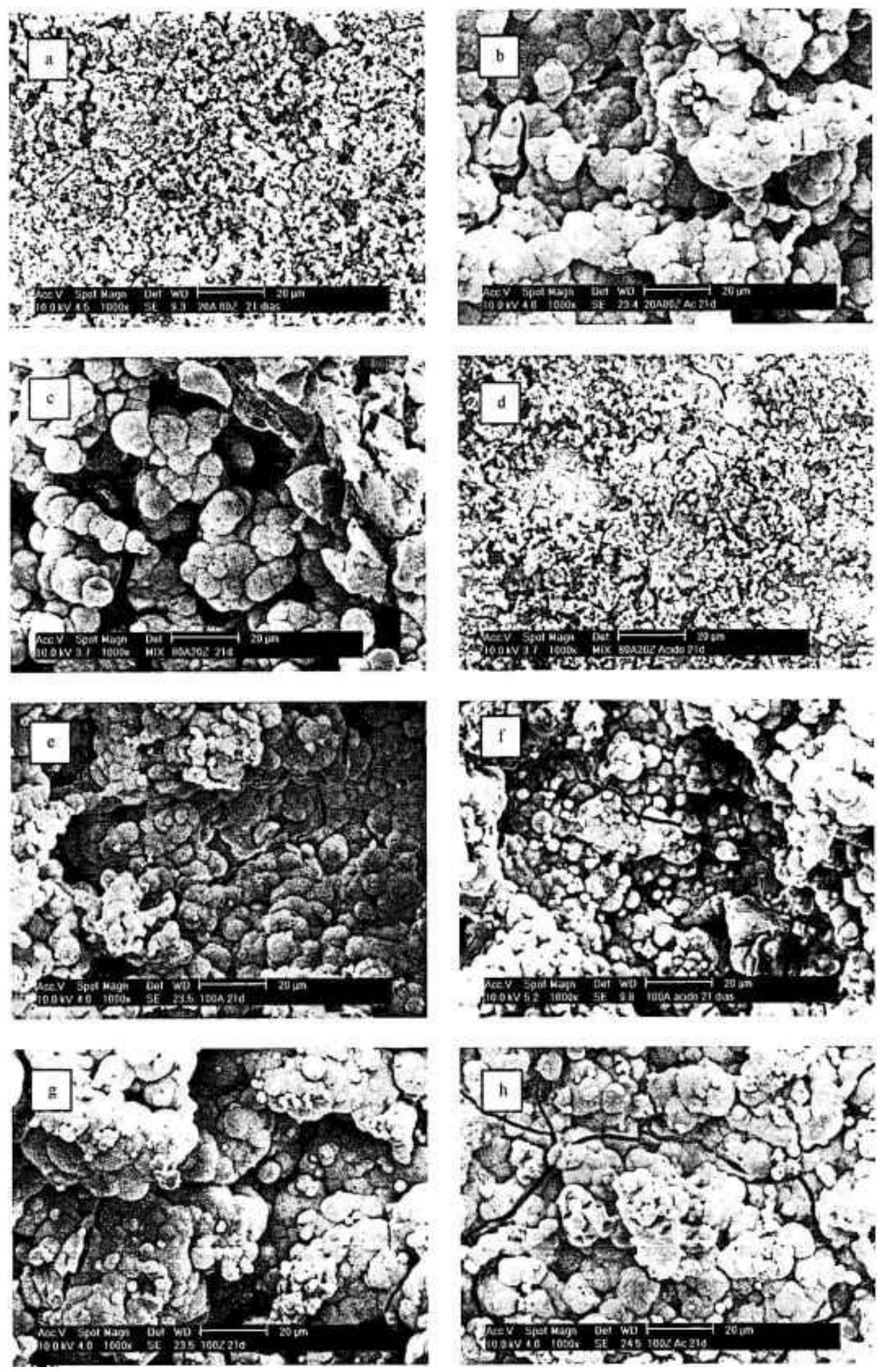

Figura 28: Micrografias obtidas por microscopia eletrônica de varredura das amostras sem tratamento e das amostras com tratamento químico superficial após a imersão em $1,5 \mathrm{SBF}$ por 21 dias. a) $20 \mathrm{~A} 80 \mathrm{Z}$; b) $20 \mathrm{~A} 80 \mathrm{Z}\left(\mathrm{H}_{3} \mathrm{PO}_{4}\right)$; c) $80 \mathrm{~A} 20 \mathrm{TZP}$; d) 80A20TZP $\left(\mathrm{H}_{3} \mathrm{PO}_{4}\right)$; e) $100 \mathrm{~A}$; f) $\left.100 \mathrm{~A}\left(\mathrm{H}_{3} \mathrm{PO}_{4}\right) ; \mathrm{g}\right) 100 \mathrm{TZP}$; $)$ 100TZP $\left(\mathrm{H}_{3} \mathrm{PO}_{4}\right)$ 
A amostra 20A80TZP sem tratamento (Fig 28a) apresenta partículas esféricas com tamanho estimado na faixa de $2 \mu \mathrm{m}$ e com tratamento químico (Fig $28 \mathrm{~b}$ ), apresenta partículas na faixa de 2 a $10 \mu \mathrm{m}$.

Já a amostra 80A20TZP sem tratamento químico (Fig 28c) apresenta partículas esféricas com tamanho estimado na faixa de 6 a $9 \mu \mathrm{m}$ e com tratamento químico (Fig 28d) apresenta partículas com tamanho estimado médio de $2 \mu \mathrm{m}$.

A amostra 100A sem tratamento (Fig 28e) apresenta partículas esféricas com tamanho estimado na faixa de 4 a $10 \mu \mathrm{m}$ e a amostra $100 \mathrm{~A}$ com tratamento químico (Fig 28f) apresenta partículas esféricas com tamanho estimado na faixa de 3 a $10 \mu \mathrm{m}$.

Já para a amostra 100 TZP, tanto para as amostras tratadas quimicamente (Fig 28h) quanto para as amostras não tratadas (Fig 28g), as partículas esféricas formadas em sua superfície apresentam tamanho estimado na faixa de $3 \mathrm{a} 11 \mu \mathrm{m}$.

O mecanismo de formação de apatita é a nucleação de pequenas partículas não esféricas. A micrografia apresentada na Figura 25 (a) relata este fato. Após a nucleação, as partículas começam a se aglomerar, conforme Figuras 25 (b), (c), (d), (e), (f), (g). Após esse estágio,ocorre a saturação e o aglomerado torna-se partículas esféricas que se ligam uma às outras formando aglomerados maiores, até a formação de uma camada que cobre toda a superfície. As Figuras 27 (b), (f), (g) e 28 (b), e ilustram este fato. Após a formação da camada, inicia-se uma nova frente de reação com o processo de nucleação, aglomeração e esferoidização criando uma nova camada de apatita. As figuras 28 (f), (g), (h) e 27 (b) ilustram este fato.

A seguir serão apresentados os difratogramas de raios $\mathrm{X}$ das amostras sem tratamento e com o tratamento de $\mathrm{H}_{3} \mathrm{PO}_{4}$, após a imersão em 1,5 SBF por 3, 6, 15 e 21 dias.

Nota-se que para os difratogramas das Figuras 29 a 36, ou seja, para as amostras sem tratamento e com tratamento químico, imersas em $1,5 \mathrm{SBF}$ por 3 e 6 dias, não foi observada a formação de hidroxiapatita, mantendo a mesma estrutura das amostras anterior à imersão no fluído. Importante ressaltar que a fase monoclínica sempre é mais intensa para amostras tratadas quimicamente, sendo bem representada pelo pico em $2 \theta$ $=28,2^{\circ}$. 


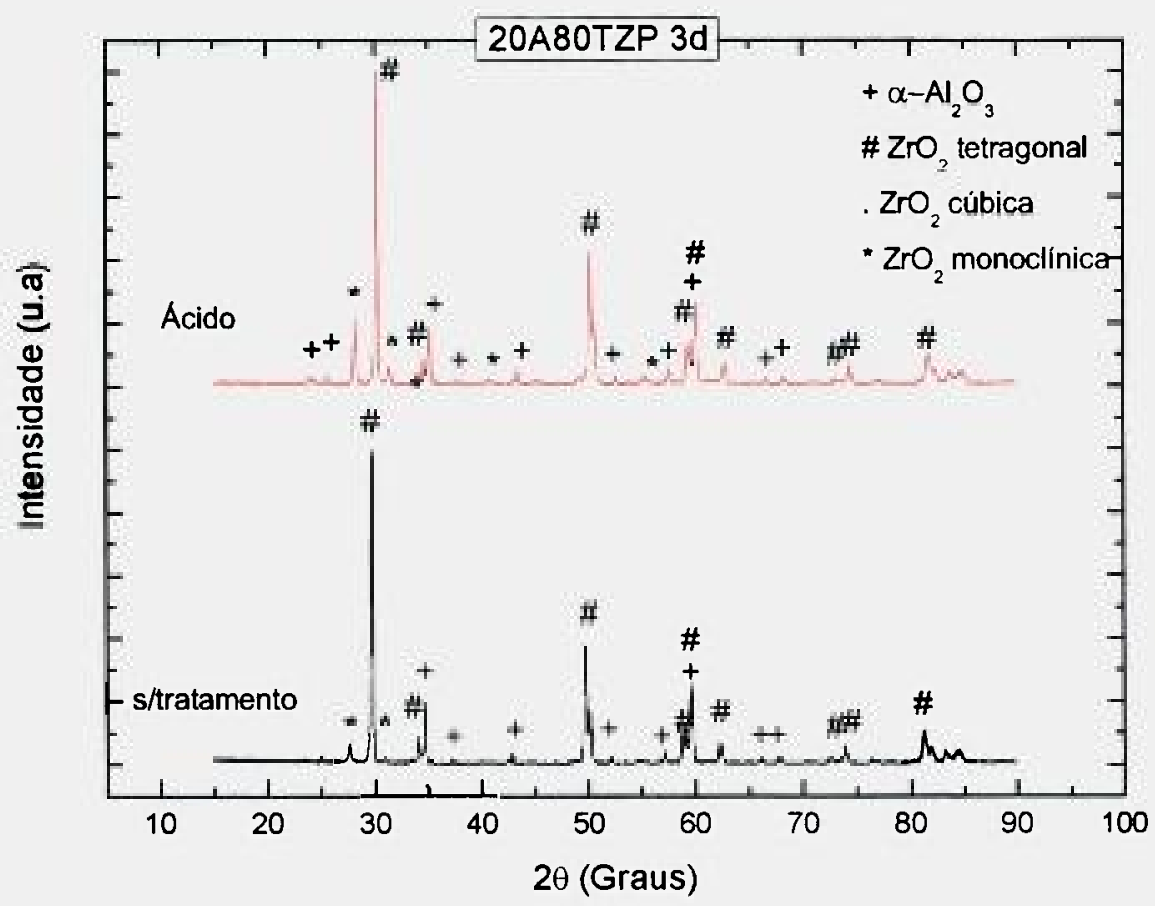

Figura 29: Difratograma da amostra 20A80TZP sem tratamento químico e com tratamento químico de $\mathrm{H}_{3} \mathrm{PO}_{4}$ após a imersão em 1,5SBF por 3 dias.

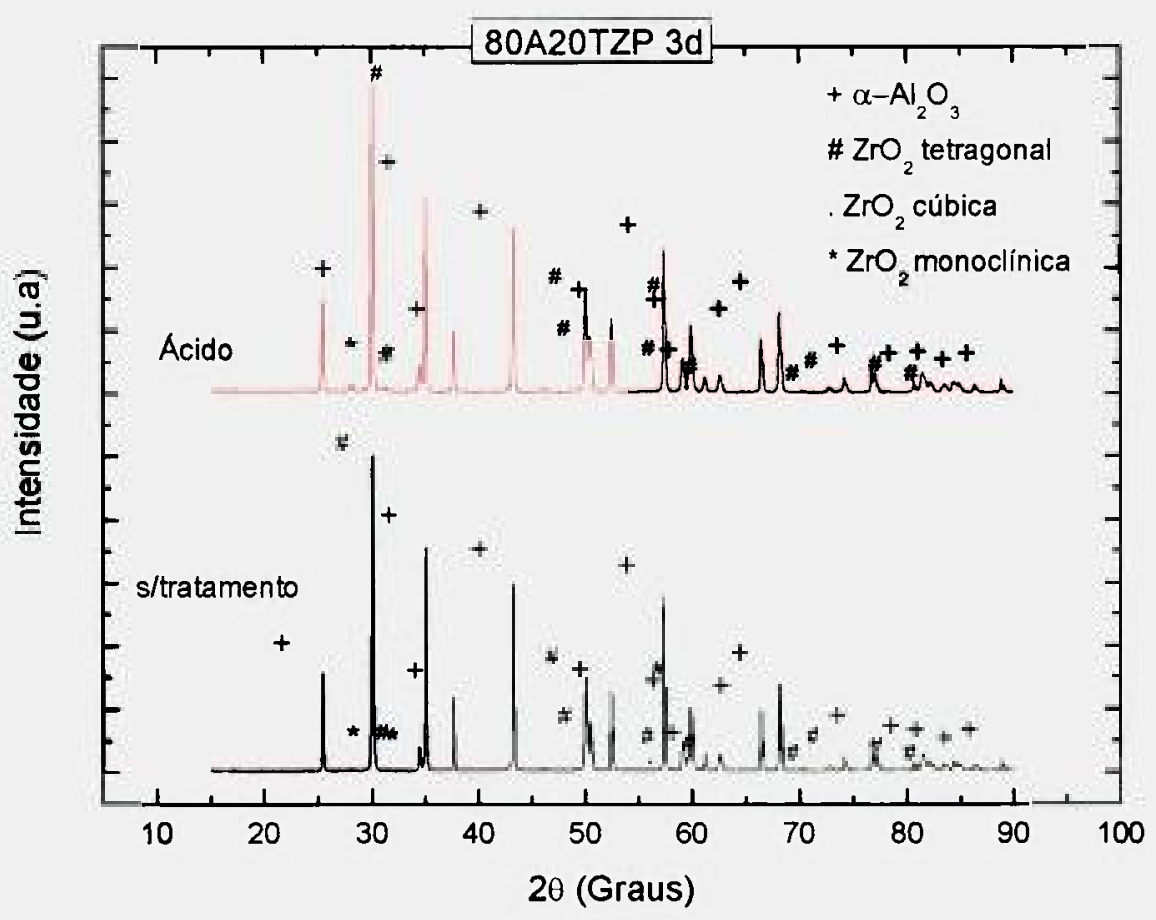

Figura 30: Difratograma da amostra 80A20TZP sem tratamento químico e com tratamento químico de $\mathrm{H}_{3} \mathrm{PO}_{4}$ após a imersão em $1,5 \mathrm{SBF}$ por 3 dias. 


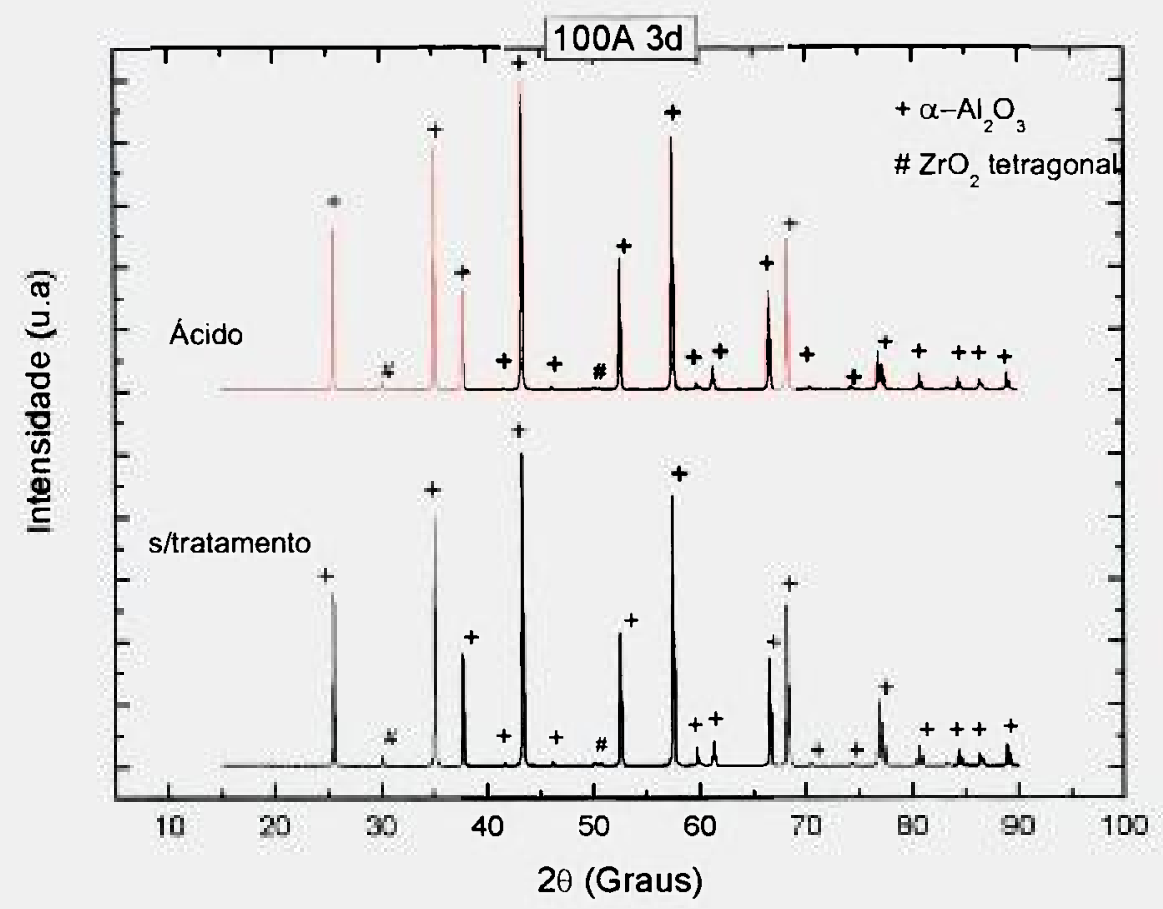

Figura 31: Difratograma da amostra 100A sem tratamento químico e com tratamento quimico de $\mathrm{H}_{3} \mathrm{PO}_{4}$ após a imersão em 1,5SBF por 3 dias.

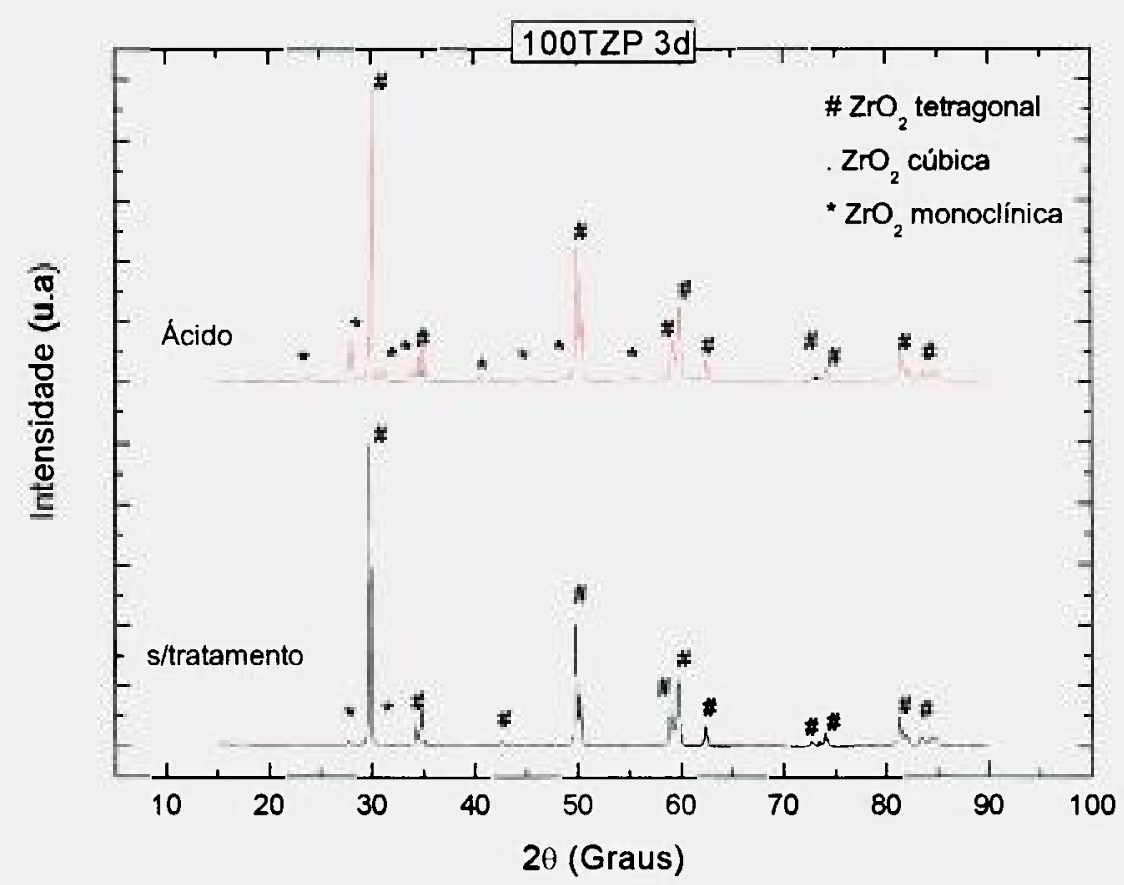

Figura 32: Difratograma da amostra 100TZP sem tratamento químico e com tratamento químico de $\mathrm{H}_{3} \mathrm{PO}_{4}$ após a imersão em 1,5SBF por 3 dias. 


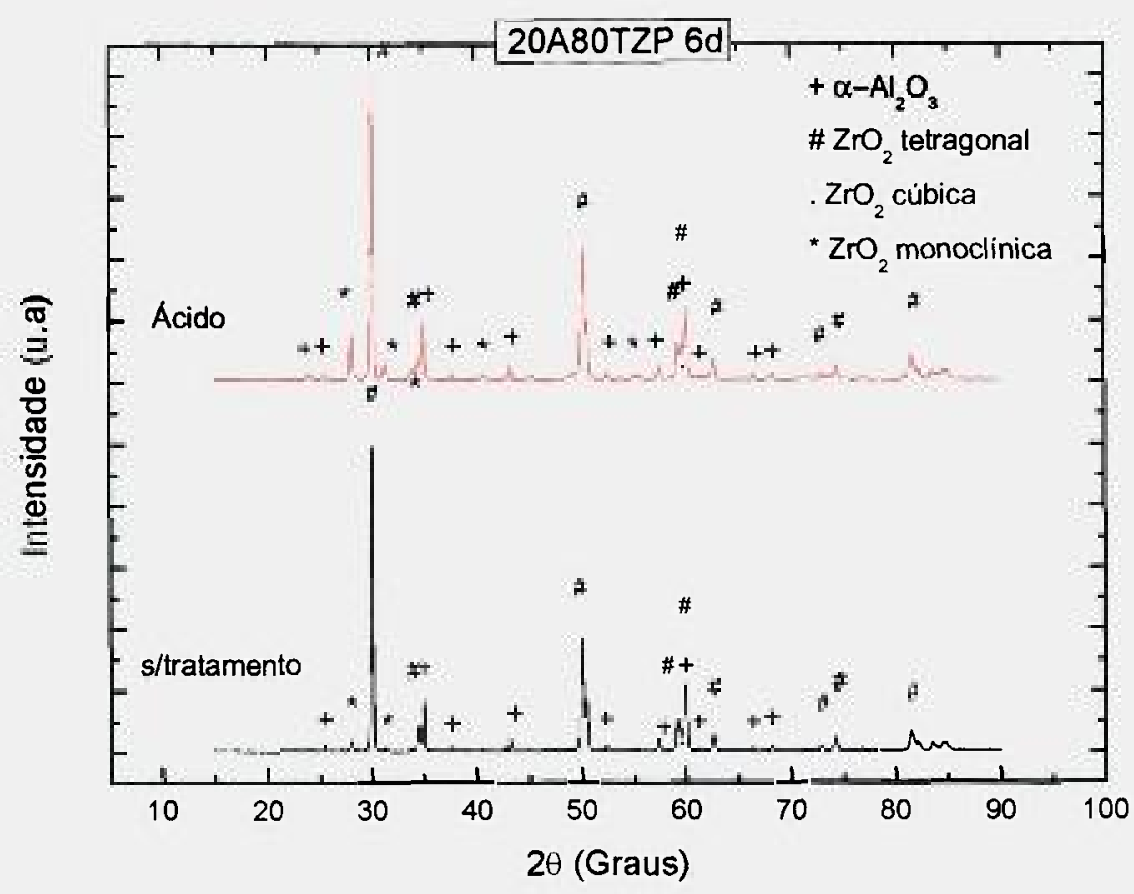

Figura 33: Difratograma da amostra 20A80TZP sem tratamento químico e com tratamento químico de $\mathrm{H}_{3} \mathrm{PO}_{4}$ após a imersão em 1,5SBF por 6 dias.

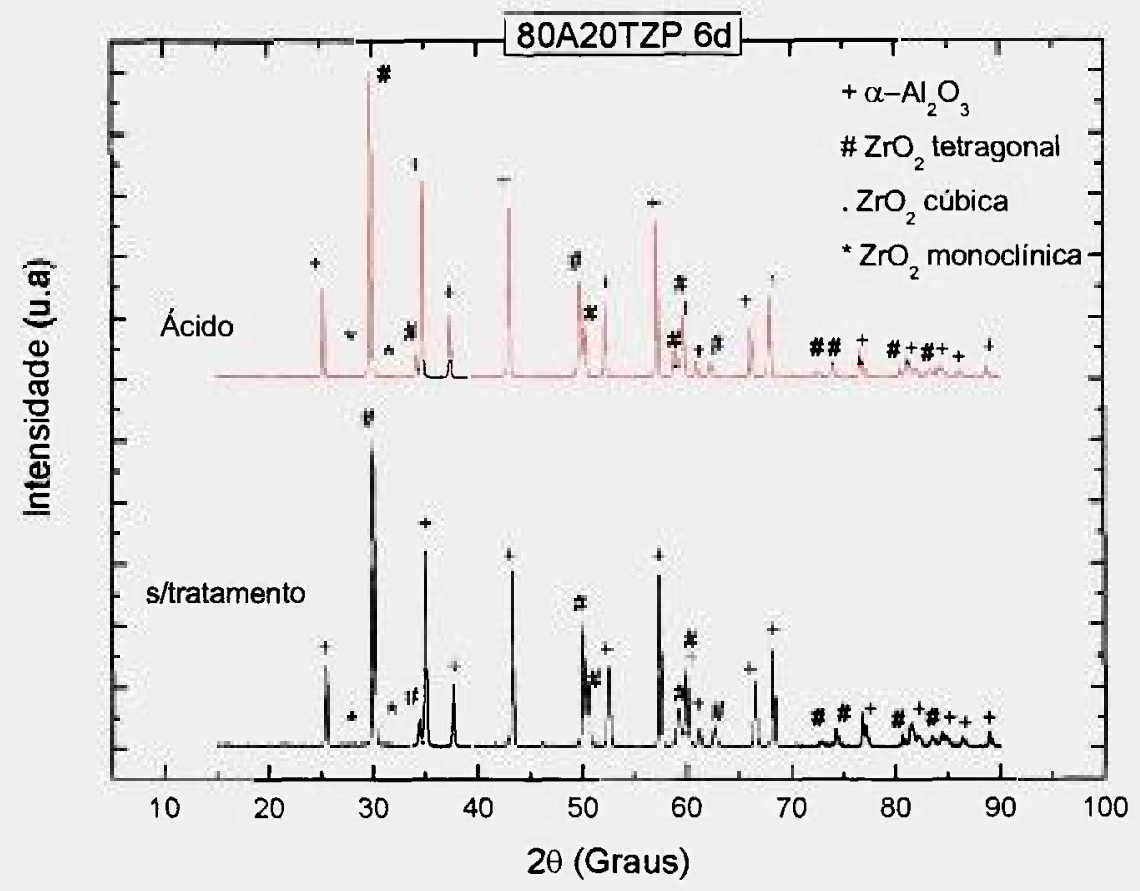

Figura 34: Difratograma da amostra 80A20TZP sem tratamento químico e com tratamento químico de $\mathrm{H}_{3} \mathrm{PO}_{4}$ após a imersão em 1,5SBF por 6 dias. 


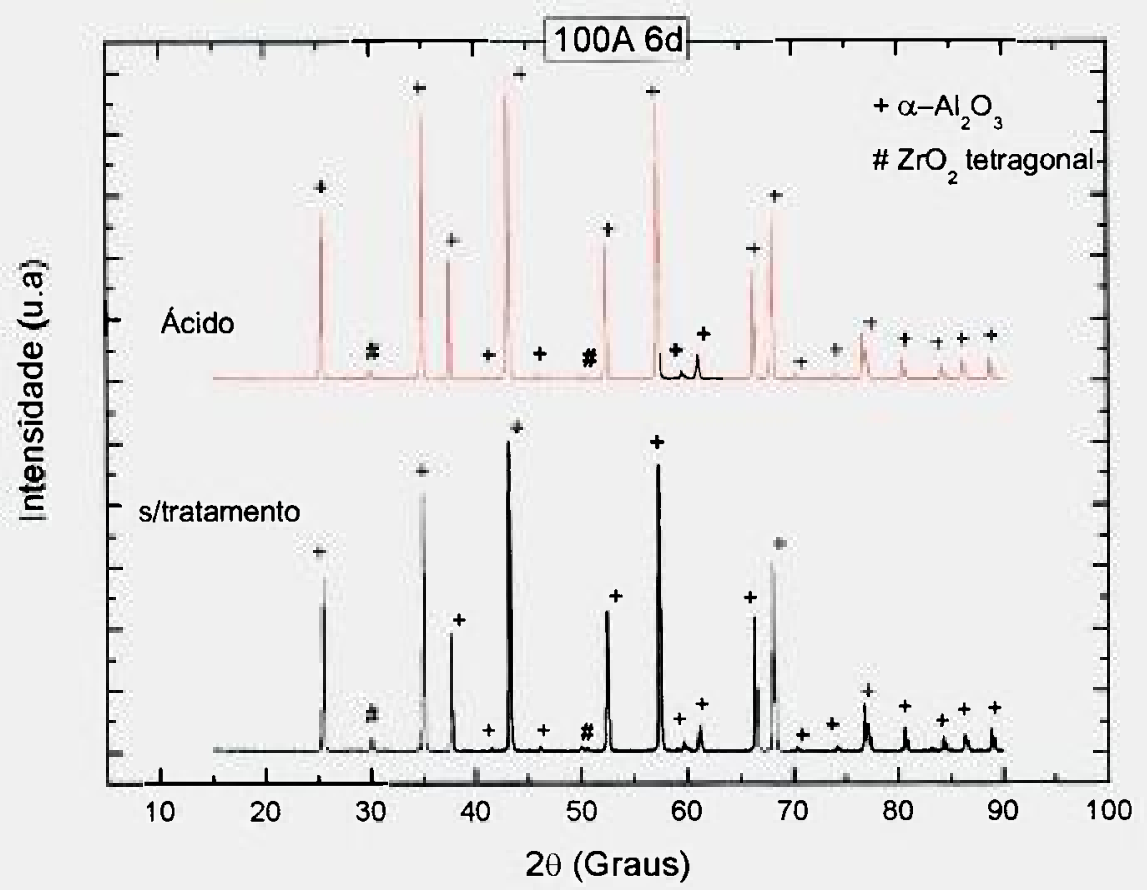

Figura 35: Difratograma da amostra 100A sem tratamento químico e com tratamento químico de $\mathrm{H}_{3} \mathrm{PO}_{4}$ após a imersão em 1,5SBF por 6 dias.

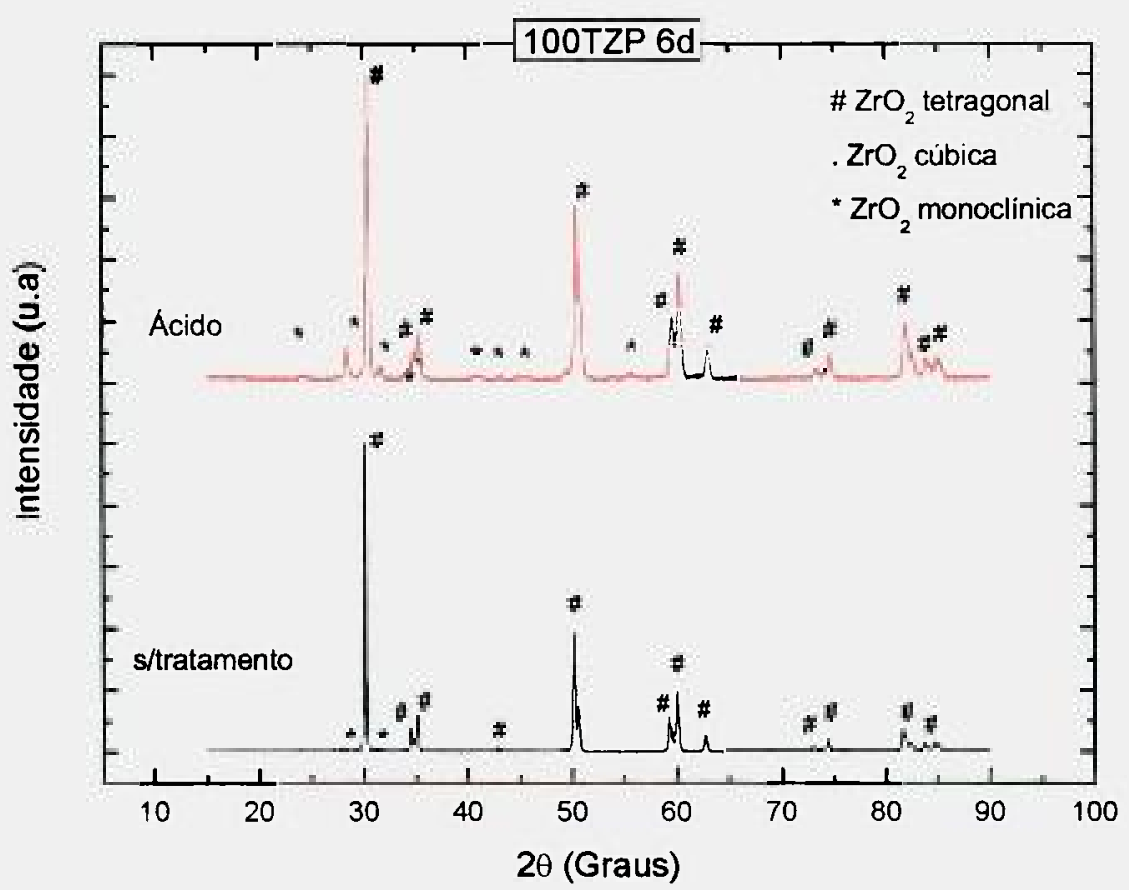

Figura 36: Difratograma da amostra 100TZP sem tratamento químico e com tratamento químico de $\mathrm{H}_{3} \mathrm{PO}_{4}$ após a imersão em $1,5 \mathrm{SBF}$ por 6 dias. 
Notam-se nos difratogramas das Figuras 37 a 44, duas bandas largas salientes localizadas aproximadamente em $26^{\circ}$ e $32^{\circ}$. Essas bandas são características dos picos referentes às fases apatitas, indicando uma estrutura pouco cristalina, bem similar a apatita biológica.

A comparação dos espectros de difração de raios $\mathrm{X}$, no que tange os picos de apatita, comparados com os valores de espessura obtidos por fluorescência de raios $\mathrm{X}$, de acordo com a Tabela 8, está em completo acordo. Podemos concluir que, até a espessura de 7,6 $\mu \mathrm{m}$, a apatita formada se apresenta amorfa, uma vez que, filmes finos cristalinos, nessa faixa de espessura é detectável por DRX.

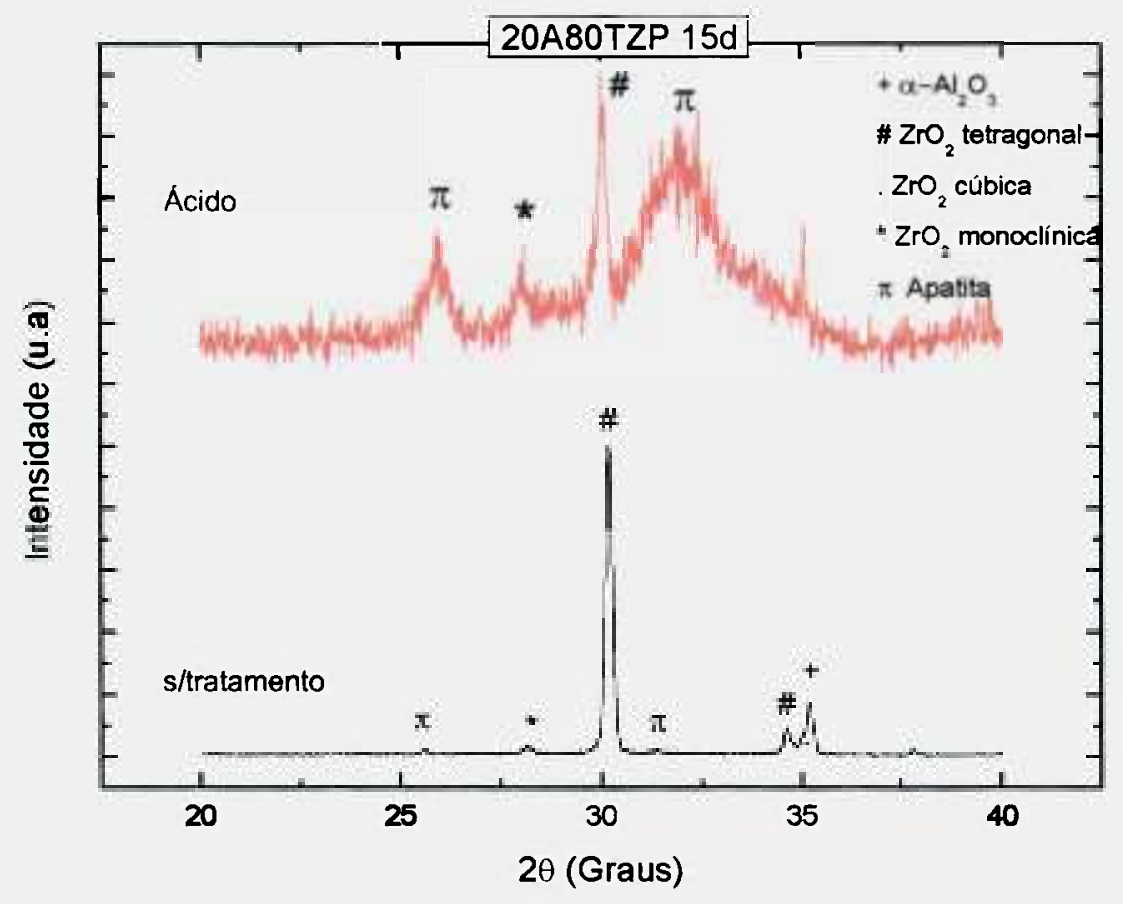

Figura 37: Difratograma da amostra 20A80TZP sem tratamento químico e com tratamento químico de $\mathrm{H}_{3} \mathrm{PO}_{4}$ após a imersão em 1,5SBF por 15 dias. 


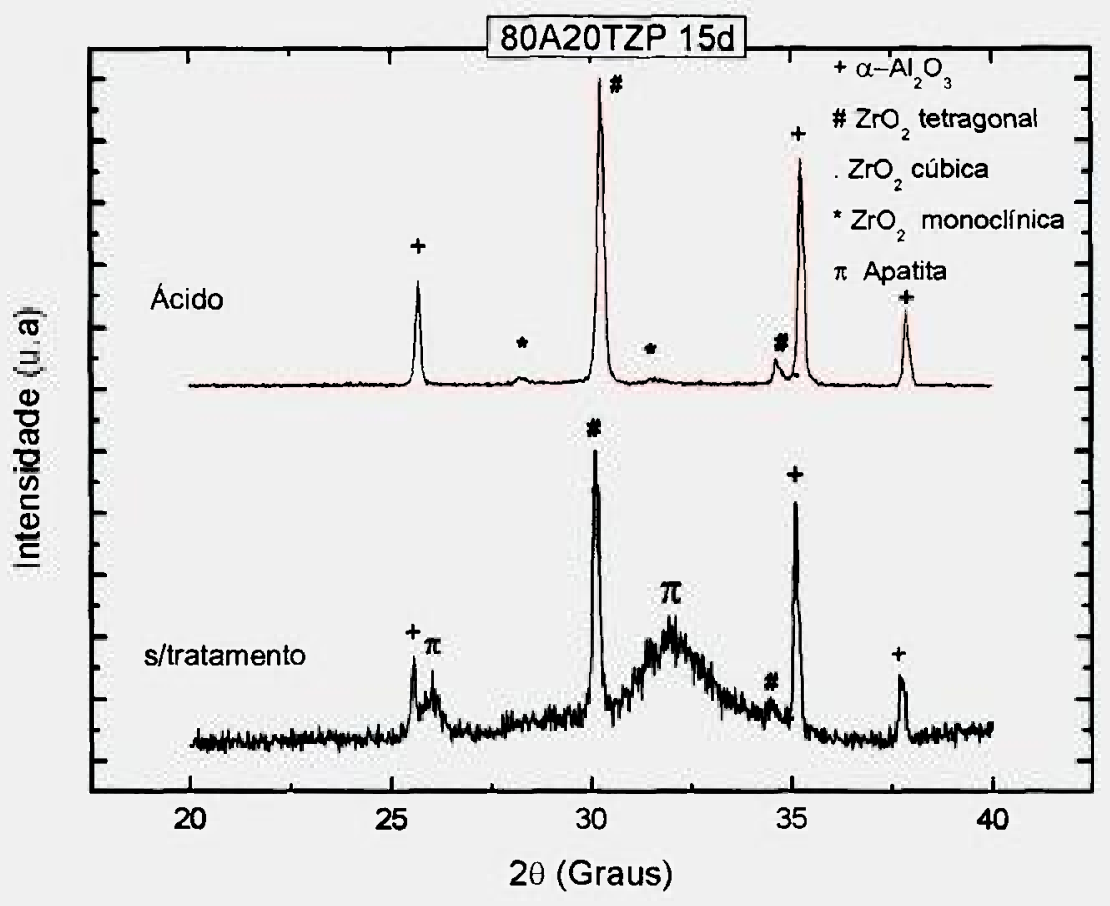

Figura 38: Difratograma da amostra 80A20TZP sem tratamento quimico e com tratamento químico de $\mathrm{H}_{3} \mathrm{PO}_{4}$ após a imersão em $1,5 \mathrm{SBF}$ por 15 dias.

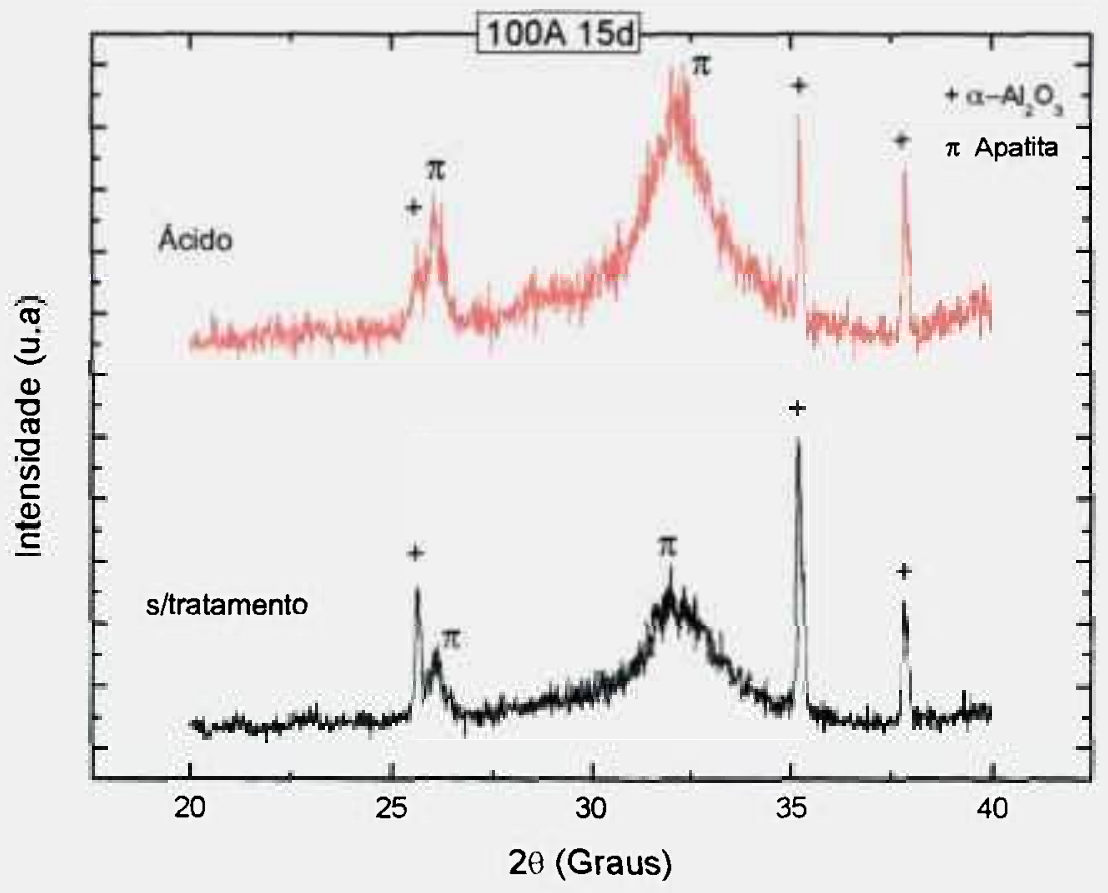

Figura 39: Difratograma da amostra 100A sem tratamento químico e com tratamento químico de $\mathrm{H}_{3} \mathrm{PO}_{4}$ após a imersão em $1,5 \mathrm{SBF}$ por 15 dias. 


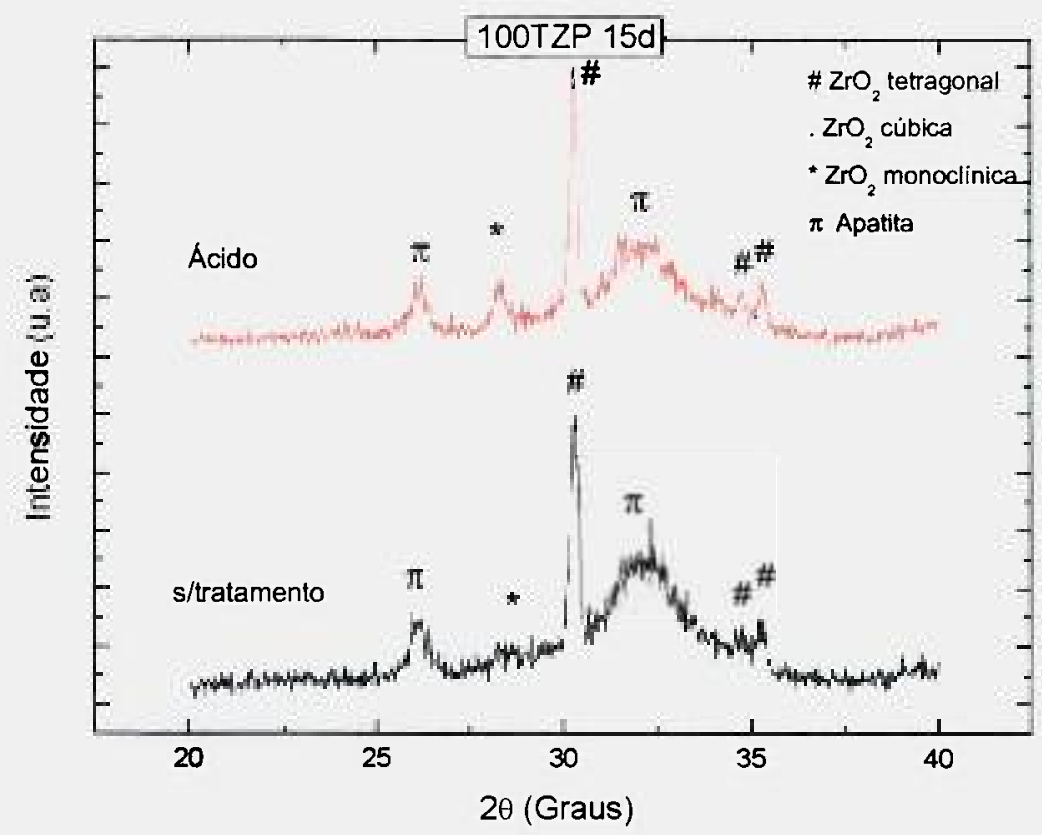

Figura 40: Difratograma da amostra 100TZP sem tratamento químico e com tratamento químico de $\mathrm{H}_{3} \mathrm{PO}_{4}$ após a imersão em 1,5SBF por 15 dias.

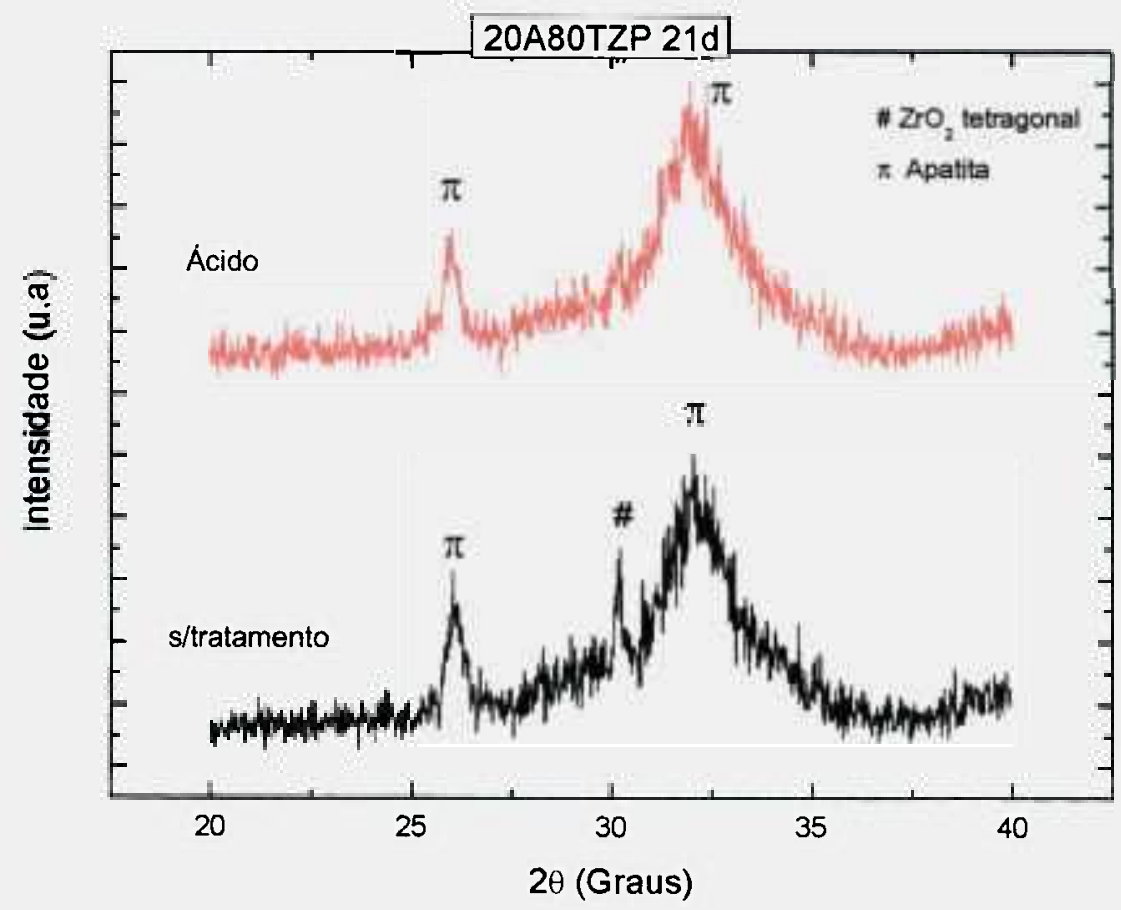

Figura 41: Difratograma da amostra 20A80TZP sem tratamento químico e com tratamento químico de $\mathrm{H}_{3} \mathrm{PO}_{4}$ após a imersão em 1,5SBF por 21 dias. 


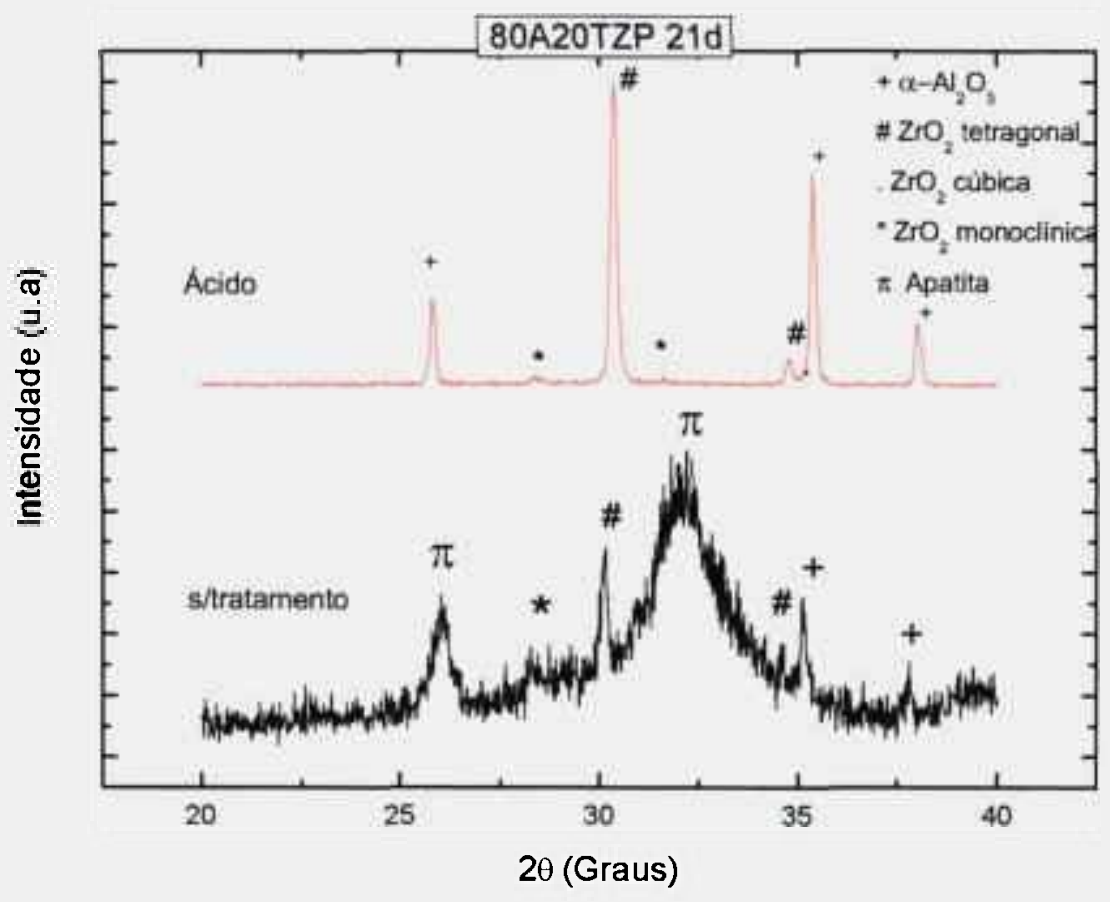

Figura 42: Difratograma da amostra 80A20TZP sem tratamento químico e com tratamento químico de $\mathrm{H}_{3} \mathrm{PO}_{4}$ após a imersão em 1,5SBF por 21 dias.

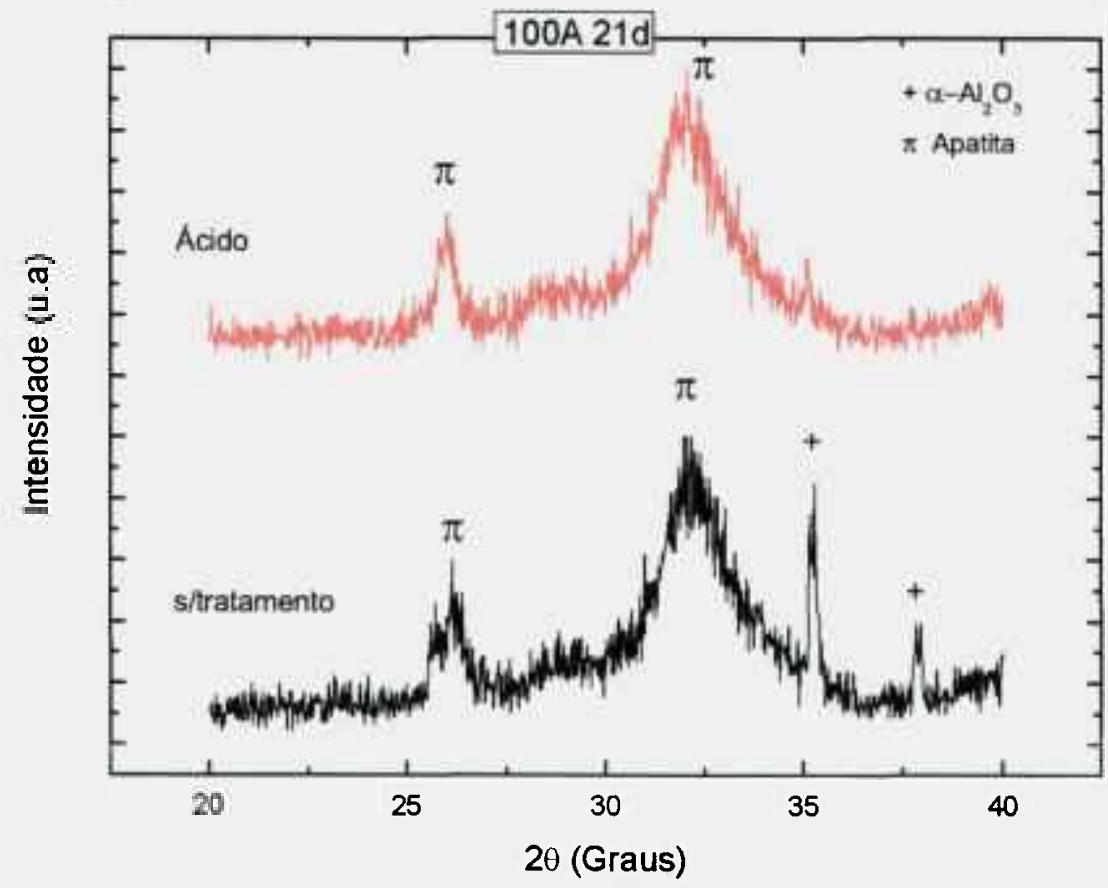

Figura 43: Difratograma da amostra 100A sem tratamento químico e com tratamento químico de $\mathrm{H}_{3} \mathrm{PO}_{4}$ após a imersão em 1,5SBF por 21 dias. 


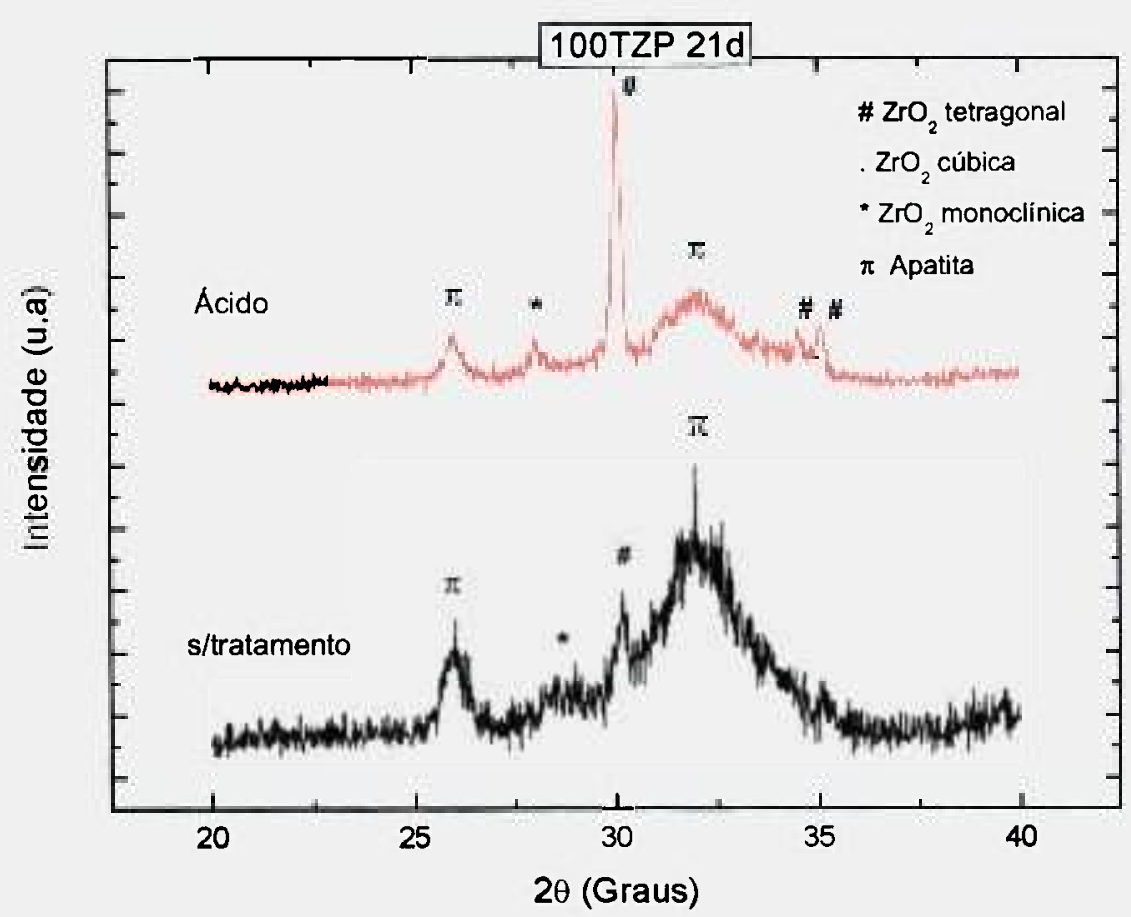

Figura 44: Difratograma da amostra 100TZP sem tratamento químico e com tratamento químico de $\mathrm{H}_{3} \mathrm{PO}_{4}$ após a imersão em $1,5 \mathrm{SBF}$ por 21 dias.

Os dados da Tabela 8 mostram o equivalente em espessura de apatita formada na superficie das amostras após a imersão em 1,5SBF por 3dias, 6 dias, 15 dias e 21 dias.

Tabela 8: Equivalente em espessura da camada de apatita nas amostras sem tratamento químico e com tratamento químico de $\mathrm{H}_{3} \mathrm{PO}_{4}$ após a imersão em 1,5 SBF por 3 dias, 6 dias, 15 dias e 21 dias.

\begin{tabular}{|c|c|c|c|c|}
\hline Amostras & $\begin{array}{c}\text { Equivalente em } \\
\text { espessura }(\mu \mathrm{m}) \\
3 \text { dias 1,5SBF }\end{array}$ & $\begin{array}{c}\text { Equivalente em } \\
\text { espessura }(\mu \mathrm{m}) \\
6 \text { dias } 1,5 \mathrm{SBF}\end{array}$ & $\begin{array}{c}\text { Equivalente em } \\
\text { espessura }(\mu \mathrm{m}) \\
15 \text { dias } 1,5 \mathrm{SBF}\end{array}$ & $\begin{array}{c}\text { Equivalente em } \\
\text { espessura }(\mu \mathrm{m}) \\
21 \text { dias } 1,5 \mathrm{SBF}\end{array}$ \\
\hline $20 \mathrm{~A} 80 \mathrm{TZP}$ & 0,12 & 1,7 & 6,2 & 192,9 \\
\hline $20 \mathrm{~A} 80 \mathrm{TZP}\left(\mathrm{H}_{3} \mathrm{PO}_{4}\right)$ & 0,27 & 2,15 & 179,1 & 189,5 \\
\hline $80 \mathrm{~A}_{2} 0 \mathrm{TZP}$ & 0,18 & 2,0 & 217,2 & 248,2 \\
\hline $80 \mathrm{~A} 20 \mathrm{TZP}\left(\mathrm{H}_{3} \mathrm{PO}_{4}\right)$ & 0,17 & 2,65 & 5,1 & 7,6 \\
\hline $100 \mathrm{~A}$ & 0,20 & 1,3 & 365,3 & 381,5 \\
\hline $100 \mathrm{~A}\left(\mathrm{H}_{3} \mathrm{PO}_{4}\right)$ & 0,25 & 2,76 & 383,4 & 386,7 \\
\hline $100 \mathrm{TZP}^{2}$ & 0,37 & 1,84 & 177,4 & 192,2 \\
\hline \hline $100 \mathrm{TZP}\left(\mathrm{H}_{3} \mathrm{PO}_{4}\right)$ & 0,06 & 2,0 & 171,4 & 150 \\
\hline
\end{tabular}


Nota-se que quanto maior o tempo de imersão em 1,5 SBF, maior é a espessura da camada de apatita. Há uma tendência de uma maior formação de apatita nas amostras de alumina em relação às amostras de zircônia. Além disso, não se verifica uma tendência de maior formação de apatita quando comparadas as amostras tratadas com $\mathrm{H}_{3} \mathrm{PO}_{4}$ e as amostras sem tratamento químico. 


\section{CONCLUSŌES}

Os resultados obtidos no presente trabalho mostraram que a densificação dos compósitos é maior do que as cerâmicas de alumina e as cerâmicas de zircônia estabilizada. O compósito contendo $20 \%$ de alumina em matriz de zircônia exibiu maior tenacidade à fratura quando comparados à cerâmica zircônia estabilizada. A diminuição está relacionada à presença das fases monoclínica e cúbica neste material em grande quantidade. Esses compósitos parecem ser materiais adequados para serem usados em implantes ao invés de óxidos puros atualmente em uso.

Foi observado, pelo método de Rietveld, que para os compósitos tratados quimicamente houve um considerável aumento da fase monoclínica da zircônia, sendo este aumento maior quando tratado com base $(\mathrm{NaOH})$. Este tratamento provoca ataque superficial menos severo do que com ácido, depositando compostos a base de sódio em forma de agulhas.

Compósitos de $\mathrm{ZrO}_{2} / \mathrm{Al}_{2} \mathrm{O}_{3}$ tratados quimicamente com base apresentam menor viabilidade para uso como biomaterial estrutural devido a grande quantidade de formação da fase monoclínica da zircônia.

Quanto maior o tempo de imersão em 1,5 SBF, maior é a espessura da camada de apatita.

Há uma tendência de uma maior formação de apatita nas amostras de alumina em relação às amostras de zircônia.

Não se verifica uma tendência de maior formação de apatita quando comparadas as amostras tratadas com $\mathrm{H}_{3} \mathrm{PO}_{4} \mathrm{e}$ as amostras sem tratamento químico. 


\section{REFERÊNCIAS BIBLIOGRÁFICAS}

ABE, Y.; KOKUBO, T.; YAMAMURO, T. Apatite oating on ceramics, metals and polymers utilizing a biological process. Journal of materials science: Materials in medicine, v.1, p. 233-238, 1990.

BOHNER, M. Calcium orthophosphates in medicine: from ceramics to calcium phosphate cements, Int.J.Care Injured, v.31, 2000.

BRAVO-LEON, A.; MORIKAWA, Y.; KAWAHARA, M.; MAYO, M.I. Fracture toughness of nanocrystalline tetragonal zirconia with low yttria content, Acta Materialia, v.50, p.4555-4562, 2002.

CHEVALIER, J. What future for zirconia as a biomaterial?.Biomaterials, v.27, p. 535$543,2006$.

CHEVALIER, J.; DEVILLE, S.; MUNCH, E.; JULLIAN, R.; LAIR, F. Critical effect of cubic phase on aging in $3 \mathrm{~mol} \%$ yttria-stabilized zirconia ceramics for hip replacement prosthesis. Biomaterials, v.25, p. 5539-5545, 2004.

CINI, L. Bioceramics: The objects achieved and future prospects, Ceramic informazione, v.102, p.159-163, 1975.

CORTES, D.A.; ORTEGA, S.; ESCOBEDO, J.C.; ALMANZA, J.M. Bioactive $\mathrm{ZrO}_{2} /$ $\mathrm{CaSiO}_{3}$ composites, In: IV Congresso Latino Americano de Órgãos Artificiais e Biomateriais, 2006, Caxambu.

CRISS, J.W.; BIRKS, L.S. Calculation methods for fluorescent X-ray spectrometry. Anal. Chem., v.40, p.1080-1086, 1968.

CULLITY, B.D.; STOCK, S.R. Elements of X-Ray diffraction. 3ed. Upeer Saddle River, NJ, Prentice Hall, 2001. p.402-433.

DE GROOT, K. Clinical usefulness of calcium phosphate ceramics. Zahnarztl Mitteil, 75, p. 1938-40, 1985.

DOROZHKIN, S.V. A Review on the dissolution models of calcium apatites. Progress in Crystal Growth and Characterization of Material. p.45-61, 2002.

ELLIOT, J.C. Structure and Chemistry of the apatites and other calcium orthophosphates, Elsevier Science B.V., 1994.

FUJIBAYASHI, S.; NEO, M.; KIM, H.M.; KOKUBO, T.; NAKAMURA, T. A comparative study between "in vivo" bone growth and in vitro apatite formation on $\mathrm{Na} 2 \mathrm{O}-\mathrm{CaO}-\mathrm{SiO} 2$ glasses, Biomaterials, v.24, p.1349-1356, 2003.

GARCIA, R. H. L. ; LAZAR, D. R. R. ; USSUI, V. ; LIMA, N. B. ; BRESSIANI, A. H A. Síntese por co-precipitação e caracterização microestrutural do compósito cerâmico $3 \mathrm{YTZP}-\mathrm{Al}_{2} \mathrm{O}_{3}$. In: 50 Congresso Brasileiro de Cerâmica, 2006, Blumenau. Anais do 50 Congresso Brasileiro de Cerâmica, 2006. 
GARCIA, R. H. L. ; USSUI, V. ; LIMA, N. B. ; LAZAR, D. R. R. 3Y-TZP-AL $\mathrm{O}_{3}$ powders synthesized by the coprecipitation route. In: Fifth International Latin-American Conference on Powder Technology- PTECH 2005, Costa do Sauipe. Proceedings of the Fifth International Latin-American Conference on Powder Technology, 2005.

GIL, F.J.; PADRÓS, A.; MANERO,J.M.; APARÍCIO,C.; NILSSON,M.; PLANELL,J. A. Growth of bioactive surfaces on titanium and its alloys for orthopedic and dental implants, Mater. Sci. Eng, v.22, p. 53-60, 2002.

GROSS, K.A.; BERNDT,C.C.; GOLDSCHLAG,D.D.; IACONO,V. In vitro changes of hydroxyapatite coatings, Quintessence, v.12, p.589-597,1997.

GUO, X.; HE, J. Hydrothermal degradation of cubic zirconia, Acta materialia, v.51, p.5123-5130, 2003.

HANNINK, R.H.J. Transformation toughening in zirconia containing ceramics, $\boldsymbol{J}$. $\mathbf{A m}$. Ceram. Soc, v.83, n.3, p.461-487, 2000.

HENCH, L.L. Bioceramics: from concept to clinic. J. Am. Ceram. Soc., v.74 n.7, p.1487-1510, 1991.

HENCH, L.L. WILSON, J. Introduction to bioceramics; World Scientific Publishing Co., $1^{\circ}$ ed, 1993.

HENCH, L. L. Bioceramics. J. Am. Ceram. Soc., v.81 n.7, p.1705-28, 1998.

HILL, J.R.; MADSEN, C.I.; Data Collection Strategies for Constant Wavelength Rietveld Analysis, Powder Diffraction.2, p.146-163,1987.

HOFFMAN, B.D.R.A.; SCHOEN,F.J.; LEMONS,J.E.; Biomaterials Science: An Introduction to Materials in Medicine; Academic Press, USA, 1996.

ISHIKAWA, K.; DUCHEYNE, P.; RADIN, S. Determination of the $\mathrm{Ca} / \mathrm{P}$ ratio in calcium- deficient hydroxyapatite using x ray diffraction analysis, J. Mater. Sci. Mater.

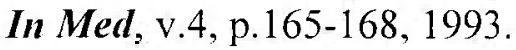

JONÁSOVÁ, L.; MULLER, F.; HELEBRANT, A. et.al.,Biomimetic apatite formation on chemically treated titanium. Biomaterials, v. 25, p. 1187-1194, 2004.

KALISZEWSKI, M.S.; HEUER, A.H. Alcohol interation with zirconia powders. $\boldsymbol{J} . \boldsymbol{A m}$. Ceram. Soc., v.73, n.6, p.1504-1509, 1990.

KATAOKA, Y. Standard less X-ray fluorescence spectrometry-fundamental parameter method using sensitivity library. The Rigaku Journal, v. 6, p. 33-39, 1989.

KEVOR.; TENHUISEN.; BROWN, P.W. Formation of caulcium-deficient hydroxyapatite from $\alpha$-tricalcium phosphate. Biomaterials, 19, p. 2209-17, 1998. 
KIM, H.M.; MIYAJI, F.; KOKUBO, T.; OHTSUKI, C.; NAKAMURA, T. Bioactivity of $\mathrm{Na}_{2} \mathrm{O}-\mathrm{CaO}-\mathrm{SiO}_{2}$ glasses, J. Am. Ceram. Soc, v.78, p. 2405-2411, 1995.

KLUG, H.P.; ALEXANDER, L.E.; X Ray Diffraction Procedures; JohnWiley\&son, Inc., New York, 1974.

KOKUBO, T.; TAKADAMA, H. How useful is SBF in predicting "in vivo" bone bioactivity?, Biomaterials, v. 27, p. 2907-2915, 2006.

KOKUBO, T. Novel Bioactive Materials. Anales de Química Int. Ed., v.93, p.4955,1997 ;

LANTERI, V.; HEUER, A.H.; MITCHELL, T.E. Tetragonal phase in the system $\mathrm{ZrO}_{2}$ $-\mathrm{Y}_{2} \mathrm{O}_{3}$. The American Ceramic Society, v.12, p.118-130, 1984.

LEGEROŚ, R.Z. Calcium phosphates in oral biology and medicine. Monographs in Oral, 15, 1991.

LEGEROS, R. et.al., Bioceramics - tissue interfaces: characterization of ultastructural properties proceedings of the $6^{\text {th }}$ International Symposium on Ceramics in Medicine Philadelphia: Nov., p. 79-84, 1993.

LIU, X.; DING, C.; CHU, P.K. Mechanism of apatite formation on wollastonite coatings in simulated body fluids, Biomaterials, v.25, p. 1755-1761, 2004.

MARCOS, P.J.B. Produção e caracterização de eletrólitos sólidos cerâmicos de $\mathrm{ZrO}_{2}$ para sensores de oxigênio conformados através da técnica de eletroforese. 2001. Dissertação (Mestrado)- Escola Politécnica da Universidade de São Paulo, São Paulo.

MATSUI, K.; OHMICHI, N.; OHGAI, M.; YOSHIDA, H.; IKUHARA, Y. Grain boundary segregation-induced phase transformation in yttria-stabilized tetragonal zirconia polycrystal, Journal of the ceramic society of Japan, v.114, p.230-237, 2006.

MERRY, J.C.; GIBSON, R.I.; BEST, M. S.; BONFIELD, W. Synthesis and characterization of carbonate hydroxyapatite, J. Mater. Sci. Mater. In Med, v.9, p.779$783,1998$.

MIYAJI, F.; KIM, H.M.; HANDA, S.; KOKUBO, T.; NAKAMURA, T. Bonelike apatite coating on organic polymers: novel nucleation process using sodium silicate solution, Biomaterials, v.20, p. 913-919, 1999.

MIYAZAKI, T.; KIM, H.; KOKUBO, T. et.al., Mechanism of bonelike apatite formation on bioactive tantalum metal in a simulated body fluid. Biomaterials, v.23, p. $827-832,2002$.

MORAES, M.C.C.S.B.; ELIAS, C.N.; FILHO, J.D.; OLIVEIRA, L.G. Mechanical properties of alumina-zirconia composites for ceramic abutments. Materials Research, v. $7, n^{\circ} 4$, p. 643-649, 2004. 
PADILHA, A.F.; FILHO, F.A.; Técnicas de Análise Microestrutural; hemus editora Ltda, São Paulo, 1985.

PICONI, C.; MACCAURO, G. Zirconia as a ceramic biomaterial, Biomaterials, v.20, p.1-25, 1999.

RENOO, J.W. et.al., Bioresorpition of ceramic strontium-85-labeled calcium phosphate implants in dog femoral. Clin. Orthopedic Relat Res., 197, p. 272-285, 1985.

RIBEIRO, C. Processamento e caracterização de cerâmicas à base de hidroxiapatita e fosfato- tricálcico. 2003. Dissertação (Mestrado)- Instituto de Pesquisas Energéticas e Nucleares (IPEN), São Paulo.

RIETVELD, H.M.; A Profile Refinement Method for Nuclear and Magnetic Structures. J.Appl.Cryst.2, p.65-71, 1969.

RIGO, E. et.al., Implantes metálicos recobertos com hidroxiapatita. Revista Brasileira de Engenharia Biomédica, V.15, p.21-29, 1999.

RÜHLE, M; CLAUSSEN, N.; HEUER, A.H. Microstructural studies of $\mathrm{Y}_{2} \mathrm{O}_{3}$ containing tetragonal polycrystals (Y-TZP). The American Ceramic Society, v.12, p.352-370, 1984.

SCOTT, H.G. Phase relationships in the zirconia-yttria system. J. Mater. Sci., v.10, p. 1527-1535, 1975.

SHERMAN, J. The theoretical derivation of fluorescent X-ray intensities from mixtures. Spectrochim, Acta, v. 7, p. 283-306, 1955.

SHIRAIWA, T.; FUJINO, N. Theoretical calculation of fluorescent X-ray intensities in fluorescent X-ray spectrochemical analysis. Jpn. J. Appl.Phys.,v.5, p.886-899, 1966.

UCHIDA, M.; KIM, M.H. ; KOKUBO,T. ; NAWA, M. ; ASANO, T. ; TANAKA, K. ; NAKAMURA,T. Apatite-forming ability of a zirconia/alumina nano-composite induced by chemical treatment. Materials Research, v.60, p. 277-282, 2002.

UCHIDA, M.; KIM, H.; MIYAJI, F. et.al., Apatite formation on zirconium metal treated with aqueous NaOH. Biomaterials, v.23, p. 313-317, 2002.

USSUI,V.; LAZAR,D.R.R.; MENEZES,F.; MENEZES,C.A.B.; PASCHOAL, J.O.A. Aplicação da técnica de destilação azeotrópica na sintese de pós cerâmicos à base de zircônio. In:40 CONGRESSO BRASILEIRO DE CERÂMICA, 12-15 junho, 1996 , Criciúma, S.C. Anais...São Paulo: Cerâmica, 1996, v.42, n.276, p.415-418.

VERCIK, L.C.; ASSIS, C.M.; FOOK, M.V.L.; SANTOS, M.L.; GUASTALDI, A.C. Recobrimento de apatitas in vitro sobre titânio- influência do tratamento térmico, eclética química, v.28, 2003.

WARREN, B.E. ; X Ray Diffraction; Reading. Mass., Addison-Wesley, 1959. 
YOUNG, R. A.; The Rietveld Method. Oxford: New York, 1995.

YOUNG, R. A.; WILES,B.D.; Profile shape functions in Rietveld Refinements. J. Appl. Cryst., v.15, p.430-438,1982.

YOUNG, R.A.; SAKTHIVEL, A.; MOSS, T.S.; PAIVA SANTOS, C.O.; User's Guide to Program DBWS9411 for Rietveld Analysis of $x$ ray and Neutron Powder Diffraction Patterns; Scholl of Physics, Georgia Institute of Technology, Atlanta, 1995. 